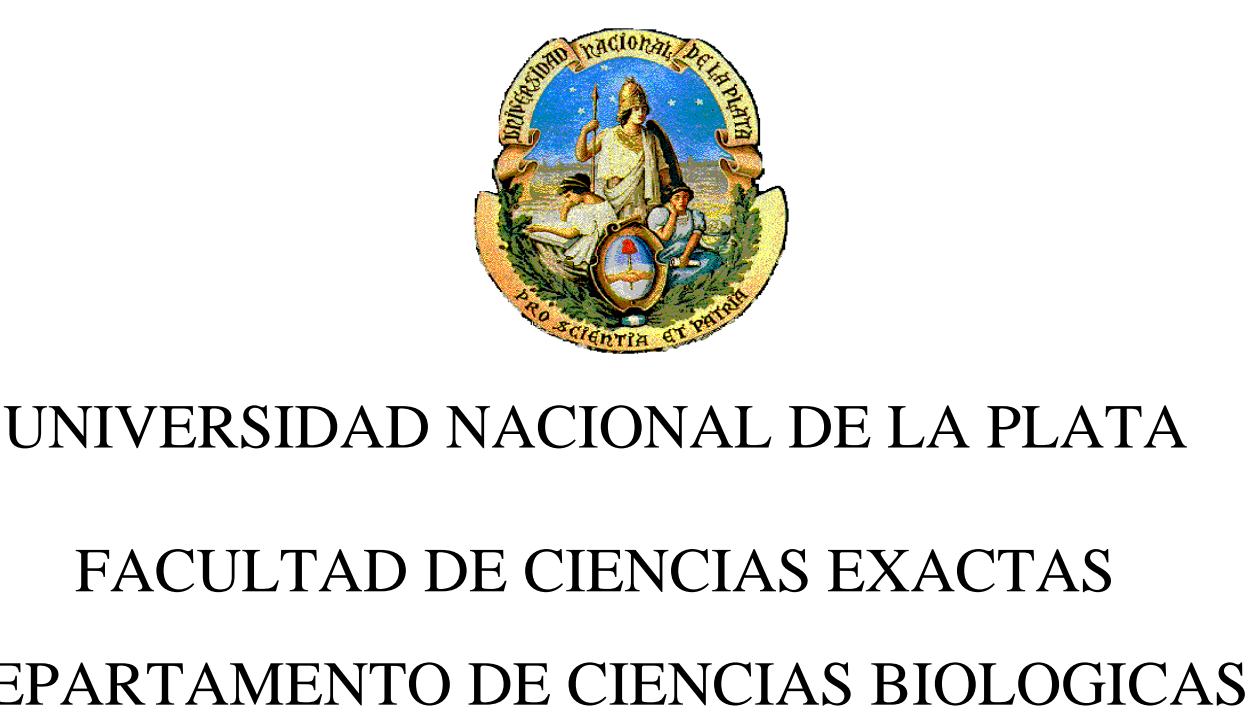

DEPARTAMENTO DE CIENCIAS BIOLOGICAS

Tesis de Maestría en Ciencias del Laboratorio Clínico

\title{
"Estudio para el mejoramiento de la calidad analítica en la determinación de hierro sérico en laboratorios de Análisis Bioquímicos”
}

Lic. María Cristina Cailliat

Directora:

Dra. Nilda E. Fink

Lugar de realización:

Asignatura Hematología. Departamento de Ciencias Biológicas. Facultad de Ciencias Exactas. Universidad Nacional de La Plata.

Año 2011 
Dedicada a mis padres, Tita y José que siempre los llevo conmigo 


\section{Agradecimientos}

En primer lugar, quiero agradecer a la Facultad de Ciencias Exactas de La Universidad Nacional de La Plata, que mediante la "Maestría en Ciencias del Laboratorio Clínico”, permitió que actualizara mis conocimientos y que este proyecto pudiera concretarse.

A mi esposo, por compartir mi vida desde mis épocas de estudiante y brindarme, además de todo su amor, su infinito apoyo y comprensión acompañándome en cada emprendimiento.

A mis hijos, para demostrarles que en la vida, con perseverancia y voluntad todo se alcanza.

A mis nietos, por las veces que no jugué con ellos y para que comprendan que no podría imaginar mi vida sin ellos.

A la Prof. Dra. Nilda Fink, por su paciencia y tolerancia en todo momento, exigiéndome siempre un poquito más, sin dejar de alentarme y apoyarme, transmitiéndome su experiencia y sus conocimientos, compartiendo conmigo su gran calidad humana.

A la Prof. Dra. María Apezteguía, que con su cordial actitud y predisposición, me enseñó a comprender la importancia de la evaluación estadística como herramienta complementaria y necesaria de los ensayos bioquímicos.

A la Dra. Laura Suarez, que muy generosamente me proporcionó muestras de sus pacientes.

Al Dr. Isaac Berizovsky, por su confianza en mi persona, abriéndome las puertas de su laboratorio para procesar ensayos automatizados, brindándome su apoyo y ayuda permanente.

A la Dra. Alejandra Fernández Alberti, por su colaboración durante la primera etapa de este trabajo.

A la Dra. Mariana González por su aliento y compañerismo a pesar de la diferencia generacional.

A la Sra. Susana Tinelli por su incondicional colaboración en la descontaminación del material de vidrio utilizado, siguiendo mis indicaciones con mucha voluntad y simpatía. 
A Susana Feregotto, a Pamela De Francesco y a Grisel Tenaglia que desde la Biblioteca de la Federación Bioquímica, siempre atendieron mis inquietudes y consultas relacionadas a la búsqueda de material bibliográfico, con infinita cordialidad y mucha eficiencia.

También quiero agradecer a todas y a cada una de las personas que trabajan en el LARESBIC, bajo la dirección del Dr. Daniel Mazziotta, por su ayuda y por hacerme sentir parte del grupo.

A las empresas BioSystems y Wiener mi eterno agradecimiento por la donación de los equipos de reactivos utilizados en este trabajo. 
"La dicha de la vida consiste en tener siempre algo que hacer, alguien a quien amar y alguna cosa que esperar"

Thomas Chalmers 


\section{Resumen}

En diversas condiciones, la medición de hierro sérico es fundamental para estudiar el "estado del hierro del paciente". Este estudio comprende una serie de determinaciones básicas que permite conocer, en primera instancia, si el paciente presenta un déficit o un exceso de este analito.

La carencia de hierro es la deficiencia nutricional de mayor prevalencia en todo el mundo, y su evaluación temprana, especialmente en niños y embarazadas, evita retrasos en el desarrollo intelectual del recién nacido como también riesgos en el momento del parto; la anemia producida por esta deficiencia puede a su vez afectar el sistema inmunitario, la capacidad de trabajo muscular y originar trastornos cognitivos. Por otra parte, la sobrecarga de hierro comúnmente conocida como hemocromatosis es una patología cuyos síntomas iniciales son inespecíficos, pues incluyen fatiga, artralgias, disfunción eréctil e incremento paulatino de la pigmentación de la piel. El diagnóstico bioquímico precoz definido en términos fenotípicos muestra las alteraciones genéticas que permiten clasificarla, y su seguimiento y control por el laboratorio clínico puede realizarse por los parámetros básicos del estado del hierro, que comprende la medición de: hemograma completo, ferremia, capacidad total de fijación de hierro (CTFH), transferrina y saturación de transferrina.

Habiendo descripto la relevancia de las alteraciones fisiopatológicas del metabolismo del hierro, el objetivo general de este trabajo, fue examinar el comportamiento de los métodos utilizados en equipos comerciales de reactivos en uso en nuestro medio, que miden hierro sérico directamente por métodos manuales y automatizados, en relación al método recomendado (MR) por el estándar H17-A del Clinical and Laboratory Standards Institute (CLSI), que utiliza desproteinización previa a la colorimetría y transferir las recomendaciones surgidas de este estudio a la red de laboratorios públicos y privados, para el mejoramiento de la calidad analítica de la determinación de ferremia. Es conocido que la precisión y la exactitud de los métodos de rutina para la determinación de hierro son bajas, debido no solo a errores técnicos sino a la elevada variabilidad biológica del analito entre individuos. 
Con respecto a la puesta a punto del MR por el CLSI, la misma se realizó utilizando soluciones estándares de trabajo preparadas a partir de hierro SRM 937 del NIST, pooles de sueros preparados en la Cátedra (pool madre) y materiales comerciales diversos. Los coeficientes de correlación obtenidos en las calibraciones efectuadas mostraron valores próximos a la unidad indicando que el rango de concentraciones empleadas es lo suficientemente amplio como para proporcionar estimaciones confiables de la pendiente y la ordenada al origen.

Asimismo, otro aspecto que aporta a la mejora de la calidad analítica fue la utilización del MR (CLSI) para asignar valores a sueros del PEEC-FBA. También se efectuaron ensayos con sueros provistos por programas internacionales de evaluación externa de calidad (UK NEQAS y WCDHNY), en los cuales, los rangos de inexactitud hallados, en ambos casos, se encontraron por debajo de los descriptos en la literatura, mientras que en las comparaciones efectuadas con sueros provenientes del PEEC-FBA se obtuvo un rango mayor de inexactitud (-14,2 a 46,5\%).

Paralelamente, se procesaron las muestras de los pooles de sueros de tres niveles de concentración $($ bajo $=0,53 \mathrm{mg} / \mathrm{L}$, mediano $=1,09 \mathrm{mg} / \mathrm{L}$, alto $=2,02 \mathrm{mg} / \mathrm{L}$ ) por el $\mathrm{MR}$ (CLSI) y por los métodos manual y automatizado con los equipos comerciales de BS y de W, incorporando también la modificación semiautomatizada del MR (CLSI) en la batería de pruebas. La evaluación estadística de las comparaciones demostró una relación relativamente fuerte entre las variables, con un p-valor inferior a 0,01 para un nivel de confianza del $99 \%$ y en general se obtuvieron CV\% menores $(0,57$ a 3,74$)$ en los especímenes con mayor concentración de hierro, con la excepción de la modificación semiautomatizada del MR que arrojó un CV\% entre 3,16 a 6,58.

A partir de los gráficos de Bland-Altman se encontró una buena concordancia entre los valores obtenidos con los métodos de los equipos comerciales y los obtenidos con el MR (CLSI) para niveles bajos de concentración de hierro sérico, tanto para técnicas manuales (BS Ma y W Ma) como para el método de BS Au, mientras que el método de $\mathrm{W}$ Au presentó valores ligeramente inferiores a los del MR (CLSI). Para los niveles medios de concentración de hierro sérico, los valores obtenidos con los métodos manuales y los automatizados de los equipos comerciales, en general, fueron inferiores a los valores obtenidos con el MR (CLSI) y, para los niveles altos de concentración de hierro sérico, si bien hubo coincidencia en las comparaciones del MR (CLSI) con el W Ma, en todas las comparaciones se observó una marcada dispersión de valores. 
Finalmente nos propusimos estudiar si la modificación de la técnica manual del MR (CLSI) podría ser de utilidad para ser incorporada en la batería diaria de pruebas de un laboratorio automatizado. La modificación consistió en el uso del sobrenadante obtenido por desproteinización en un procedimiento directo y automatizado. En este caso se obtuvieron CV\% superiores a los hallados con el MR (CLSI) mientras que en los análisis estadísticos de comparación se obtuvieron valores inferiores a los del MR (CLSI) para los tres niveles de concentración de hierro y un considerable aumento de dispersión para concentraciones altas $(2,02 \mathrm{mg} / \mathrm{L} \pm 2 \mathrm{DE})$.

Se concluyó que en este estudio de correlación entre el MR(CLSI) y los métodos comerciales estudiados, especialmente los métodos automatizados de ambos equipos, teniendo en cuenta la diversidad de las características metodológicas y considerando la optimización de todo el procedimiento analítico, las diferencias de las Medias $\left(\mathrm{X}_{\text {media }}\right)$ obtenidas se encuentran dentro de los rangos aceptables para el propósito del diagnóstico clínico, enfatizando una vez más la importancia de utilizar la medida de hierro sérico como parámetro inicial en el diagnóstico del metabolismo del hierro.

A su vez, siguiendo el protocolo del documento de la IFCC (1995), parte 1, se realizó el examen de la presentación de los equipos comerciales de reactivos utilizados en este trabajo, en el que se observaron mínimas diferencias de ambos en relación con la reglamentación solicitada por el ANMAT y con los requerimientos previstos por la Dirección Europea 98/79 CE.

En diversos trabajos se hace mención a la importancia relativa de la medida del hierro sérico utilizado como único parámetro de evaluación de un déficit o de un exceso de hierro sino que sea parte integrante de un conjunto de pruebas en el estudio del estado del hierro. En algunas publicaciones mas recientes encontramos la preferencia por el empleo, entre otros marcadores, de la ferritina y el receptor de transferrina con la omisión de la medida del hierro sérico para el estudio y seguimiento de una anemia. Es real que estos marcadores de última generación, a los que en estos momentos se podría sumar el dosaje de hepcidina, son parámetros muy sensibles para diagnosticar un desbalance en el metabolismo de hierro, pero requieren de un equipamiento que muchas veces no se encuentra en todos los laboratorios, en los cuales, el estudio básico del estado del hierro puede ser el paso inicial para establecer dicho diagnóstico. 
En nuestro caso particular, para la medición de la ferremia en el laboratorio, es importante profundizar, en primer término, en las medidas de descontaminación del material utilizado en las fases pre-analítica y analítica y utilizar estándares o calibradores de reconocida trazabilidad, ajustando el procedimiento de medida con un procedimiento de control interno sistemático de manera que los posibles errores sean mínimos. A su vez, si bien es importante contar con un método definitivo o de referencia para la evaluación de este analito, en estos momentos, la participación de todo laboratorio en programas de evaluación externa de la calidad conjuntamente con la mejor selección de reactivos, instrumento de medición y recurso humano nos permitirán detectar errores analíticos y evitar que los mismos se trasladen a los resultados. La calidad de nuestros resultados estará asegurada por todas las razones esgrimidas anteriormente, pero la más importante es nuestra responsabilidad profesional de realizar el mayor esfuerzo posible para garantizar la confiabilidad de los resultados que emitimos, siempre en beneficio del paciente pues es la manera de colaborar en la toma de decisión para el tratamiento adecuado de una alteración en el metabolismo del hierro.

Palabras clave: Hierro, método recomendado (CLSI), métodos directos. 


\section{Abreviaturas y Siglas utilizadas en la presente tesis}

- ANMAT = Administración Nacional de Medicamentos, Alimentos y Tecnología Médica.

- $\quad$ TTC = Ácido tricloroacético

- $\mathrm{AU}=$ Adenina-Uracilo

- $\mathrm{BS}=$ BioSystems Reactivos e Instrumentos.

- $\quad$ ad $=$ Concentración adicionada

- $\mathrm{CDC}=$ Centro para el Control y la Prevención de Enfermedades de Estados Unidos

- $\mathrm{Ci}=$ Concentración inicial

- CLSI = Instituto de Estandarización para el Laboratorio Clínico de Estados Unidos

- $\mathrm{Cob}=$ Concentración obtenida

- CitbD $=$ Citocromo $b$ duodenal

- $\mathrm{CTFH}=$ Capacidad total de fijación de hierro

- $\mathrm{CV}=$ Coeficiente de variación

- CYPBRD1 = Reductasa férrica

- $\mathrm{DE}=$ Desviación estándar

- DMT1 $=$ Transportador de metales divalentes

- ENNyS = Encuesta Nacional de Nutrición y Salud

- EP5-A = Guía aprobada para Evaluación de Precisión en Química Clínica-NCCLS

- EP9-A2 = Guía aprobada para Comparación de métodos y estimación del sesgoNCCLS

- EP10-A = Guía aprobada para Evaluación preliminar de métodos del Laboratorio Clínico-NCCLS.

- Fnp = Ferroportina

- $\mathrm{HFE}=$ Proteína reguladora del hierro en hemocromatosis

- HJV = Hemojuvelina

- $\mathrm{ICSH}=$ Comité Internacional de Estandarización en Hematología - OMS

- IFCC = Federación Internacional de Química Clínica y Laboratorio Clínico

- $\mathrm{IL}_{1}=$ Interleuquina 1

- $\mathrm{IL}_{6}=$ Interleuquina 6 
- $\operatorname{IRE}=$ Elemento de respuesta al hierro

- $\mathrm{IRE}-\mathrm{BP}=$ Proteína fijadora del elemento de respuesta al hierro

- $\quad$ IVD = Uso diagnóstico in vitro

- LARESBIC = Laboratorio de Referencia y Estandarización en Bioquímica Clínica de la Fundación Bioquímica Argentina

- $\mathrm{MR}=$ Método Recomendado

- $\quad$ MRT $=$ Método Recomendado calculado por la calibración con Titrisol

- NCCLS = Comité Nacional de Estandarización en el Laboratorio Clínico de Estados Unidos (actualmente CLSI)

- $\quad$ NIST = Instituto Nacional de Estandarización y Tecnología de Estados Unidos

- OMS = Organización Mundial de la Salud

- PEEC-FBA = Programa de Evaluación Externa de Calidad de la Fundación

Bioquímica Argentina

- $\mathrm{PTT}=$ Tiempo parcial de tromboplastina

- $\operatorname{TfR}=$ Receptor de Transferrina

- $\mathrm{TfR}_{2}=$ Receptor de Transferrina 2

- TfRs $=$ Receptor soluble de Transferrina

- Transferrina $=\mathrm{Tf}$

- $\mathrm{TNF}=$ Factor de necrosis tumoral

- $\quad$ TPTZ $=2,4,6$-tripiridil-triazina

- UK NEQAS = Programa de Evaluación Externa de Calidad del Reino Unido

- $\mathrm{VR}=$ Valor de referencia

- $\mathrm{W}=\mathrm{Wiener}$ Lab

- WCDHNY = Centro Wadsworth, Departamento de Salud del Estado de Nueva York 


\section{Índice de Contenidos}

Agradecimientos

Página

III

Resumen

Abreviaturas y Siglas utilizadas en la presente tesis

Índice de Contenidos

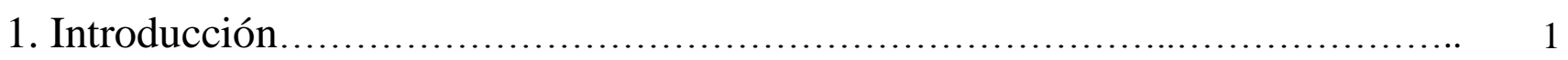

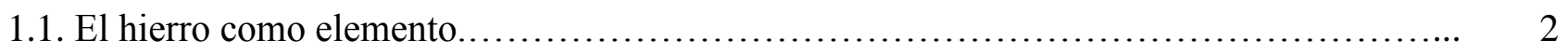

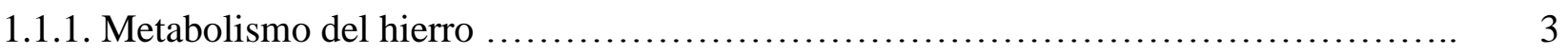

1.1.2. Conceptos actuales del metabolismo del hierro.............................. 7

1.2. Importancia del estudio del estado del hierro................................... 11

1.3. Parámetros mínimos del diagnóstico diferencial................................... 13

1.4. Evolución de la metodología empleada para medir hierro sérico....................... 15

1.5. Interferencias en la medición de hierro sérico .................................... 21

1.6. Antecedentes relacionados con los objetivos de este trabajo ......................... 22

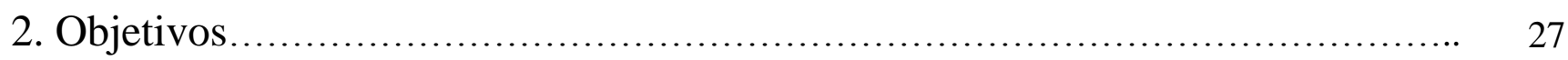

2.1. Generales................................................................ 28

2.2. Específicos........................................................... 28

3. Esquema de Trabajo..................................................... 29

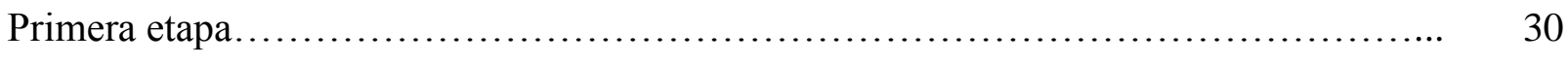

Segunda etapa........................................................... 31

4. Materiales y Métodos....................................................... 32

4.1. Materiales ......................................................... 33

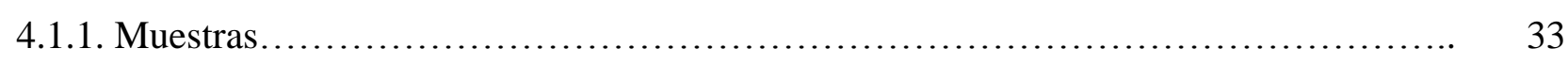

4.1.1.1. Materiales de Control comerciales.................................. 33

4.1.1.1.1. Soluciones estándares de hierro................................. 33

4.1.1.1.2. Titrisol ${ }^{\circledR}$ Patrón de hierro $1000 \mathrm{mg} \mathrm{Fe}$ - Merck........................ 33

4.1.1.2. Materiales de Control de preparación propia - Pool de sueros.................... 33

4.1.1.3. Materiales de Control de Programas de Evaluación Externa..................... 35

4.1.1.3.1. Sueros control del UK NEQAS ................................ 35

4.1.1.3.2. Sueros control del WCDHNY .................................. 35

4.1.1.3.3. Sueros control del PEEC - FBA................................. 35

4.1.2. Drogas y equipos de reactivos comerciales..................................... 35

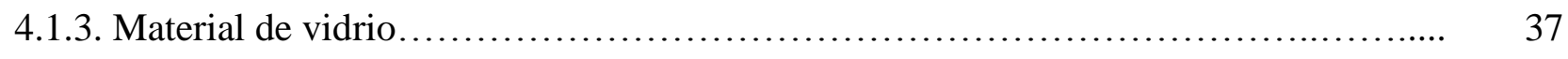

4.1.4. Instrumental ....................................................... 38 


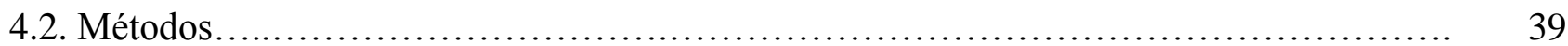

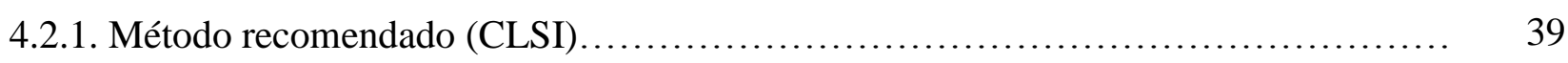

4.2.1.1. Preparación de reactivos............................................... 40

4.2.1.2.Preparación de Soluciones Estándares................................... 41

4.2.1.3. Calibración............................................................. 41

A. Prueba preliminar de la técnica manual a utilizar en este trabajo.............. 41

B. Empleo de material de referencia proveniente del NIST................... 42

C. Empleo de materiales comerciales.................................... 42

4.2.1.4. Ensayos de prevalidación............................................. 43

A. Linealidad........................................................... 43

B. Recuperación..................................................... 43

C. Imprecisión intraensayo.............................................. 43

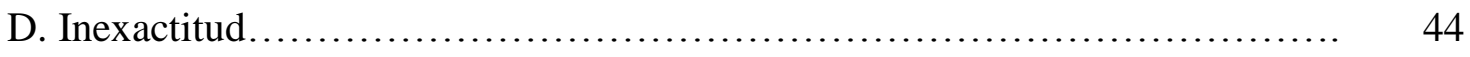

4.2.1.5. Procedimiento con las diferentes muestras............................... 44

4.2.2. Métodos comerciales..................................................... 45

4.2.2.1. Determinación de hierro con el equipo Hierro-Ferrozina, marca BioSystems SA 45

4.2.2.2. Determinación de hierro con el equipo Fer-color, marca Wiener lab............. 46

4.2.3. Método semiautomatizado............................................. 47

4.2.4. Métodos Estadísticos.................................................. 47

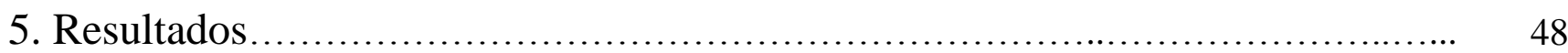

5.1 Controles de las condiciones de trabajo........................................ 49

5.1.1 Control de lavado y de descontaminación del material de vidrio.................... 49

5.1.2. Calibración de pipetas.................................................... 49

5.1.3. Control de calidad del instrumental empleado................................. 49

5.1.3.1. Control de calidad del espectrofotómetro Shimadzu......................... 49

5.1.3.2. Control de calidad del Analizador automático Random Access BioSystems..... 51

5.2 Puesta a punto del Método Recomendado - MR (CLSI) ........................... 51

5.2.1 Calibración utilizando hierro marca Anedra..................................... 51

5.2.2 Calibración con hierro patrón del NIST ...................................... 53

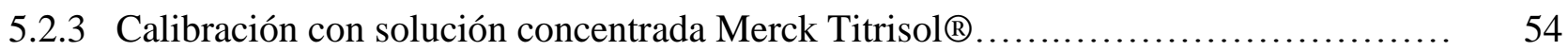

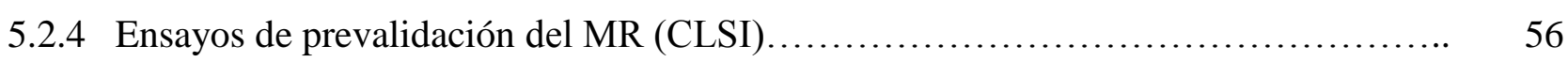

5.2 .4 .1 Linealidad............................................................... 56

5.2 .4 .2 Recuperación....................................................... 57

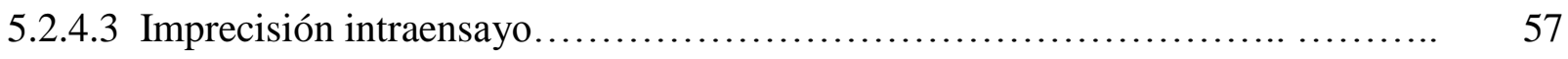

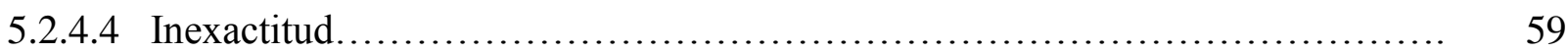

5.3 Aplicación del Método Recomendado para la asignación de valores de hierro en diferentes

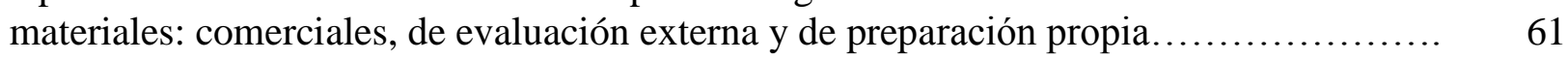

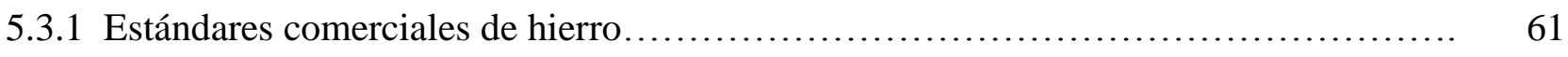

5.3.2. Estudio comparativo de la medida de hierro en Sueros del UK NEQAS............... 62

5.3.3. Estudio comparativo de la medida de hierro en Sueros del WCDHNY ................. 64

5.3.4 Estudio comparativo de la medida de hierro en Sueros del PEEC-FBA................. 66

5.3.5 Comparación de los valores de las medias, desviación estándar y coeficientes de variación obtenidos con el MR, utilizando la calibración con Titrisol 
5.3.6 Ensayos con pool de sueros

5.3.6.1 A - Medición de hierro con el MR (CLSI) ............................... 71

5.3.6.1 B - Medición de hierro por el método semiautomatizado (CLSI Se Au).......... 73

5.3.6.2 Medición de hierro con el método comercial de BS manual y automatizado..... 74

A - Calibración....................................................... 74

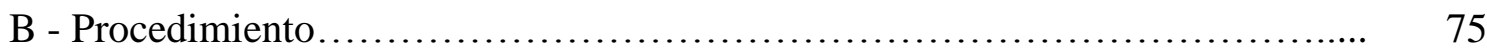

5.3.6.3 Medición de hierro con el método comercial de W manual y automatizado...... 76

A - Calibración....................................................... 76

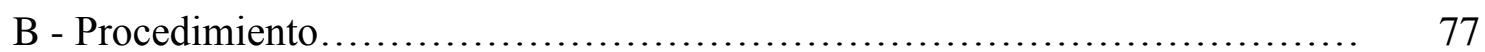

5.4 Análisis Estadístico de los datos obtenidos en pooles de sueros con el MR (CLSI) y con equipos comerciales..................................................... 78

5.4.1 Comparación de Medias.................................................... 78

5.4.2 Correlación de los datos obtenidos por: análisis de regresión lineal, histogramas de distribución y gráficos de Blan-Altman

5.5 Evaluación de la presentación de los equipos de reactivos comerciales utilizados en este trabajo.

A - Examen de la rotulación del equipo: TABLA I............................... 93

B - Examen del inserto: TABLA II............................................... 94

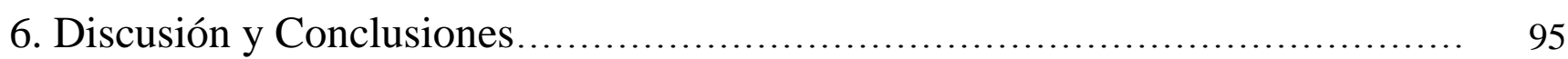

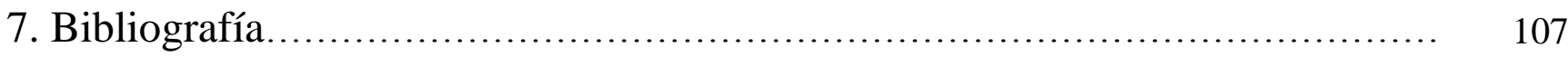

8. Glosario................................................................. 118

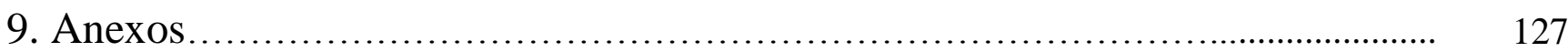




\section{Introducción}




\subsection{EI hierro como elemento}

El hierro, considerado un elemento de importancia vital en el metabolismo humano, desempeña un papel básico en la eritropoyesis y también está implicado en muchos procesos intracelulares de todos los tejidos del cuerpo, pues se encuentra presente en una amplia variedad de sistemas moleculares (Beutler E. et al., 2005).

Entre todos los micronutrientes, el hierro posee la historia más larga y mejor descripta. Este micronutriente esencial, que interviene en numerosos procesos bioquímicos y fisiológicos abarca aproximadamente el 4,7\% de la corteza terrestre, en la forma de los minerales hematita, magnetita y siderita. Compuestos de hierro primordial fueron probablemente responsables de la generación catalítica de parte del oxígeno atmosférico del que dependen las formas modernas de vida (de Duve C., 1990; Beard J.L. et al., 1997).

A principios del siglo XVIII el hierro fue identificado como un componente del hígado y la sangre animal (McCay C.M., 1973), y el contenido de hierro en la hemoglobina fue estimado en $0,35 \%$ en 1825, un valor extremadamente cercano a 0,347\% (Bennington J. L., 1991) el valor calculado por métodos modernos.

Es el metal más abundante de nuestro planeta y uno de los predominantes en la corteza terrestre y se halla incorporado como elemento esencial a todas las formas de vida, desde las más elementales como bacterias y organismos unicelulares hasta las más complejas. Como metal de transición, oscila con facilidad donando o captando electrones entre sus iones $\mathrm{Fe}^{+2}$ y $\mathrm{Fe}^{+3}$, por lo que se encuentra en el grupo prostético de numerosas proteínas involucradas en el transporte de oxígeno y en los fenómenos de oxido reducción, como citocromos, flavoproteínas, peroxidasas, catalasas, las enzimas que contienen complejos de azufre y hierro, como la aconitasa, y un heterogéneo grupo de proteínas que contienen hierro en una gran diversidad de configuraciones moleculares. También es un componente esencial de enzimas que intervienen en el metabolismo de los desoxirribonucleótidos, como la nucleótido-reductasa, y casi la mitad de las enzimas y cofactores del Ciclo de Krebs contienen hierro.

El hierro cumple un papel fundamental en el transporte de oxígeno como componente metálico del grupo hemo de la hemoglobina y de la mioglobina. El hierro libre es fácilmente oxidado en medio acuoso, originando radicales muy reactivos, potencialmente nocivos, motivo por el cual se encuentra en todos los organismos vivos 
estrechamente vinculado a proteínas u otros complejos orgánicos, y solo existen mínimas cantidades de hierro tisular libre.

$\mathrm{Su}$ elevado potencial redox, junto a su facilidad para promover la formación de compuestos tóxicos altamente reactivos, determina que el metabolismo del hierro sea controlado por un potente sistema regulador (Forrellat Barrios M. et al., 2000; Pintado Cros T. el al., 2001; Boccio et al., 2003).

El hierro es fisiológicamente esencial y bioquímicamente peligroso. El metabolismo del hierro y el metabolismo de los superóxidos están claramente relacionados, especialmente bajo condiciones patológicas. Cada uno puede exacerbar la toxicidad del otro. La sobrecarga de hierro puede amplificar los efectos dañinos determinando una superproducción de superóxidos en un muy amplio espectro de inflamaciones o isquemias. Además, el estrés oxidativo crónico puede modular tanto la distribución como el depósito y preceder a los efectos citotóxicos y a los eventos mutagénicos (McCord J.M., 1998).

Además, el hierro participa en los procesos de inmunidad innata (primera línea de defensa inmunitaria) como parte de los mecanismos bactericidas y bacteriostáticos; es también un elemento necesario para la proliferación y maduración de las células inmunitarias, particularmente de los linfocitos asociados con la generación de una respuesta específica frente a agentes infecciosos. Existen estudios que señalan que la deficiencia leve y moderada de hierro, aún sin anemia, además de producir alteraciones en el crecimiento y desarrollo puberal, retardo en la maduración de las capacidades intelectuales y neurológicas, trastornos en el epitelio gastrointestinal, reducción de la capacidad física y de trabajo en adolescentes y adultos, es capaz de provocar trastornos en la respuesta inmunitaria (Leal M.J. et al., 2008).

\subsubsection{Metabolismo del hierro}

La circulación del hierro entre los compartimientos de depósito y de utilización constituye un ciclo muy eficiente y prácticamente cerrado. Debido a que sólo una pequeña parte del hierro es excretada, la necesidad diaria de incorporación del mismo en un individuo es baja. Aproximadamente se absorbe el 10\% del total de hierro ingerido. 
El hierro de la dieta se encuentra mayormente en estado férrico o como hierro hémico, mientras que el que se incorpora a través de productos farmacológicos generalmente está presente como sal ferrosa.

Ambos iones $\left(\mathrm{Fe}^{+3}\right.$ y $\left.\mathrm{Fe}^{+2}\right)$ pueden presentarse ante las células intestinales: los iones férricos son absorbidos vía una proteína de membrana, la $\beta_{3}$ integrina que en presencia de la proteína CitbD (citocromo b duodenal) son transferidos a otra proteína chaperona mobilferrina para ser incorporados vía el transportador de metales divalentes DMT1, mientras que la absorción de los iones ferrosos es realizada directamente por el DMT1. Una vez en el interior del enterocito, el hierro puede ser almacenado en la ferritina o alcanzar la membrana basolateral del mismo para unirse a la apotransferrina circulante. La membrana basolateral del enterocito expresa receptores para transferrina (Tf) que permiten la entrada del hierro transportado por esta proteína (Pérez G. et al, 2005) y así circula en la sangre.

Las concentraciones intracelulares de hierro están reguladas con gran precisión, porque tanto el exceso como la carencia de este mineral son nocivos para las células.

El complejo transferrina-hierro se introduce en las células mediante la interacción con el receptor de transferrina (TfR) y cuando los depósitos de hierro dentro de las células son suficientes, la importación del complejo transferrina-hierro se reduce mediante el aumento de la velocidad de degradación del mRNA de TfR, que conduce con rapidez a una disminución de la cantidad de receptor de transferrina. Cuando los depósitos intracelulares de hierro disminuyen, el mRNA de TfR se estabiliza y aumenta la síntesis de la proteína receptora.

Esta regulación de la estabilidad del mRNA de TfR depende de elementos de respuesta al hierro (IRE = iron-response elements), en la región no traducible $3^{\prime}$ del mRNA, y de una proteína citosólica llamada proteína fijadora de IRE (IRE-BP = IRE-binding proteína), cuya conformación difiere según haya concentraciones altas o bajas de hierro (Fig.1-1).

Cada IRE forma una estructura en tallo-asa en la cual el asa contiene cinco bases específicas y el tallo posee secuencias ricas en AU, similares a las que desestabilizan los mRNA de las citocinas (Lodish H. et al., 2002; Sabater Baudet L., 2007). Se cree que cuando las concentraciones de hierro son adecuadas, estas secuencias ricas en AU promueven la degradación del mRNA de TfR por el mismo mecanismo que lleva a la degradación rápida de los mRNA de las citocinas. Cuando la concentración de hierro disminuye levemente, la conformación de la IRE-BP cambia de manera que se pueda 
unir a los IRE y se cree que la unión de la IRE-BP a los IRE bloquea el reconocimiento de las secuencias desestabilizantes, ricas en AU, por las proteínas que de otro modo degradarían el mRNA de TfR.

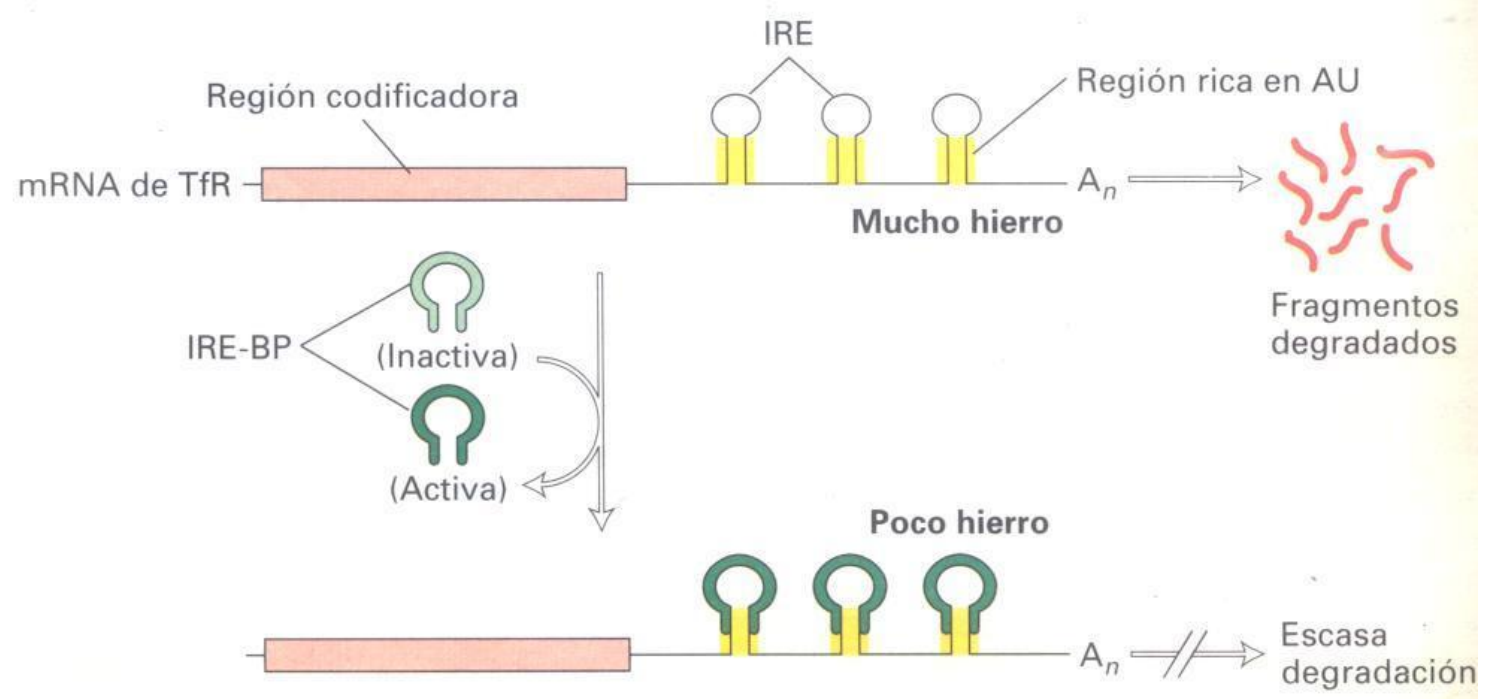

Figura 1-1: Regulación dependiente de hierro de la estabilidad del mRNA del TfR. Los elementos de respuesta al hierro (IRE) 3' en este mRNA poseen una estructura en tallo-asa con secuencias ricas en AU (en amarillo), que promueven la degradación del mRNA. Con concentraciones intracelulares bajas de hierro, la conformación de la IREBP (en verde oscuro) es tal que ésta se une a los IRE e inhibe la degradación. En consecuencia, la cantidad de receptor de transferrina aumenta, de modo que la célula puede incorporar más hierro (tomado de Lodish H. et al., 2002).

Del mismo modo se regula la traducción del mRNA de la ferritina, donde interviene una proteína intracelular que fija iones hierro, con lo cual impide la acumulación de cantidades tóxicas de iones libres. Cuando los depósitos de hierro son escasos, la traducción de los mRNA de ferritina se reprime, de manera que el hierro introducido en la célula por el receptor de transferrina esté disponible para las enzimas que requieren este mineral; cuando hay exceso de hierro, la síntesis de ferritina deja de estar reprimida, de manera que los iones de hierro libres sean fijados por la ferritina neosintetizada. 
La traducción de los mRNA de ferritina está regulada por la unión de la IRE-BP a los IRE (elementos de respuesta al hierro) en los extremos 5'de los mRNA (Fig.1-2).

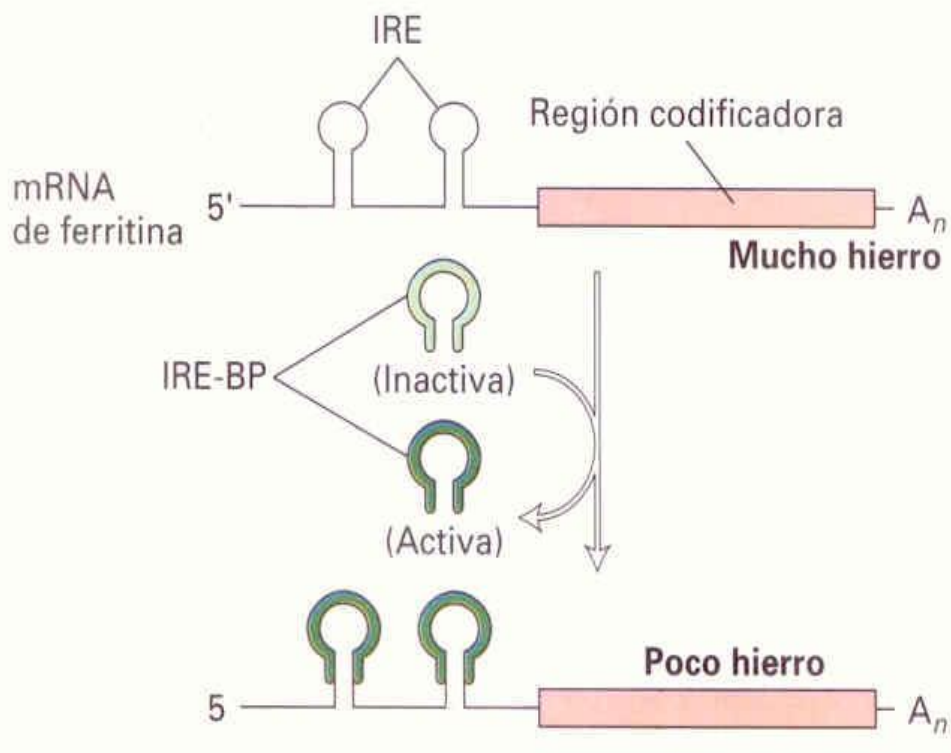

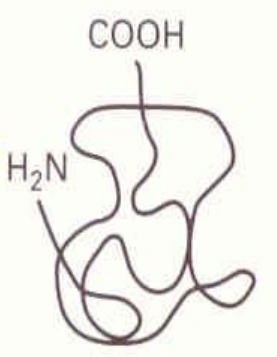

Ferritina traducida

No hay iniciación de la traducción

Figura 1-2: Regulación dependiente de hierro de la traducción del mRNA de la ferritina. Con bajas concentraciones de hierro, la unión de IRE-BP activa bloquea la iniciación de la traducción. Los IRE están ubicados en el extremo 5'y no contienen las secuencias ricas en AU, promotoras de la degradación, presentes en los IRE 3' del mRNA del receptor de transferrina (tomado de Lodish et al., 2002).

A diferencia de los IRE $3^{\prime}$ de los mRNA de TfR, los IRE 5’ de los mRNA de ferritina no tienen tallos ricos en AU ni promueven la degradación del mRNA. Cuando las concentraciones de hierro son bajas la IRE-BP es activa y se une a los IRE, con lo cual se inhibe la iniciación de la traducción porque se bloquea la capacidad de la subunidad ribosómica 40S de rastrear o buscar el codón de inicio. 
Cuando las concentraciones de hierro son altas, la IRE-BP es inactiva y no se une a los IRE 5', de modo que puede proseguir la iniciación de la traducción (Lodish et al, 2002). Este delicado mecanismo de regulación del hierro mantiene un balance adecuado siempre y cuando los requerimientos diarios de hierro elemental se encuentren entre 1 a $2 \mathrm{mg} / \mathrm{día}$.

En las dietas occidentales, generalmente este requerimiento se sobrepasa y de no existir esta regulación en su absorción, el exceso de hierro, puede causar daños al depositarse en tejidos y órganos vitales como el corazón, el hígado, las glándulas endocrinas, entre otros, generando disfunciones a través de la producción de radicales libres.

Para mantener la homeostasia del hierro, los organismos deben ser sensibles a los cambios en sus niveles y responder a ellos alterando los procesos de absorción y almacenamiento del mineral. En los humanos, el control se ejerce fundamentalmente sobre la cantidad de hierro que se absorbe, más que sobre su excreción. La respuesta inadecuada o la pérdida de respuesta ante las variaciones de los niveles de hierro pueden conducir a la anemia o a su sobrecarga.

\subsubsection{Conceptos actuales del metabolismo del hierro}

Hasta hace algo más de una década solo se conocían tres proteínas que intervenían en el metabolismo del hierro: la ferritina - principal proteína de reserva -, la transferrina principal transportador - y, el receptor de transferrina - indispensable para la internalización del mineral.

En los últimos años se han producido significativos avances en el campo de este metabolismo, que han modificado la visión clásica del mismo, como consecuencia del descubrimiento de un número importante de nuevas moléculas proteicas y también de diferentes funciones de algunas proteínas ya conocidas. Entre estas proteínas se encuentran transportadores de hierro ferroso como el transportador de metales divalentes 1 (DMT1) y la ferroportina (Fpn); enzimas con actividad ferrooxidasa como la hefastina y la ceruloplasmina, o ferrirreductasa como el citocromo b duodenal y proteínas reguladoras como HFE (sigla de términos en inglés conformada por la contracción del gen HLA-H de la hemocromatosis hereditaria, localizado en el 
cromosoma 6p21, y FE por el símbolo del hierro), la hepcidina y la hemojuvelina (HJV), y también un segundo receptor de transferrina $\left(\mathrm{Tf}_{2} \mathrm{R}\right)$.

El hallazgo de estas proteínas, así como la vinculación de las alteraciones de su síntesis con estados patológicos del metabolismo del hierro, han conducido a una mejor comprensión del mismo y han modificado los modelos previos de regulación de la homeostasia del hierro.

Como vimos, a nivel intestinal, el hierro es absorbido por el enterocito en la porción proximal del duodeno. Lo incorpora en estado ferroso por medio del transportador de membrana llamado DMT1 (Transportador Divalente de Metales 1), a través del cual se absorben otros cationes como lo son el Calcio, el Cobre, el Magnesio, entre otros, los cuales pueden competir con el hierro a la hora de su absorción. La conversión del metal de su estado férrico a ferroso requiere de una enzima llamada reductasa férrica duodenal (CytbRD1), localizada en la membrana apical del enterocito junto al canal DMT1.

La CytbRD1, requiere de un $\mathrm{pH}$ ácido para su adecuado funcionamiento como agente reductor, de lo contrario, en un ambiente alcalino se favorece el mantenimiento del hierro en su estado férrico y de esta manera se obstaculiza el paso del mismo a través del DMT1.

A nivel de la membrana basolateral del enterocito se requiere de otro transportador llamado ferroportina y junto a esta se encuentra la proteína hefastina (enzima ferrooxidasa similar a la ceruloplasmina), que se encarga de la conversión del hierro para que pueda ser transportado por la transferrina en el torrente sanguíneo.

A nivel de los macrófagos, el hierro obtenido de los eritrocitos senescentes, es liberado o captado por la transferrina, lo mismo que por la ferroportina, la cual en estas células se encuentra junto a la ceruloplasmina y no junto a la hefastina que si está presente en los enterocitos.

En los hepatocitos probablemente exista un proceso de liberación similar, aún no esclarecido por completo. 
Se dice que existen tres mecanismos por los cuales el organismo controla la absorción intestinal del hierro. El primero de los mecanismos se encuentra modulado por la cantidad del elemento consumido durante la dieta, de manera que si este sobrepasa el límite establecido durante la maduración del enterocito en las criptas, se puede bloquear en cierta forma el porcentaje del metal absorbido. Este mecanismo opera en forma independiente de que el hierro corporal total y las reservas se encuentren disminuidos. El segundo de los mecanismos reguladores responde al hierro corporal total y a sus reservas, más que a la dieta, y posee la capacidad de modificar la absorción según sea la disminución o aumento del hierro corporal total. En este mecanismo de regulación se ha propuesto la participación de un péptido llamado hepcidina (Ganz T., 2003), el cual es sintetizado por los hepatocitos y tiende a sobreexpresarse en casos de sobrecarga de hierro. Su mecanismo de acción tiene como efecto la disminución en la biodisponibilidad del hierro, por medio de la intervención en el paso del metal a través de la membrana basolateral del enterocito hacia la transferrina en el plasma. Esto lo realiza a través de la unión a la ferroportina, la proteína transportadora que actúa como receptor de la hepcidina, y que tras su unión la ferroportina es internalizada y conducida a proteólisis, con lo que la capacidad de transporte del hierro a través de dicha membrana disminuirá.

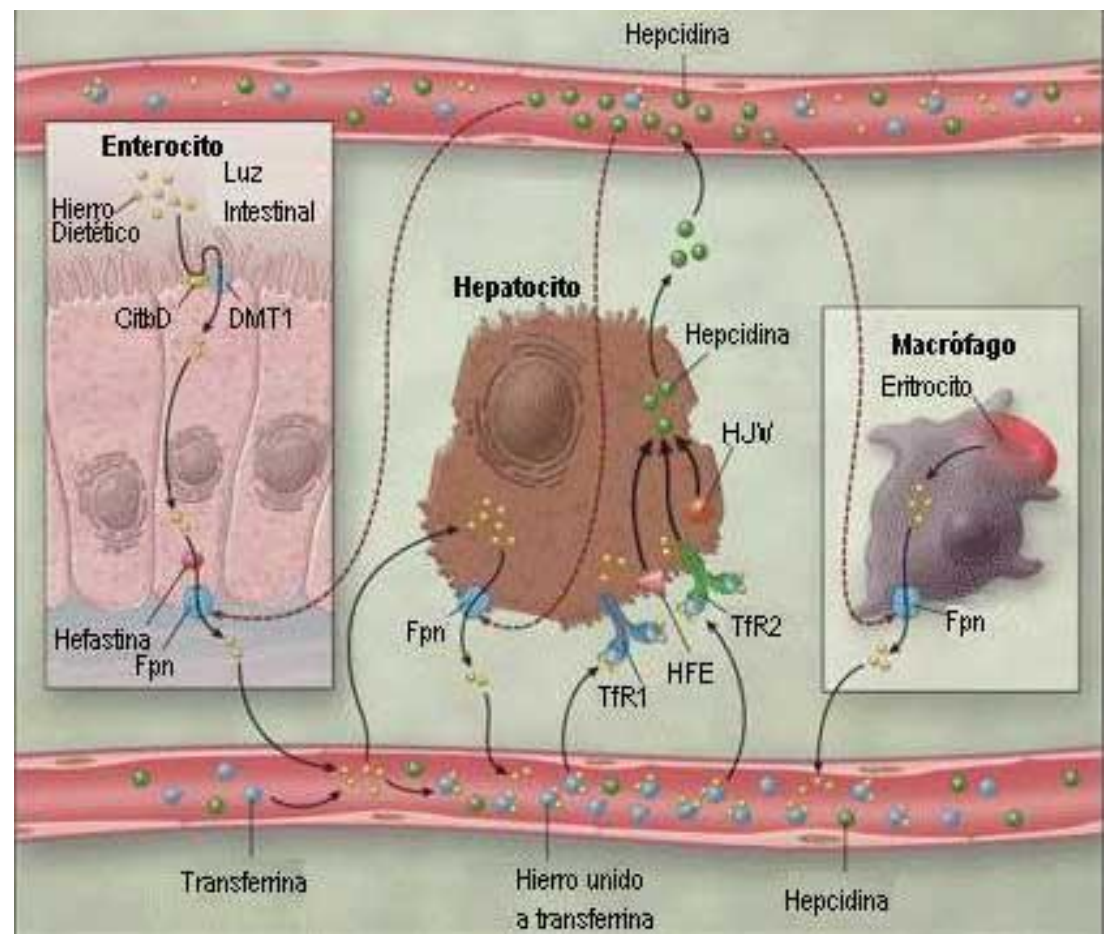

Figura1-3: Participación de las nuevas proteínas en la homeostasia del hierro (tomado de Forrellat Barrios et al., 2005) 
Lo mismo sucede a nivel de los macrófagos, donde la hepcidina se une a la ferroportina, y limita la liberación del hierro reciclado a la circulación (Fig.1-3). Este es el mecanismo que influye en la fisiopatología de la anemia por enfermedad crónica, ya que agentes inflamatorios como IL-1, IL-6, entre otros, estimulan la producción de hepcidina por los hepatocitos y de esta manera se disminuiría la liberación del hierro desde las reservas hacia los sitios de utilización.

El tercero de los mecanismos reguladores, es el llamado regulador eritropoyético, el cual se ejecuta a través de una señal evocada por la médula ósea, conduciendo a una supresión de la hepcidina y, por tanto, a un aumento en la absorción intestinal del hierro. Esto sucede, independientemente de que las reservas corporales del elemento estén aumentadas. Suele presentarse en casos de eritropoyesis ineficaz y en anemias hemolíticas, originando cuadros de hemocromatosis adquiridas.

La identificación y caracterización de las proteínas mencionadas ha conducido a la modificación de los modelos clásicos de regulación de la homeostasia del hierro. Así, actualmente, es un hecho casi indiscutible, el papel central del hígado en determinar cuánto hierro se absorbe en el intestino y su influencia en la liberación del metal a partir de los sitios de reserva. Además, hay que tener en cuenta que no se conocen mecanismos fisiológicos que regulen la pérdida de hierro, por lo que la homeostasia del mismo dependerá de la retroalimentación que se establece entre las necesidades corporales y la absorción intestinal de hierro.

El descubrimiento de la hepcidina ha revelado la importancia del hígado en el monitoreo del estado de hierro y en la modulación de la liberación del hierro celular mediada por la ferroportina, pues la hepcidina, disminuye la actividad funcional de la ferroportina mediante la unión directa a esta proteína, que conduce a la internalización y degradación de la ferroportina. En el enterocito, esta acción podría disminuir el transporte basolateral del hierro y así disminuir su absorción. Asimismo, en los macrófagos y hepatocitos, la hepcidina puede intervenir en la exportación del hierro y en la disminución de las reservas.

La expresión de la hepcidina en el hígado es regulada por los mismos factores que afectan la absorción del hierro, por lo tanto, cuando alguno de estos factores se altera, la absorción de hierro varía inversamente con la expresión hepática de la hepcidina.

A su vez, la expresión de esta proteína es afectada por el Tf $\mathrm{R}_{2}$, la HFE y la HJV y se ha planteado que estas moléculas operan en la ruta de control de la homeostasia del 
hierro por encima de la hepcidina, mientras que la ferroportina está por debajo de dicha molécula (Forrellat Barrios et al., 2005).

Actualmente se piensa que el hepatocito no solo es el sitio de almacenamiento de los depósitos de hierro, sino que es el centro de control del mantenimiento de la homeostasia de este mineral, pues él recibe múltiples señales relacionadas con el balance del hierro y es el responsable del control transcripcional de la hepcidina.

\subsection{Importancia del estudio del estado del hierro}

El desequilibrio de los mecanismos de regulación dependientes de la concentración de hierro, puede originar trastornos hematológicos como ciertas anemias o estados de sobrecarga de hierro cuya exploración, por medio del estudio del estado del hierro, permitirá llegar al diagnóstico más confiable y preciso.

Entre las anemias, la anemia ferropénica causada por una deficiencia en la calidad o en la cantidad de hierro en la dieta, es la carencia nutricional más frecuente, afectando a un $34 \%$ de la población mundial, de los cuales un $80 \%$ viven en los países en vías de desarrollo, en los cuales los grupos mas afectados son los niños debido a los mayores requerimientos determinados por el crecimiento, y la mujer en edad fértil por la pérdida de hierro debida al sangramiento menstrual o a las mayores necesidades de este mineral durante el embarazo.

En estos países, se estima que entre 30 y $40 \%$ de los niños más jóvenes y las mujeres pre-menopaúsicas están afectados por la deficiencia de hierro, llegando a valores de hasta un $80 \%$ en algunas poblaciones infantiles de Latinoamérica, mientras que en los países desarrollados su prevalencia es de un $10 \%$ o inferior a dicho valor (Olivares G. M. et al, 2003; Boccio et al., 2004).

Nuestro país se encuentra en proceso de transición nutricional, en el cual predomina el retraso del crecimiento, el sobrepeso y la carencia de micronutrientes (Britos S., 2008). Entre estas últimas, el déficit de hierro representa una problemática prioritaria, debido a la gran cantidad de personas que se encuentran afectadas, como también por las 
consecuencias funcionales que produce y que, en algunas ocasiones, es irreversible (Hallberg L. et al., 2001).

La anemia por deficiencia de hierro, compromete el desarrollo intelectual de los niños, el sistema inmunitario, la capacidad de trabajo muscular, y representa riesgos durante el embarazo y el parto (Schwarcz R. et al., 2001).

De acuerdo con la Encuesta Nacional de Nutrición y Salud, en nuestro país presentan anemia $16 \%$ de los menores de 5 años, $35 \%$ de los niños de 6-24 meses de edad y $20 \%$ de las mujeres en edad fértil. Esta prevalencia varía en las distintas regiones, con valores considerablemente mayores en las de peores condiciones socioeconómicas; por ejemplo, en el noreste, la prevalencia de anemia en menores de 2 años llega a casi 46\% (ENNyS, 2007).

Se han comunicado cifras aun más elevadas. Un estudio sobre prevalencia en niños de 6-24 meses del Gran Buenos Aires mostró que 60\% presentaba deficiencia de hierro y 47\% estaban anémicos (Calvo E.B. et al., 1990; Morasso M.C. et al., 2003; Donato H. et al., 2009).

El estado nutricional de hierro de una persona depende del balance determinado por la interacción entre contenido en la dieta, biodisponibilidad, pérdidas y requerimientos por crecimiento. Existen períodos de la vida - Primer año de vida, Adolescencia, Embarazo - en que este balance es negativo y el organismo debe recurrir al hierro de depósito para sostener una eritropoyesis adecuada. Durante estos tres períodos, una dieta con insuficiente cantidad o baja disponibilidad de hierro agrava el riesgo de desarrollar una anemia ferropénica (Donato H. et al., 2005).

Si bien el descenso de la ferremia o hipoferremia es característico de la anemia ferropénica, también puede observarse en todas aquellas situaciones que se acompañan de un bloqueo del hierro en las células del sistema mononuclear fagocítico, tales como los síndromes inflamatorios crónicos, enfermedades sistémicas y los procesos neoplásicos avanzados.

En estos casos la anemia se instaura por una desaceleración general de la eritropoyesis pues las citocinas $\left(\mathrm{TNF}, \mathrm{IL}_{1}, \mathrm{IL}_{6}\right)$ liberadas por los macrófagos tienen un efecto inhibidor sobre la eritropoyetina. Se origina una anemia normocítica de largo tiempo que deviene microcitaria cuando está muy evolucionada por retención del hierro por los macrófagos (Lafay M., 2003). 
En casos de sobrecarga de hierro, el hallazgo de una hipersideremia juntamente con el estudio del estado del hierro puede ser de gran utilidad para patologías de menor frecuencia como hemocromatosis y algunas anemias tal como las hemolíticas, macrocitarias y aplásicas. Es típica en la anemia sideroblástica y, así mismo, el hierro aumenta en síndromes talasémicos, por intoxicación con plomo, isoniazidas, alcohol y radioterapia, y en la porfiria hepatocutánea tardía.

\subsection{Parámetros mínimos del diagnóstico diferencial}

El diagnóstico diferencial de la hipoferremia se establece mediante la certeza de una carencia marcial. Generalmente la medida del hierro sérico se acompaña de una determinación de la transferrina, de la capacidad total de fijación de hierro (CTFH) y del coeficiente de saturación de la transferrina que estará disminuido; pudiendo agregar a este perfil, la valoración de la ferritina cuyo valor si es muy bajo ayudará a confirmar una carencia de hierro, pero un resultado normal no asegura descartar esta etiología.

La ferremia y la CTFH son parámetros que se relacionan con el intercambio de hierro entre el sistema retículoendotelial y la médula ósea. La transferrina es la principal proteína relacionada con el transporte de hierro en sangre, y como consecuencia de ello, el contenido de hierro en el suero refleja el número de átomos de hierro unidos a la transferrina. Cada molécula de transferrina puede unir hasta dos átomos de hierro, razón por la cual la CTFH está relacionada con la fracción de sitios libres que posee la transferrina para el transporte de hierro; en consecuencia el porcentaje de saturación de transferrina puede calcularse como la relación entre la ferremia y la CTFH multiplicada por 100. Estos tres parámetros son particularmente útiles para diferenciar los estados deficitarios de hierro de causas nutricionales con respecto de aquellos que son consecuencia de diferentes patologías, asociadas a procesos de infección e inflamación crónicos.

En los casos en que la anemia se asocia a las patologías crónicas puede utilizarse otro marcador, el receptor soluble de la transferrina (TfRs) que indica el número de receptores de $\mathrm{Tf}$ presentes en la superficie de las células y especialmente de los 
eritroblastos y cuya síntesis está sujeta a las reservas de hierro funcional, pues aumenta en las anemias por carencia de hierro, mientras que es normal en los casos de una mala utilización del hierro como en las anemias inflamatorias o sideroblásticas.

Sin embargo, tanto el hierro del suero como la transferrina están sujetos a grandes fluctuaciones debido a factores como la dieta, y no siempre reflejan de forma fiable las reservas de hierro. Además, la transferrina es una ß-proteína de fase aguda y como tal sus niveles en suero pueden variar (normalmente disminuir, como una proteína de fase aguda negativa) en condiciones de inflamación. Existe un solapamiento considerable entre los niveles de hierro en suero y la capacidad de unir hierro en la anemia ferropénica y en la enfermedad crónica.

Una medida un poco más discriminatoria de la anemia ferropénica es la relación de hierro en suero y la CTFH. Esta relación es de alrededor de 1:3 en individuos normales, mientras que en la anemia ferropénica aparecen valores muy reducidos de 1:5 o inferior. De nuevo, existe un solapamiento importante incluso de esta relación entre pacientes con anemia ferropénica y de enfermedad crónica, de modo que los valores siempre deben interpretarse con cuidado (Henry et al., 2005).

Por el contrario, en exceso de hierro, el diagnóstico diferencial de hemocromatosis se define en términos fenotípicos y las alteraciones genéticas muestran la susceptibilidad para su desarrollo. También, en este caso, la investigación debe iniciarse con el estudio del perfil o estado del hierro y completarse con estudios genéticos (Del Castillo Rueda A. et al., 2002).

En la sobrecarga de hierro, los valores de hierro sérico elevados y la saturación de transferrina (indicador analítico más sensible) superior a 50\% en la mujer y $70 \%$ en el hombre (Garrido L. L., 2003) ya indican la posibilidad de diagnosticar una hemocromatosis. Asimismo, una vez confirmado el diagnóstico de hemocromatosis por la presencia de un trastorno autosómico recesivo con sobrecarga de hierro, asociado con la mutación del gen HFE ubicado en el cromosoma 6, el seguimiento del tratamiento, desde el laboratorio clínico, se puede realizar por la evaluación de la saturación de transferrina hasta que esta disminuya por debajo del $30 \%$, y la ferritina del suero sea menor de $50 \mathrm{ng} / \mathrm{ml}$ (Pietrangelo A., 2004). 
Aquí es importante recordar que del $6 \%$ de población americana con un significativo balance negativo del hierro, menos del $1 \%$ presenta una sobrecarga de hierro que puede estar implicada como factor de riesgo en el infarto del miocardio, y también como un factor de la patogénesis de la artritis reumatoide (Tietz N.W., 1994; Herbert V., 1992; Salonen J.T. et al., 1992; Vreugdenhil G. et al., 1992).

\subsection{Evolución de la metodología empleada para medir hierro sérico}

La medición de hierro sérico o ferremia y de su proteína trasportadora transferrina, así como la determinación de la capacidad total de fijación de hierro, juegan un rol sobresaliente como herramientas de diagnóstico en el estudio de los pacientes hematológicos, especialmente en la diferenciación de las anemias microcíticas y de procesos crónicos y en los procesos de sobrecarga de hierro libre.

Sin embargo, con frecuencia, se sospecha de la precisión y exactitud de los métodos de rutina utilizados en el laboratorio de análisis clínicos para la determinación de la ferremia, los cuales son muy sensibles a errores técnicos y están sujetos a variaciones nicteméricas atribuibles a vaivenes en las transferencias del hierro entre sitios de almacenamiento y los sitios de utilización. Además, la sola medida del hierro no es fácilmente interpretable debido a la elevada variabilidad biológica intraindividuo (Zilva J.F. et al., 1979; Eckfeldt J.H. et.al., 1994; Fraser C.G., 2001; Thomas C. et al., 2002; Brugnara C. 2002).

Uno de los métodos pioneros en la determinación de hierro sérico fue el de Barkan y Walker (Barkan G.y Walker B.S., 1940) que midió el color rojo desarrollado por el ión ferroso con la o-fenantrolina en una alícuota del sobrenadante obtenido por precipitación del suero con ácido tricloroacético (ATC).

A partir de 1950, se establecieron varios procedimientos que bien pueden considerarse analíticamente correctos, en términos generales. Todos incluyen tres fases analíticas: separación del $\mathrm{Fe}^{+3}$ de la transferrina, reducción del $\mathrm{Fe}^{+3}$ a Fe ${ }^{+2}$ y por último, reacción del $\mathrm{Fe}^{+2}$ con algún cromógeno. 
Varios han sido los métodos manuales propuestos como los de Trinder P. (1956); Ramsay, W. N. (1958); Levy A.L.y Vitacca P. (1961); Caraway W.T. (1963), y muchos otros, los cuales resultan engorrosos cuando se deben procesar múltiples análisis en un laboratorio clínico.

Así surgieron los métodos automatizados, especialmente basados en los procedimientos de Young D.S. y Hicks J.M. (1965) y los de Zak B. y Epstein E. (1965). Estos métodos automatizados para la determinación de hierro sérico utilizaron el Autoanalizer System of Technicon Instruments Company Ltd. y el Technicon Auto Analyzer Continuos Filter equipados con resinas de intercambio iónico para las muestras en las que también se midió la CTFH y se debía remover el hierro no unido (Giovanniello T.J., et al., 1968).

El incremento de la solicitud de la determinación de hierro en los pacientes pediátricos, motivó la propuesta de microtécnicas simples y adaptables a pequeños laboratorios de química clínica. Con este motivo, Giovanniello T.J. et al. en el año 1979 presentaron una adaptación del método de Barkan G.y Walker B.S. (1940) modificado por Peters T., et al.(1956), utilizando $20 \mathrm{ml}$ de suero y reemplazando la batofenantrolina por ferrozina. El cromógeno ferrozina ya había sido introducido, por el ICSH en1978 y revisado en 1990 (Iron Panel-ICSH, 1990).

Investigaciones posteriores preconizaron métodos que no utilizan la desproteinización previa y determinan directamente el hierro en el suero. Estos procedimientos tienen la desventaja de producir turbiedad debido a la alta proporción de suero empleado debido a que la reacción cromogénica desarrolla a un $\mathrm{pH}$ cercano al punto isoeléctrico de muchas seroproteínas.

Para mejorar este inconveniente se ensayaron técnicas con soluciones buffer de tiosemicarbazida en medio clorhídrico que a un $\mathrm{pH}$ de 1,65 permite que se forme el complejo coloreado de ferrozina con hierro $\mathrm{y}$, a ese rango de $\mathrm{pH}$ y en presencia de un agente reductor, se asegura que el hierro es rápida y completamente liberado de la transferrina (Ceriotti F.y Ceriotti G., 1980).

En otro trabajo (Mori L., et al., 1981) se utliza Triton X-100, un surfactante, para disminuir la turbidez y tiosemicarbazida que elimina la interferencia del cobre pues forma un complejo incoloro. Es la modificación y adaptación del método de Ceriotti y Ceriotti al analizador ABA-100 bicromático (Abbott Diagnostics Division Analytical Systems, South Pasadena, CA 91030). 
También Levinson S.S., en1980, adaptó y modificó el método para el ABA-50 que es similar al recomendado por Sigma (Sigma Chemical Co., St. Louis, M0 63178).

Ambos procedimientos comparten las desventajas de la dependencia sobre un equipo comercial, que si bien disminuye el trabajo intensivo en un laboratorio clínico aumenta el costo del reactivo (Mori L. et al., 1981).

También se realizó otra adaptación del método de Ceriotti y Ceriotti utilizando el COBAS BIO centrifugal analizer (Roche Analytical Instruments, Inc., Nutley, NJ 07110) y se encontró una excelente correlación entre los resultados obtenidos por este procedimiento y el método que emplea el ACA III (DuPont, Wilmington, DE 19898). Durante el curso de los estudios de precisión surgió, como fuente de error, que una leve turbidez al momento de la lectura del blanco, si bien es rara, cuando ocurre es causa de medidas de absorbancia muy altas. Asimismo se observó que, cuando las concentraciones de hierro son bajas, existe una diferencia del $1 \%$ entre los valores de los duplicados que se estimó entre 0,05 a $0,18 \mathrm{mg} / \mathrm{L}$; este error no pudo ser eliminado por cambios en la concentración de Triton X-100 agregado, en el pH o en el volumen de muestra utilizado (Schlosnagle D. C., 1982).

En la Tabla 1-1 se muestran varios de los métodos que se han empleado en la evaluación del hierro sérico, desde los tediosos métodos con incubación previa a la desproteinización, incluyendo el método recomendado por el estándar H17-A del Clinical and Laboratory Standards Institute (CLSI), hasta los primeros métodos automatizados.

Tabla 1-1: Características metodológicas de los métodos que se han utilizado en la determinación de hierro sérico

\begin{tabular}{|c|c|c|c|}
\hline \multicolumn{3}{|c|}{ Métodos manuales } \\
\hline $\begin{array}{c}\text { Volumen suero/ } \\
\text { otras } \\
\text { condiciones }\end{array}$ & Reductor & $\begin{array}{c}\text { Cromógeno/ } \\
(\lambda)\end{array}$ & Método \\
\hline $\begin{array}{l}\text { CDe* } 2 \mathrm{ml} \\
+\mathrm{HCl} \mathrm{a} 37^{\circ} \mathrm{C}, 1 \mathrm{~h} \\
+\mathrm{ATC} 1 \mathrm{~h} ; \mathrm{pH} 4,5\end{array}$ & $\begin{array}{c}\text { Acetato de sodio } \\
1 \mathrm{~h}\end{array}$ & $\begin{array}{c}\text { Fenantrolina. } \\
(490 \mathrm{~nm})\end{array}$ & $\begin{array}{c}\text { Barkan G.y Walker B.S. } \\
(1940)\end{array}$ \\
\hline
\end{tabular}




\begin{tabular}{|c|c|c|c|}
\hline $\begin{array}{l}\text { CDe* } 2 \mathrm{ml} \\
+ \text { ATC a } 90-95^{\circ} \mathrm{C}, \\
10^{\prime}\end{array}$ & $\begin{array}{l}\text { Ác.tioglicólico } \\
+ \text { Acetato de } \\
\text { sodio }\end{array}$ & $\begin{array}{c}\text { 4:7 Difenil 1:10 } \\
\text { fenantrolina+ Ac. } \\
\text { clorosulfónico. } \\
\text { (624 nm) }\end{array}$ & $\begin{array}{c}\text { Trinder P. } \\
\text { (1956) }\end{array}$ \\
\hline $\begin{array}{l}\text { CDi** } \\
0,5 \mathrm{ml}(\mathrm{f}=4) \text { ó } 2 \mathrm{ml} \\
\text { +reductor a } 100^{\circ} \mathrm{C}, \\
\quad 5^{\prime} \\
\quad \text { pH: } 5,3\end{array}$ & $\begin{array}{l}\text { Sulfito de sodio } \\
+ \text { Ác.acético }\end{array}$ & $\begin{array}{c}\text { 2,2’ Di - piridil } \\
\text { fenantrolina. } \\
\text { Extrae con } \\
\text { Cloroformo } 30^{\prime \prime} . \\
\text { (520 nm })\end{array}$ & $\begin{array}{c}\text { Ramsay W.N. } \\
\text { (1958) }\end{array}$ \\
\hline $\begin{array}{c}\text { SDe }^{\mathbf{a}} \quad 0,6 \mathrm{ml} \\
+ \text { Buffer fosfato } \\
\text { pH: } 4,3\end{array}$ & Ác.ascórbico & $\begin{array}{c}\text { Terperidine } \\
\text { a } 45^{\circ} \mathrm{C}, 20^{\prime} \\
(552 \mathrm{~m})\end{array}$ & $\begin{array}{c}\text { Levy A.L.y Vitacca P. } \\
\text { (1961) }\end{array}$ \\
\hline $\begin{array}{l}\text { CDe* } \\
\begin{array}{c}0,1 \mathrm{ml}(\mathrm{f}=20) \text { ó } 2 \mathrm{ml} \\
+ \text { ATC } \\
+ \text { Cloroformo } \\
\text { pH: } 4-5\end{array}\end{array}$ & $\begin{array}{c}\text { Ác.ascórbico } \\
\text { + HCL }\end{array}$ & $\begin{array}{c}\text { TPTZ } \\
+ \text { Ac. Acético }+ \\
\text { Acetato de amonio. } \\
\quad(590 \mathrm{~nm})\end{array}$ & $\begin{array}{c}\text { Caraway W.T. } \\
\text { (1963) }\end{array}$ \\
\hline $\begin{array}{c}\text { CDe }^{*} \quad 2 \mathrm{ml} \\
+ \text { ATC + reductor } \\
\text { a } 56^{\circ} \mathrm{C}, 15^{\prime}\end{array}$ & $\begin{array}{l}\text { Ác.tioglicólico } \\
+ \text { HCL }\end{array}$ & $\begin{array}{c}\text { Disodio 4:7 Difenil } \\
\text { 1:10 fenantrolina } \\
\text { disulfonato }+ \\
\text { acetato de sodio. } \\
\quad(535 \mathrm{~nm})\end{array}$ & $\begin{array}{l}\text { Bothwell T.H. et al. } \\
\text { (ICSH Expert Panel) } \\
\text { (1978) }\end{array}$ \\
\hline $\begin{array}{c}\text { CDe }^{*} \quad 0,2 \mathrm{ml} \\
+ \text { ATC } \\
+ \text { reductor }\end{array}$ & $\begin{array}{c}\text { Ác.tioglicólico } \\
+ \text { HCL }\end{array}$ & $\begin{array}{c}\text { Ferrozina } \\
+ \text { Acetato de sodio. } \\
(562 \mathrm{~nm})\end{array}$ & $\begin{array}{l}\text { Giovanniello T.J. et al. } \\
\text { (1979) }\end{array}$ \\
\hline
\end{tabular}




\begin{tabular}{|c|c|c|c|}
\hline $\begin{array}{l}\mathrm{CDe}^{*} 0,5 \mathrm{ml}(\mathrm{f}=4) \\
+\mathrm{ATC}+ \\
\text { reductor a } 56^{\circ} \mathrm{C}, 15^{\prime} \\
\text { pH: } 4,5\end{array}$ & $\begin{array}{l}\text { Ác.tioglicólico } \\
+ \text { HCL }\end{array}$ & $\begin{array}{c}\text { Ferrozina }(562 \mathrm{~nm}) \\
\qquad o \\
\text { Ferene }(593 \mathrm{~nm})\end{array}$ & $\begin{array}{l}\text { Iron panel of ICSH } \\
\qquad(1990)\end{array}$ \\
\hline $\begin{array}{c}\text {----------- } \\
\text { SeAu }^{\mathbf{a} a} \quad 0,3 \mathrm{ml} \\
+\mathrm{ClNa}+\mathrm{HCL}+\text { Brij } \\
\text { (diálisis) } \\
\text { + reductor }\end{array}$ & $\begin{array}{c}\begin{array}{c}\text { Ác.ascórbico } \\
+\mathrm{HCl}\end{array} \\
\text { ClNa + HCL+ } \\
\text { Ac.ascórbico }\end{array}$ & $\begin{array}{c}\text { Ferrozina }(562 \mathrm{~nm}) \\
\text { ó } \\
\text { Ferene }(593 \mathrm{~nm}) \\
\text { +Tiourea } \\
\text { +Acetato de sodio } \\
\text {----------- } \\
\text { Ferrozina }(562 \mathrm{~nm}) \\
\text { ó } \\
\text { Ferene }(593 \mathrm{~nm}) \\
\text { +Tiourea } \\
\text { +Acetato de sodio } \\
\text { (570 nm) }\end{array}$ & $\begin{array}{l}\text { Van Assendelft O.et al. } \\
\text { (1998) }\end{array}$ \\
\hline \multicolumn{4}{|c|}{ Métodos automatizados } \\
\hline $\begin{array}{l}\text { Vol. dilución de } \\
\text { suero (Dil)/ otras } \\
\text { condiciones }\end{array}$ & Reductor & $\begin{array}{c}\text { Cromógeno } \\
(\lambda)\end{array}$ & Método \\
\hline $\begin{array}{c}\text { Dil + reductor + } \\
\text { Tween } 20 . \\
\text { (diálisis) }\end{array}$ & $\begin{array}{c}\text { Ác.ascórbico } \\
+\mathrm{HCl}\end{array}$ & $\begin{array}{c}\text { TPTZ + } \\
+ \text { HCL+Tween }+ \\
\text { Acetato de amonio. } \\
\quad(600 \mathrm{~nm})\end{array}$ & $\begin{array}{l}\text { Young D.S.y Hicks J.M. } \\
\text { (1965) }\end{array}$ \\
\hline $\begin{array}{c}\text { Dil + reductor } \\
\text { (diálisis) } \\
+ \text { acetato de sodio } \\
\text { pH: } 4,65\end{array}$ & $\begin{array}{l}\text { Ác.ascórbico } \\
+\mathrm{HCl}\end{array}$ & $\begin{array}{c}\text { 4,7-Difenil-1,10 } \\
\text { fenantrolina } \\
\text { sulfonato } \\
(534 \mathrm{~nm})\end{array}$ & $\begin{array}{l}\text { Zak B.y Epstein E. } \\
\qquad(1965)\end{array}$ \\
\hline $\begin{array}{c}\text { Dil + reductor + } \\
\text { ClNa + Tween20. } \\
\text { (filtros / resina) }\end{array}$ & $\begin{array}{l}\text { Ác.tioglicólico } \\
+ \text { HCL }\end{array}$ & $\begin{array}{l}\text { Batofenantrolina } \\
\qquad(535 \mathrm{~nm})\end{array}$ & $\begin{array}{c}\text { Giovanniello T.J. et al. } \\
\text { (1968) }\end{array}$ \\
\hline
\end{tabular}




\begin{tabular}{|c|c|c|c|}
\hline $\begin{array}{c}\text { Dil + reductor }+ \\
\text { Tiosemicarbazida }\end{array}$ & $\begin{array}{c}\text { Ác.ascórbico } \\
+\mathrm{HCl}\end{array}$ & $\begin{array}{c}\text { Ferrozina } \\
(562 \mathrm{~nm})\end{array}$ & $\begin{array}{c}\text { Ceriotti F.y Ceriotti G. } \\
(1980)\end{array}$ \\
\hline $\begin{array}{c}\text { Dil + reductor } \\
\text { a } 37^{\circ} \mathrm{C}, 10^{\prime}\end{array}$ & Hidroxilamina & $\begin{array}{c}\text { Batofenantrolina } \\
(550 / 560 \mathrm{~nm})\end{array}$ & $\begin{array}{c}\text { Levinson S.S. } \\
(1980)\end{array}$ \\
\hline $\begin{array}{c}\text { Dil + reductor }+ \\
\text { Tiosemicarbazida }+\end{array}$ & Ác.ascórbico & Ferrozina & Mori L. et al. \\
TritonX-100 & $+\mathrm{HCl}$ & $(550 / 560 \mathrm{~nm})$ & (1981) \\
& & & \\
\hline Dil + reductor & Ác.ascórbico & Ferrozina & Schlosnagle D.C. et al. \\
& $+\mathrm{HCl}$ & $(562 \mathrm{~nm})$ & (1982) \\
\hline
\end{tabular}

\section{Referencias:}

\section{*: con desproteinización \\ a: sin desproteinización}
**: con digestión
a a : semiautomatizado

En la práctica clínica los métodos colorimétricos para hierro sérico son procedimientos que se siguen usando. A pesar del advenimiento de los métodos automatizados, es aún frecuente en países en desarrollo la utilización de métodos manuales para la determinación de este analito (Sosa M. et al., 2001).

En nuestro medio, con el objeto de estimar los recursos que están en uso en los laboratorios participantes del Programa de Evaluación Externa de la Calidad (PEEC) en el Subprograma Hematología de la Fundación Bioquímica Argentina, se realizó una encuesta con la finalidad de conocer los métodos y reactivos empleados (Fernández Alberti M.A. et al., 2002). Los métodos más utilizados según dicho relevamiento, usan 
colorimetría directa en un 84,3\%. El fundamento del mismo es la liberación del ión férrico de su proteína transportadora, posterior reducción a ión ferroso y medición espectrofotométrica de un complejo coloreado que forma el hierro con un reactivo cromogénico.

Por otra parte, el método propuesto por el Comité Internacional para Estandarización en Hematología (Bothwell T.H. et al., 1978) y recomendado por el CLSI utiliza un método que en una primera etapa incluye la precipitación de las proteínas con ácido tricloroacético; se reduce el hierro férrico al estado ferroso con ácido ascórbico y se mide el hierro en el sobrenadante, por formación de un complejo coloreado con un cromógeno (Van Assendelft O.W.et al., 1998).

\subsection{Interferencias en la medición de hierro sérico}

En química clínica, un problema es la interferencia que frecuentemente producen las proteínas del suero y del plasma en ciertos procedimientos.

En situaciones clínicas especiales, como son los pacientes sometidos a hemodiálisis renal, se han obtenido resultados elevados para hierro sérico medido por métodos directos, atribuidos a la interferencia del fibrinógeno. En el mismo estudio se evaluó el hierro en pacientes cardíacos anticoagulados con heparina pero dicha interferencia no fue observada, debido a que los pacientes renales son anticoagulados hasta obtener un rango de PTT (tiempo parcial de tromboplastina) entre 175 a 200 segundos, mientras que los pacientes cardíacos reciben mucho menos heparina: hasta obtener valores de PTT en el rango de 40 a 70 segundos.

En relación a la medida del hierro sérico el ICSH en 1978 recomienda que las proteínas se remuevan por precipitación con ATC. En este estudio se utilizó como instrumento de medida el American Monitor KDA que por un proceso de flujo continuo remueve las proteínas por diálisis a través de una membrana semipermeable (Technicon Information Bulletin, 1976). El procedimiento del ICSH insume mas tiempo y la mayoría de los analizadores no tienen incorporadas membranas para diálisis. Una alternativa puede ser el uso de detergente para dejar las proteínas en solución, pero ocurre que 
frecuentemente la naturaleza del detergente no es revelada por las casas comerciales que proveen los equipos reactivos (Bunting P.S.y Aggarwal M, 1983).

Otro trabajo recomendó el uso de SDS (dodecil sulfato de sodio) comprobando que las proteínas del suero y del plasma quedan en solución cuando se lo usa diluido 1:3 con ácido clorhídrico $0,1 \mathrm{~mol} / \mathrm{L}$, pero este proceso requiere mayor volumen de muestra (Tietz N., 1976).

A su vez, en otro estudio realizado por comparación entre una adaptación semiautomatizada del método propuesto como método de referencia del CDC y un método que emplea el procedimiento de solubilización con detergente (Triton X-100) y que utiliza el Roche Cobas - Bio analyzer, se encontró que este método automatizado es susceptible a interferencias por hemoglobina, lipemia y bilirrubina (Valcour A.A. et al., 1990).

Aquí es importante mencionar las principales interferencias y fuentes de error a que hacen referencia las recomendaciones del estándar H17-A del CLSI: contaminación, hierro de la hemoglobina, cobre, zinc, materiales de control liofilizados, plasma y la variación diurna propia del analito hierro.

Por otra parte, otros investigadores (Eckfeldt J.H.y Witte D.L., 1994) han señalado la marcada interferencia positiva del cobre, y en menor grado del zinc, como principales iones no ferrosos interferentes.

\subsection{Antecedentes relacionados con los objetivos de este trabajo}

El interés creciente en torno al metabolismo y transporte del hierro en el hombre, ha estimulado la necesidad de establecer métodos exactos, sensibles y reproducibles para la determinación de la ferremia.

La gran diversidad de metodologías y marcas comerciales, en uso en laboratorios locales, para la determinación de hierro sérico, dificultan la comparación de los resultados obtenidos en los diferentes laboratorios.

Entre los antecedentes relacionados con los objetivos del proyecto, organizaciones internacionales como la Federación Internacional de Química Clínica (IFCC) y la Organización Mundial de la Salud (OMS) publicaron los principios y recomendaciones 
sobre evaluación de los juegos de reactivos para diagnóstico utilizados en los laboratorios de salud con recursos limitados, estableciendo que como primera orientación en la validación, selección de métodos y productos analíticos, estos deberán responder a:
a) las necesidades y posibilidades variables de los laboratorios.
b) procesos de evaluación relativamente simples y directos, y
c) la reducción al mínimo de costos y personal para llegar a una decisión.

En la Parte 1 del documento de la IFCC (Logan J.E. et al., 1985a) se establecieron: Consideraciones generales para la selección de Juegos para Evaluación, en base a los estudios realizados por Büttner y otros autores (Büttner J. et al., 1979) quienes confirmaron que las características de factibilidad y de confiabilidad, usadas para describir las particularidades de un método analítico, son válidas para la descripción de un equipo de química clínica. En primer lugar, se debe realizar el examen de la rotulación del producto para la información contenida en los rótulos e inserto, información que deberá contener: denominación, uso que se le va a dar, cantidad, composición, número de lote, almacenamiento, fecha de caducidad, precauciones, método y fabricante (Rubin M. et al., 1979).

Además, el prospecto del envase deberá incluir: pruebas que garanticen la idoneidad del empleo y duración del producto después de abrir el recipiente, aplicaciones concretas de uso y limitaciones según muestras con tipo de interferencias; reactivos y materiales suministrados con el producto y si se necesitara otro material o equipo, especificar la calidad, composición y concentración de los componentes, detalles de los principios de la prueba para identificar su base química, estabilidad de los reactivos abiertos o reconstituidos, detalles sobre tipo de muestras, obtención, conservación, anticoagulantes y almacenamiento, procedimiento de prueba detallado, condiciones experimentales, calibración, registros, incluyendo referencias bibliográficas, especificaciones de la calidad alcanzable, limitaciones de veracidad y precisión, linealidad, sensibilidad y marco útil de concentración, fecha del prospecto del envase, entre otros. 
En la parte 1B del mismo documento se detallan:

Consideraciones generales para: Evaluaciones del funcionamiento analítico de un método, pues los ensayos deberán planearse de modo que permitan calcular la magnitud del error analítico que pueda estar presente en el resultado final de la muestra del paciente, que debe expresarse en las mismas unidades utilizadas para el resultado del paciente.

Las definiciones de necesidades de confiabilidad y de error permisible se basan frecuentemente en premisas diferentes para los requisitos analíticos y clínicos.

La confiabilidad de un solo resultado en el laboratorio como criterio decisivo, si bien depende en parte de la confianza que el médico deposite en él, está determinada por tres elementos de confiabilidad:

1. Confiabilidad horizontal: los resultados obtenidos por distintos laboratorios deben ser comparables.

2. Confiabilidad vertical: la calibración del procedimiento analítico debe estar relacionada con referencias establecidas.

3. Confiabilidad durable: la comparabilidad horizontal se mantiene en el tiempo (Mazziotta D., 2004).

La estimación del error permisible se basa en la dispersión observada en los datos de las pruebas de competencia de los laboratorios y suele expresarse como \pm 2 desviaciones estándar (DE) para abarcar el $95 \%(0,95)$ de la variabilidad prevista alrededor de la media.

En la Parte 2 del documento (Logan J.E. et al., 1985b) de la IFCC/OMS, considerando el desacuerdo existente en cuanto a los métodos de referencia y la limitada disponibilidad, que aún a la fecha existen, de estos últimos en escala mundial, se propone el empleo de una base arbitraria de veracidad fundada en material de referencia, de manera que pueda procederse a la evaluación de un modo directo con una inversión mínima de tiempo y materiales. 
El protocolo, propuesto por Logan J.E. y colaboradores, considera:

- compra de suministros y materiales para una evaluación previa, dos sueros de referencia, una solución madre del analito de concentración conocida y preparación de materiales para el Estudio Ampliado Final

- ejecución de la evaluación preliminar que consiste en tres ensayos de la serie de soluciones de calibración del analito (incluido un blanco a cero) y dos o tres sueros de referencia, analizando cada muestra por triplicado

- con los datos preliminares determinar la linealidad de la prueba y la estabilidad del juego de reactivos

- usando simples criterios de precisión y exactitud, determinar si se continúa con la evaluación

- se comprobará el error causado por sustancias interferentes conocidas o sospechadas, realizando 40 a 60 análisis del juego

- $\quad$ si hasta aquí, el funcionamiento del juego parece satisfacer las necesidades del laboratorio se procede al Estudio Ampliado Final, que consiste en series analíticas de 30 muestras en seis días separados durante un período de tres semanas, a fin de medir el sesgo y la imprecisión obtenidos

- registro de los datos y cálculos. Determinar las desviaciones estándar, el coeficiente de variación y la exactitud del análisis y decidir si el juego de reactivos reúne las condiciones de calidad exigidas.

A su vez, la Guía Aprobada del CLSI, EP10-A sobre Evaluación Preliminar de Métodos Cuantitativos en el Laboratorio Clínico, describe un proceso para la evaluación preliminar de la linealidad, desviaciones, arrastre de la muestra y precisión de un método en el laboratorio clínico, destacando la necesidad de realizarla siempre antes de que el método sea utilizado en muestras de pacientes (Garber C.C. et al, 1998). El objetivo básico es encontrar los posibles problemas que pudiera presentar el método en evaluación, para determinar la aceptabilidad o no del mismo. Como materiales, propone el empleo de tres pooles estables de sueros de pacientes que cubran el rango requerido o el rango clínicamente relevante, que no excedan los límites requeridos. También pueden usarse materiales obtenidos del comercio, como controles o calibradores. 
Establece, como mínimo, la realización de una corrida diaria de diez muestras durante cinco días, para conocer la linealidad y la precisión, sin dejar de inspeccionar los valores marginales en las representaciones gráficas de las corridas. Además, propone el registro de los datos obtenidos para estimar la desviación estándar y computar la variancia dentro y entre cada corrida. Asimismo, indica incorporar en cada corrida sueros de pacientes, con nivel bajo y con nivel alto, que han sido valorados por otros métodos, a modo de control cruzado experimental.

Teniendo en cuenta los antecedentes antes mencionados y dado que, en ausencia de un método definitivo aceptado internacionalmente como método de referencia para la medida de hierro sérico, las comparaciones relativas son válidas, se resolvió realizar este trabajo.

A los fines de evaluar la metodología a seguir, se consideraron diferentes normas como las del EP5-A, EP9-A2, EP10-A del CLSI y las del CDC, y se optó por definir un protocolo de evaluación que se describe en las secciones 4.2.1.5, 4.2.2 y 4.2.3 y que se estableció sobre la siguiente hipótesis de trabajo:

"La determinación de hierro sérico por método directo sin previa desproteinización, presenta buena correlación con el método recomendado por el CLSI, que utiliza desproteinización previa, y asegura un resultado confiable en el momento de diagnosticar patologías en el metabolismo del hierro". 


\section{Objetivos}




\subsection{Generales}

1- Comparación del método recomendado para la determinación de hierro sérico por el CLSI, que utiliza desproteinización previa a la colorimetría, con los métodos utilizados en equipos comerciales de reactivos en uso en nuestro medio, que miden el analito directamente en el suero sin previa desproteinización, por métodos manuales y automatizados.

2- Transferencia de las recomendaciones surgidas de la evaluación comparativa a la red de laboratorios públicos y privados, para el mejoramiento de la calidad analítica de la determinación de ferremia.

\subsection{Específicos}

1- Puesta a punto del método recomendado por el CLSI.

2- Preparación de pooles de materiales controles propios en tres niveles.

3- Asignación de valores de materiales controles propios y de materiales de evaluación externa empleados en Programas nacionales (PEEC-FBA) y extranjeros (Centro Wadsworth, Departamento de Salud del Estado de New York - WCDHNY - y Programa de Evaluación Externa de Calidad del Reino Unido - UK NEQAS) como así también la verificación de valores asignados a controles comerciales.

4- Evaluación de equipos comerciales disponibles en nuestro medio:

4.1- Definir una estrategia de evaluación basado en las recomendaciones actuales.

4.2- Análisis de la presentación del producto.

4.3- Análisis de la factibilidad de la prueba.

4.4- Evaluación del funcionamiento analítico. 


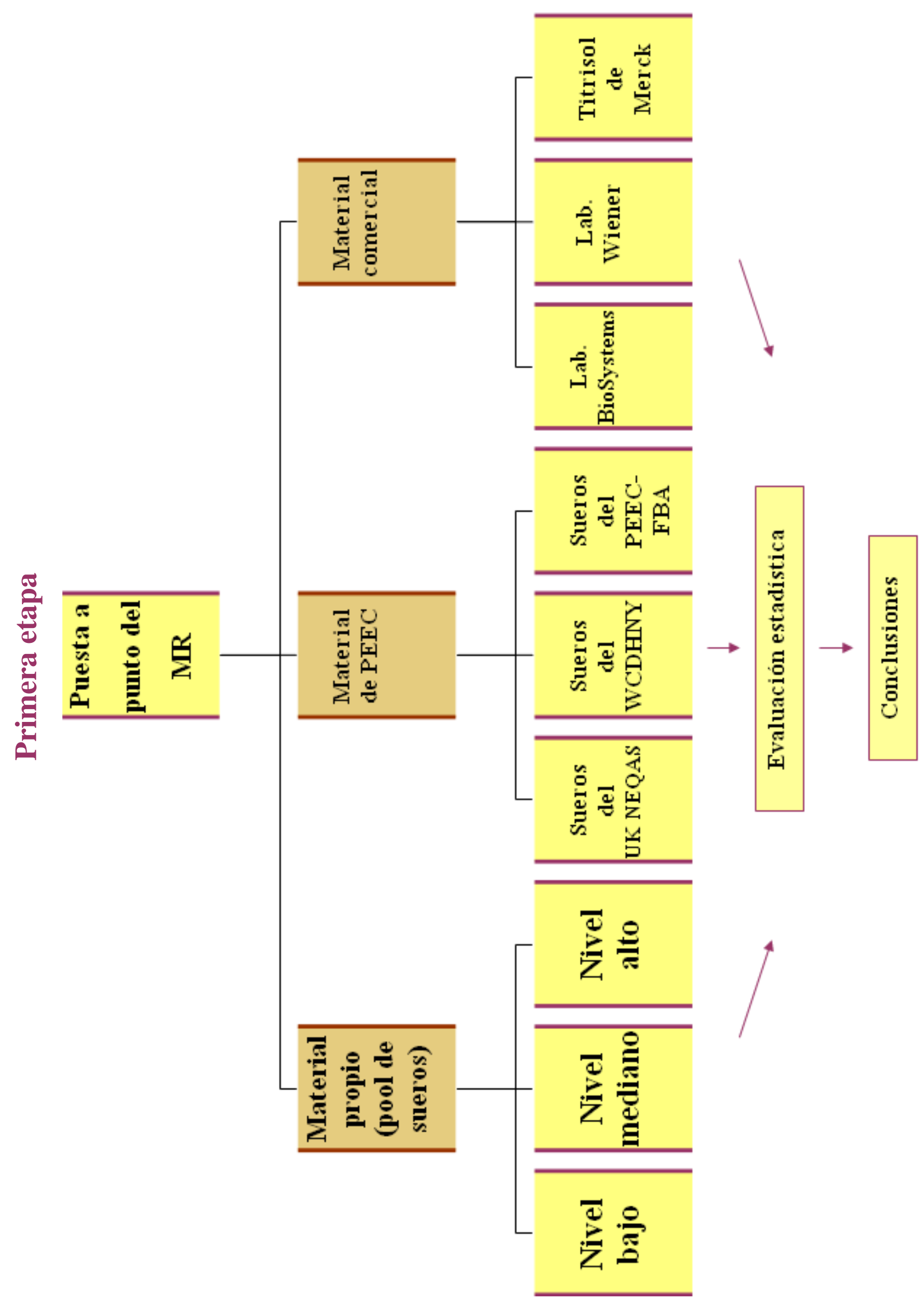




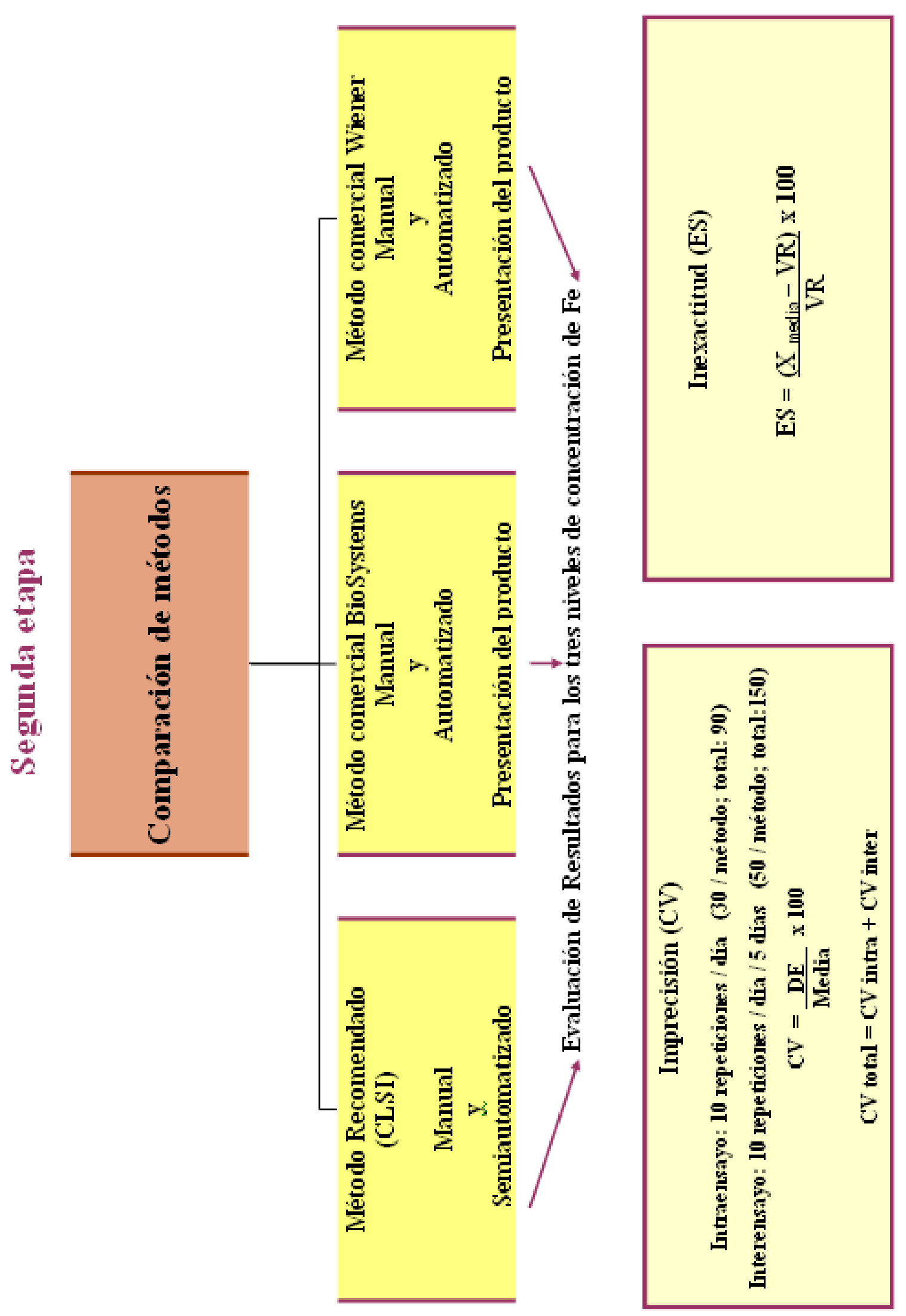




\section{Materiales y Métodos}




\title{
4.1 Materiales
}

\subsubsection{Muestras}

\subsubsection{Materiales de Control comerciales}

\subsection{Soluciones estándares de hierro}

\author{
A - Sueros calibradores \\ Calibrador Bioquímica-Lote 040 AD Ref 18011, BS \\ Calibrador A plus-Lote 0010018240, W \\ B - Sueros controles \\ Control de Bioquímica I-Lote 055 AB Ref 18006, BS \\ Control de Bioquímica II-Lote 055 AA Ref 18008, BS \\ Standatrol S-E nivel 1-Lote 021560, W \\ Standatrol S-E nivel 2-Lote 021560, W
}

\subsection{Titrisol $^{\circledR}$ Patrón de hierro $1000 \mathrm{mg}$ Fe-Merck}

Soluciones de 0,25 - 0,50 - 1,00 - 1,50 - 2,00 y 3,00 mg/L respectivamente, preparadas a partir de la solución de Titrisol ${ }^{\circledR}$ por dilución con agua bidestilada

\subsubsection{Materiales de Control de preparación propia - Pool de sueros}

Se utilizó una mezcla de sueros frescos, obtenidos por punción venosa de personas adultas sanas con un ayuno de 12 horas, sin enfermedad aparente detectada sobre la 
base de los análisis químico-clínicos. Se seleccionaron los sueros de pacientes con datos hematológicos dentro del rango de referencia considerado normal: eritrosedimentación no mayor de $10 \mathrm{~mm}$, hemoglobina no menor de $120 \mathrm{~g} / \mathrm{L}$ y hematocrito no menor de 0,40 .

Las muestras de sangre total obtenidas se dejaron reposar, se retiraron los coágulos cuidadosamente, se centrifugaron a $5.000 \mathrm{rpm}$ durante 20', se decantaron los sueros y se recentrifugaron antes de volcarlos dentro de botellas plásticas que se guardaron en freezer a $-20^{\circ} \mathrm{C}$. Para preparar el pool de sueros y de acuerdo a las indicaciones del PEEC Noticias (Mazziotta D., 1995) se retiraron las botellas del freezer y se dejaron a temperatura ambiente dentro de un recipiente plástico. Cuando la descongelación fue completa, se volcaron los volúmenes de sueros en un erlenmeyer, se colocó un buzo y se llevó a un agitador magnético durante una hora, tapando el erlenmeyer con parafilm. Se filtró a través de gasa estéril y se realizó la determinación de hierro para verificar si la concentración se encontraba dentro del valor considerado normal o mediano.

Inmediatamente, este pool de sueros se dividió en tres lotes, siguiendo las recomendaciones del estándar H17-A del Clinical and Laboratory Standards Institute (CLSI) - Apéndice B sobre la preparación de material de control de calidad (Van Assendelft O.W. et al., 1998b) y se obtuvo:

Lote 1: al que se agregó agua bidestilada comenzando con $1 \mathrm{ml}$ por litro de pool de suero y se fue midiendo el hierro hasta obtener un valor menor de 0,60 mg/L: Nivel Bajo

Lote 2: sin agregados : Nivel Normal o Mediano

Lote 3: al que se agregó $1 \mathrm{ml}$ de solución stock de hierro (1,000 g/L) por cada litro de pool de suero: Nivel Alto

Estos tres lotes de pooles de sueros se fraccionaron en viales libres de hierro a razón de $5 \mathrm{ml}$ por vial utilizando un dispensador Pipet-Aid y se almacenaron a $-35^{\circ} \mathrm{C}$ hasta su uso. 


\subsubsection{Materiales de Control de Programas de Evaluación Externa}

\subsection{Sueros control del Programa de Evaluación Externa de Calidad del Reino Unido (UK NEQAS)}

Se utilizaron 8 sueros pertenecientes a los lotes: 676, 677, 678, 679, 680, 681, 682, y 683. Se trata de material biológico líquido y homogéneo provisto por el UK NEQAS.

\subsection{Sueros control del Programa de Evaluación Externa de Calidad del Centro Wadsworth, Departamento de Salud del Estado de Nueva York (WCDHNY)}

Se utilizaron 5 sueros pertenecientes a los lotes: C41, C42, C43, C44, y C45. Se trata de material biológico líquido y homogéneo provisto por el WCDHNY.

\subsection{Sueros control del Programa de Evaluación Externa de Calidad de la Fundación Bioquímica Argentina (PEEC-FBA)}

Se utilizaron 24 sueros liofilizados del PEEC-FBA: lotes 173, 178, 182, 185, 187, 190, 194, 197, 199, 202, 204, 206, 207, 208, 211, 213, 215, 220, 221, 222, 223, 224, 225, у 226 que fueron reconstituidos agregando $5 \mathrm{ml}$ de agua bidestilada, mezclando por inversión suave y dejando en reposo durante 30 minutos antes de su procesamiento.

\subsubsection{Drogas y equipos de reactivos comerciales}

- Agua bidestilada I, obtenida en la Cátedra de Hematología por redestilación de agua destilada y controlada por fotometría de llama con el objeto de asegurar la no contaminación con sodio, que se utilizó para realizar las pruebas preliminares. 
- Agua bidestilada II, proporcionada por el Laboratorio de Referencia y Estandarización en Bioquímica Clínica de la Fundación Bioquímica Argentina (LARESBIC - FBA) con las siguientes especificaciones: Resistividad $=15.0$ MS.cm y Conductividad $=19.5 \mu \mathrm{s}$. La misma fue utilizada en todos los ensayos posteriores.

- Ácido nítrico 65\% p.a. ACS - Biopack, Argentina

- Hierro, polvo fino $99 \%$ p.a. - Laboratorio Anedra, Argentina

- Hierro SRM 937 (granallas > 99,9\% de pureza) del National Institute of Standards and Technology (NIST) - USA

- Ácido clorhídrico 37\% p.a. - Merck KGaA, Alemania

- Ácido tricloroacético 99\% p.a. - Laboratorio Anedra, Argentina

- Ácido tricloroacético 99\% p.a. - Biopack, Argentina

- Acetato de sodio trihidratado 99,5-100,5\% p.a. ACS, importado, fraccionado en Argentina por Merck Química Argentina S.A.I.C.

- Ácido L-ascórbico 99\% p.a. ACS-ISSO, importado, fraccionado en Argentina por Merck Química Argentina S.A.I.C.

- Tiourea 99\%, Riedel-de Haën, Seelze - Hanover- Alemania

- Ferene® - Sigma-Aldrich Chemie GmbH - Alemania

- Equipo comercial Hierro-Ferrozina - Laboratorios BioSystems (BS).

- Equipo comercial Fer-color, línea líquida - Laboratorios Wiener (W). 


\subsubsection{Material de vidrio}

Se utilizó el siguiente material de vidrio requerido para la implementación del método recomendado:

- Matraces de $50 \mathrm{ml}, 100 \mathrm{ml}, 200 \mathrm{ml}, 500 \mathrm{ml}, 1000 \mathrm{ml}$ y $2000 \mathrm{ml}$.

- Tubos de centrífuga de $10 \mathrm{ml}$, con tapa esmerilada.

- Pipetas de simple y doble aforo de $1 \mathrm{ml}, 2 \mathrm{ml}, 3 \mathrm{ml}$ y $5 \mathrm{ml}$ cuyo control volumétrico fue realizado en el LARESBIC-FBA, por gravimetría a 20 ${ }^{\circ} \mathrm{C}$, como material volumétrico grado B.

- Otras pipetas de $10 \mathrm{ml}$ utilizadas en la preparación de las soluciones descontaminantes.

- Tubos de Khan

- Elementos varios (erlenmeyers, vasos de precipitado, varillas).

Un requisito a tener en cuenta, dentro de la fase pre-analítica, es que todo el material utilizado debe estar libre de hierro.

Procedimiento de descontaminación: el material de vidrio se lavó con una solución de detergente no-iónico, se enjuagó con agua destilada y se dejó sumergido en una solución ácida durante 24 hs. Se eliminó la acidez mediante numerosos lavados con agua bidestilada y se secó en ambiente libre de polvo.

Las soluciones ácidas empleadas, según la metodología seleccionada, fueron:

b) Solución de ácido nítrico 0,75 mol/L, para el MR (CLSI)

c) Solución de ácido nítrico al 50\% (v/v), para el Método de BS, y

d) Solución de ácido clorhídrico al 10\% (v/v), para el Método de W

El control randomizado de descontaminación se realizó con $2 \mathrm{ml}$ de reactivo precipitante-reductor y $1 \mathrm{ml}$ de reactivo cromógeno que se mezclaron en los tubos 
seleccionados del lote a controlar dejándolos durante 30’ en reposo. Se aceptan lecturas menores a 0,015 UAbs entre 562 y 593 nm, según normas CLSI.

\subsubsection{Instrumental}

- Balanza Mettler modelo AB 204 (sensibilidad = 0,1 mg) calibrada en el LARESBICFBA, especialmente utilizada para realizar las pesadas de las drogas necesarias para la preparación de los reactivos del MR (CLSI).

- Espectrofotómetro Shimadzu modelo1601 con ancho de banda de $2 \mathrm{~nm}$ que utiliza una cubeta con $1 \mathrm{~cm}$ de camino óptico, donde se realizaron las lecturas de las absorbancias de todas las determinaciones realizadas por métodos manuales. Este equipo realiza una verificación automática de calibración al encendido del mismo y verifica estar dentro de especificaciones predeterminadas (Manual Shimadzu Corporation, 1994).

Antes de comenzar la fase analítica y durante la misma, se efectuaron controles de calidad del espectrofotómetro utilizando soluciones elaboradas por el LARESBIC-FBA con valores de absorbancias certificadas por el NIST:

a) Soluciones de concentraciones conocidas de dicromato de potasio en ácido perclórico $0,001 \mathrm{~N}\left(\mathrm{~A} 1, \mathrm{~A}_{2}, \mathrm{~A}_{3}\right.$ y $\left.\mathrm{A}_{4}\right)$ para controlar la exactitud y linealidad fotométrica en el UV.

b) Soluciones de concentraciones conocidas de nitrato de cobalto en ácido sulfúrico $0,37 \mathrm{~N}\left(\mathrm{~B} 1, \mathrm{~B}_{2}, \mathrm{~B}_{3}\right.$ y $\left.\mathrm{B}_{4}\right)$ para controlar la exactitud y linealidad fotométrica en el Visible.

c) Soluciones de concentraciones conocidas de cianmetahemoglobina (H1 y $\mathrm{H}_{2}$ ) para controlar la exactitud fotométrica; para la preparación de estas soluciones se utilizó cianuro de potasio y ferricianuro de potasio grado analítico, pureza 99,0\%, sangre entera humana con serología negativa para HIV, HVC y HVB y agua grado reactivo tipo I. 
d) Solución de nitrito de sodio 50 g/L, para evaluar la presencia de luz parásita.

- Analizador automático Random Access BioSystems A15 en el que se midieron las absorbancias de las series de determinaciones efectuadas en forma automática. Este equipo es controlado periódicamente según las normas establecidas por el Sub Programa de Control de Instrumental del PEEC-FBA.

- Micropipeta Capilettor® de $200 \mu 1$ (valor nominal) calibrada en el LARESBIC-FBA por pesada de agua destilada y controlada periódicamente.

\subsection{Métodos}

\subsubsection{Método recomendado (CLSI)}

Se utilizó el procedimiento recomendado por el estándar H17-A del CLSI (Van Assendelft et al., 1998a).

El fundamento del mismo, en su primera etapa, incluyó la precipitación de las proteínas séricas con ácido tricloroacético, liberación del ión férrico de su proteína transportadora en un medio ácido y reducción a ión ferroso con ácido ascórbico. En el segundo paso, el hierro del sobrenadante se midió por la formación de un complejo coloreado con un reactivo cromogénico. 


\subsubsection{Preparación de Reactivos}

Ácido tricloroacético (ATC) 50\% (p/v): En un matraz volumétrico se disolvieron 250,0 $\mathrm{g}$ de ATC en agua bidestilada y se diluyeron a $500 \mathrm{ml}$. Este reactivo, almacenado a $4^{\circ} \mathrm{C}$, es estable durante 6 meses.

Solución de acetato $4 \mathrm{~mol} / \mathrm{L}$ : En un matraz volumétrico se disolvieron 544,4 g de acetato de sodio trihidratado en agua bidestilada, se diluyó a 1,0 L y se filtró a través de una membrana de acetato de celulosa con un tamaño de poro de $0,45 \mu \mathrm{m}$ de diámetro. Esta solución, almacenada a temperatura ambiente $\left(18-25^{\circ} \mathrm{C}\right)$ es estable por un mes.

Ácido Clorhídrico $6 \mathrm{~mol} / \mathrm{L}$ : En un matraz volumétrico se agregaron $500 \mathrm{ml}$ de ácido clorhídrico concentrado a $250 \mathrm{ml}$ de agua bidestilada y se diluyeron a 1,0 L.

Ácido Clorhídrico 0,1 mol/L: En un matraz volumétrico se agregaron 8,3 $\mathrm{ml}$ de ácido clorhídrico concentrado a $500 \mathrm{ml}$ de agua bidestilada y se diluyeron a 1,0 L.

Reactivo reductor precipitante: En un matraz volumétrico se disolvieron 5,0 g de ácido L-ascórbico en $200 \mathrm{ml}$ de la solución de ATC al 50\%. Se adicionaron $33 \mathrm{ml}$ de ácido clorhídrico $6 \mathrm{~mol} / \mathrm{L}$ y se ajustó el volumen a 1,0 L con agua bidestilada. Este reactivo, almacenado a $4^{\circ} \mathrm{C}$ es estable durante una semana.

Reactivo cromogénico: En un matraz volumétrico se disolvieron $600 \mathrm{mg}$ de Ferene ${ }^{\circledR}$ (sal disódica del 3-(2-piridil)-5,6-bis (5-sulfo-2-furil)-1, 2,4-triacina) y 15,0 g de tiourea en solución de acetato $4 \mathrm{~mol} / \mathrm{L}$ ajustando el volumen a 1,0 L. Se dejó durante una noche a $4^{\circ} \mathrm{C}$ antes de usar. Este reactivo almacenado a $4^{\circ} \mathrm{C}$ es estable durante una semana. 


\subsubsection{Preparación de Soluciones Estándares}

Solución Estándar Stock de Hierro, 1,000g Fe/L: Se disolvieron 1,000 g de granallas de hierro (NIST) en $12 \mathrm{ml}$ de ácido clorhídrico concentrado calentando suavemente. Una vez disuelto, se enfrió a temperatura ambiente y se diluyó a 1,0 L con agua bidestilada. Esta solución, almacenada entre $18-25^{\circ} \mathrm{C}$ y bien tapada, es estable indefinidamente.

Solución Estándar Intermedia, $50 \mathrm{mg} \mathrm{Fe} / \mathrm{L}$ : Se diluyeron $25 \mathrm{ml}$ de la solución stock a $500 \mathrm{ml}$ con ácido clorhídrico $0,1 \mathrm{~mol} / \mathrm{L}$. Esta solución es estable por al menos tres meses si es almacenada entre $18-25^{\circ} \mathrm{C}$ en un recipiente bien tapado.

Soluciones Estándares de Trabajo: Se transfirieron 0 - 0,5 - 1,0 - 2,0 - 3,0 - 4,0 y 6,0 ml de solución estándar intermedia a una serie de matraces volumétricos de $100 \mathrm{ml}$ y se llevaron a volumen con la solución de Ácido Clorhídrico 0,1 mol/L. Se obtuvieron la siguientes concentraciones finales de hierro: 0 (reactivo blanco) - 0,25 - 0,50 - 1,00 1,50 - 2,00 y 3,00 mg/L respectivamente. Estas soluciones son estables, por al menos tres meses, cuando son almacenadas entre $18-25^{\circ} \mathrm{C}$.

\subsubsection{Calibración}

\section{A - Prueba preliminar de la técnica manual a utilizar en este trabajo}

Se prepararon soluciones para calibración a partir de Hierro - Anedra (calidad analítica 99\%) y se efectuaron curvas de calibración según el siguiente procedimiento:

Se mezclaron $2 \mathrm{ml}$ de cada una de las soluciones estándares con $2 \mathrm{ml}$ de reactivo reductor precipitante en un tubo de vidrio con tapa esmerilada. Se homogeneizaron en vortex, se dejaron reposar durante 15 minutos y se centrifugaron durante 15 minutos a 1500 g. Se transfirieron $2 \mathrm{ml}$ de cada sobrenadante a otros tubos de vidrio y se les adicionó $1 \mathrm{ml}$ de reactivo cromogénico. Se mezclaron bien usando el vortex, se centrifugaron los tubos a $1.100 \mathrm{~g}$ durante 15 minutos y se leyeron las absorbancias de cada solución a $593 \mathrm{~nm}$ usando como blanco solución reductora precipitante. 


\section{B - Empleo de material de referencia proveniente del NIST}

Se realizó la calibración utilizando el material de referencia Hierro SRM 937 (calidad analítica > 99,9\%) siguiendo el mismo procedimiento empleado en $\mathbf{A}$.

\section{$\mathrm{C}$ - Empleo de materiales comerciales}

C1 - En las calibraciones $\mathrm{n}^{\circ} 13 \mathrm{y} \mathrm{n}^{\circ} 14$ del MR se realizaron, comparativamente, calibraciones con la solución patrón de hierro 1.09972 Titrisol® de Merck. Esta solución que contiene $1000 \mathrm{mg} \mathrm{Fe},\left(\mathrm{FeCl}_{3}\right.$ en $\left.15 \% \mathrm{HCl}\right)$ se llevó a $1.000 \mathrm{ml}$ con agua bidestilada fresca. A partir de la misma se preparó la solución intermedia de $50 \mathrm{mg} / \mathrm{L}$ y con ésta última se prepararon las soluciones de trabajo: 0,25 - 0,50 - 1,00 - 1,50 - 2,00 y $3,00 \mathrm{mg} / \mathrm{L}$ respectivamente.

C2 - En el proceso de calibración $n^{\circ} 15$, realizado según el MR, se incorporaron en la corrida los sueros calibradores y los sueros control de bioquímica en dos niveles, de los equipos comerciales de BS y de W. Los lotes utilizados fueron:

Calibrador Bioquímica Lote 040 AD Ref 18011, BS

Calibrador A plus Lote 0010018240, W

Suero Control de Bioquímica nivel 1- Lote 055 AB Ref 18006, BS

Suero Control de Bioquímica nivel 1l- Lote 055 AA Ref 18008, BS

Standatrol S-E nivel 1- Lote 021560, W

Standatrol S-E nivel 2- Lote 021560, W 


\subsubsection{Ensayos de prevalidación}

Para estimar la magnitud de los diferentes tipos de errores analíticos del método recomendado se midieron parámetros que servirán como criterios de confianza del método analítico:

\section{A - Linealidad}

En este ensayo se procesaron diluciones preparadas a partir de la solución estándar intermedia de hierro de $50 \mathrm{mg} / \mathrm{L}$, obteniéndose concentraciones de: 0,10- 0,50- 1,00$5,00-10,00 \mathrm{mg} / \mathrm{L})$ respectivamente.

\section{B - Recuperación}

I - Se realizó agregando volúmenes de la solución intermedia de hierro (50 mg/L), en concentraciones de 0,025-0,050-0,075-0,100 y 0,125 mg/L, a $2 \mathrm{ml}$ de diferentes muestras: tres pool de sueros de nivel normal, un pool de sueros de nivel bajo, un pool de sueros de nivel alto, sueros control Standatrol 1 y 2 de Wiener y lote 190 del PEECFBA.

II - Asimismo se realizó otro ensayo de recuperación agregando el doble de los volúmenes de la solución intermedia empleados en $\mathbf{I}$, a $2 \mathrm{ml}$ de un pool de sueros de nivel bajo.

III - Se realizó otro ensayo sobre el lote 190 del PEEC, con el agregado de un rango más amplio de concentraciones: 0,050- 0,100- 0,150- 0,200- 0,250- 0,375 y 0,500 mg/L.

\section{C - Imprecisión intraensayo}

En este ensayo se realizaron 45 repeticiones de la medida de hierro en una solución de $1 \mathrm{mg} / \mathrm{L}$ de hierro estándar SRM 937 del NIST con el objeto de conocer la DE y el CV\% del MR (CLSI). 


\section{D - Inexactitud}

En esta etapa, se calculó la inexactitud del MR (CLSI) en las series de replicaciones procesadas en $\mathbf{C}$.

\subsubsection{Procedimiento con las diferentes muestras}

I - En tubos cónicos de vidrio, con tapa esmerilada, se mezclaron $2 \mathrm{ml}$ de las muestras correspondientes a los incisos: 4.1.1.1.1, 4.1.1.1.2, 4.1.1.3.1, 4.1.1.3.2 y 4.1.1.3.3 con 2 $\mathrm{ml}$ de reactivo reductor precipitante.

Se homogeneizaron las mezclas en vortex, se dejaron reposar durante 15 minutos y se centrifugaron durante 15 minutos a $1500 \mathrm{~g}$. Se transfirieron $2 \mathrm{ml}$ de cada sobrenadante a otros tubos de vidrio y se les adicionó $1 \mathrm{ml}$ de reactivo cromogénico. Se mezclaron bien usando el vortex, se centrifugaron los tubos a $1.100 \mathrm{~g}$ durante 15 minutos y se leyeron las absorbancias de cada solución usando como blanco solución reductora precipitante. Las concentraciones se calcularon a partir de la curva de calibración realizada dentro del rango comprendido entre 0 y $3,00 \mathrm{mg} / \mathrm{L}$.

II - Para medir el hierro en los tres niveles de pool de sueros (4.1.1.2) se mezclaron, también en tubos de vidrio cónicos con tapa esmerilada, $3 \mathrm{ml}$ de estas muestras con $3 \mathrm{ml}$ de reactivo reductor precipitante, con el propósito de obtener mayor volumen de sobrenadante que se reservó para determinar hierro, en forma comparativa, por la modificación del MR (CLSI) en método semiautomatizado del MR (CLSI Se Au).

Utilizando $2 \mathrm{ml}$ de cada sobrenadante se procedió a la medición de hierro siguiendo la misma técnica del inciso anterior (I).

Asimismo, las absorbancias de la reacción final de estas mezclas reactivas se leyeron por método espectrofotométrico en el Analizador automático Random Access BioSystems A15 a $600 \mathrm{~nm}$. 


\subsubsection{Métodos comerciales}

En esta etapa del estudio se realizó el ensayo comparativo entre los métodos manuales y los métodos automatizados de los equipos comerciales de BS y de W sobre las muestras del mismo pool de sueros.

Se siguieron las recomendaciones de la Guía Aprobada del NCCLS - EP10-A (Garber C.C. et al, 1998) que establece, como mínimo, la realización de una corrida diaria de diez muestras durante cinco días. Es decir que cada día se corrieron diez muestras de cada uno de los tres niveles de pool de sueros por el método recomendado y por el método comercial a evaluar; este último se realizó por método manual y por método automatizado, con los dos equipos de reactivos comerciales ensayados.

\subsubsection{Determinación de hierro con el equipo comercial Hierro - Ferrozina, marca BioSystems S.A.}

La medición de hierro se realizó directamente sobre las muestras de los tres niveles del pool de sueros por método manual y por método automatizado, de acuerdo a las instrucciones del fabricante (BioSystems, 2006) y según el protocolo detallado en la

\section{Tabla 4-1.}

Este método directo se basa en la propiedad del ión férrico presente en las muestras y que se encuentra unido a la transferrina, de ser liberado por acción del cloruro de guanidinio y ser reducido a ferroso por la hidroxilamina. El ión ferroso forma un complejo coloreado con el cromógeno ferrozina, el que se cuantifica por espectrofotometría a $560 \mathrm{~nm}$.

Tabla 4-1: Protocolo para la determinación de hierro utilizando el equipo de BS

\begin{tabular}{|l|c|c|c|c|}
\cline { 2 - 5 } \multicolumn{1}{c|}{} & Blanco reactivo & Blanco muestra & Muestra & Patrón \\
\hline Agua bidestilada & $200 \mu \mathrm{l}$ & & & \\
\hline Muestra & & $200 \mu \mathrm{l}$ & $200 \mu \mathrm{l}$ & \\
\hline Patrón de Hierro & & & & $200 \mu \mathrm{l}$ \\
\hline Reactivo A* & & $1,00 \mathrm{ml}$ & & \\
\hline React. de trabajo* & $1,00 \mathrm{ml}$ & & $1,00 \mathrm{ml}$ & $1,00 \mathrm{ml}$ \\
\hline
\end{tabular}

* Ver Anexo I, para la descripción de los reactivos 
Con el objeto de minimizar cualquier error sistemático que pudiera producirse en una corrida, las mediciones analíticas de cada muestra fueron procesadas por técnica manual y automatizada con una diferencia menor de 2 horas entre una y otra.

\subsubsection{Determinación de hierro con el equipo comercial Fer - color, marca Wiener} lab.

La medición de hierro se realizó directamente sobre las muestras de los tres niveles del pool de sueros por métodos manual y automatizado, de acuerdo a las instrucciones del fabricante (Wiener, 2002) y según el protocolo detallado en la Tabla 4-2.

En este método el hierro a $\mathrm{pH}$ ácido fue liberado de su unión con la transferrina y por acción del ascorbato fue reducido a ión ferroso. Posteriormente reaccionó con el cromógeno ferene para dar un complejo de color azul que se midió a $600 \mathrm{~nm}$.

\section{Tabla 4-2: Protocolo para la determinación de hierro utilizando el equipo de W}

\begin{tabular}{|c|c|c|c|}
\hline & Blanco & Estándar & $\mathrm{M}$ \\
\hline Agua bidestilada & $200 \mu \mathrm{l}$ & & \\
\hline Estándar & & $200 \mu 1$ & \\
\hline Muestra & & & $200 \mu 1$ \\
\hline Reactivo A* & $1 \mathrm{ml}$ & $1 \mathrm{ml}$ & $1 \mathrm{ml}$ \\
\hline \multicolumn{4}{|c|}{$\begin{array}{l}\text { Mezclar. Leer la absorbancia del tubo M (Blanco de suero) a } 600 \\
\text { nm llevando el espectrofotómetro a cero con agua. } \\
\text { Luego agregar: }\end{array}$} \\
\hline Reactivo B* & $200 \mu \mathrm{l}$ & $200 \mu \mathrm{l}$ & $200 \mu \mathrm{l}$ \\
\hline \multicolumn{4}{|c|}{$\begin{array}{l}\text { Mezclar. Volver a leer los tubos a los } 5 \text { minutos, llevando a cero } \\
\text { con agua. }\end{array}$} \\
\hline
\end{tabular}

* Ver Anexo II, para la descripción de los reactivos

En este ensayo también, las distintas mediciones analíticas de cada muestra fueron procesadas por técnica manual y automatizada con una diferencia menor de 2 horas entre una y otra. 


\subsubsection{Método semiautomatizado del MR (CLSI Se Au)}

Esta etapa de la investigación fue diseñada con el objeto de adaptar el método recomendado a la automatización, de modo de, en primer lugar incorporar la medición de hierro a la batería total de muestras de química clínica que resuelve el laboratorio utilizando menor volumen de muestra, y en segundo término, disminuir el tiempo de procesamiento de las muestras.

Este proceso semiautomatizado se realizó, utilizando el remanente del sobrenadante, obtenido en 4.1.1.2, de la precipitación de los tres niveles de pooles de sueros. El procedimiento consistió en mezclar $20 \mu \mathrm{l}$ de cada sobrenadante con $200 \mu \mathrm{l}$ de reactivo cromógeno, preparado según las recomendaciones del CLSI.

Esta modificación (elección de la relación $20 \mu \mathrm{l}$ de sobrenadante/200 $\mu \mathrm{l}$ de reactivo cromógeno) se evaluó sobre la base de cinco ensayos preliminares en los cuales se fueron variando los volúmenes de los sobrenadantes de los tres niveles de pooles de sueros y del reactivo cromógeno necesarios hasta obtener lecturas de absorbancia dentro del rango de concentración de hierro de cada nivel.

Si bien el complejo coloreado formado entre el ión ferroso y el ferene tiene un máximo de absorción a $593 \mathrm{~nm}$, las absorbancias, en el Analizador automático Random Access BioSystems A15, se midieron a $600 \mathrm{~nm}$ pues este autoanalizador posee una configuración del tambor de filtros que incluye 340, 405, 505, 535, 560, 600, 635 у 670 $\mathrm{nm}$.

\subsubsection{Métodos estadísticos}

Los datos obtenidos se analizaron por métodos paramétricos y no paramétricos, previo examen del tipo de distribución de los resultados. Con el objeto de descartar valores marginales, se realizó el test de Dixon a todas las series de determinaciones efectuadas en los pooles de sueros.

Se emplearon programas convencionales de estadística: Microsoft Excel 2003, SPSS V13.0 y Statgraphics® Plus V5.1. 


\section{Resultados}




\subsection{Controles de las condiciones iniciales de trabajo}

\subsubsection{Control de lavado y de descontaminación del material de vidrio}

Por observación a simple vista de la reacción de control en los tubos seleccionados no se detectó una contaminación marcada.

Para detectar la aparición de trazas de hierro se realizó el mismo control y se procedió a la lectura de las absorbancias por espectrofotometría, en cuyo caso la absorbancia a 593 $\mathrm{nm}$ arrojó valores menores a 0,007 UAbs.

\subsubsection{Calibración de pipetas}

En todos los casos los volúmenes asignados coincidieron con los volúmenes nominales o se encontraron dentro del rango de tolerancia aceptado comprendido entre $\pm 0,02 \mathrm{ml}$ y $\pm 0,03 \mathrm{ml}$ (LARESBIC-FBA).

\subsubsection{Control de calidad del instrumental empleado}

\subsubsection{Control de calidad del espectrofotómetro Shimadzu 1601}

La Tabla 5-1 muestra la inexactitud fotométrica promedio hallada en dos controles realizados al espectrofotómetro Shimadzu 1601. Del total de los controles realizados el $57 \%$ tuvo un desempeño óptimo $(\leq 2,0 \%)$ y el $43 \%$ un desempeño aceptable $(\leq 3,0)$ de acuerdo a la zona del espectro estudiada. 
Tabla 5-1: Inexactitud fotométrica a distintas longitudes de onda

\begin{tabular}{|c|c|c|c|}
\hline \multirow{2}{*}{$\begin{array}{c}\text { Soluciones } \\
\text { de control }\end{array}$} & $\begin{array}{c}\text { Longitud de } \\
\text { onda }\end{array}$ & \multicolumn{2}{|c|}{ Inexactitud fotométrica \% } \\
\cline { 2 - 4 } & $(\lambda$ nm) & Ensayo I & Ensayo II \\
\hline \multirow{2}{*}{$\begin{array}{c}\mathrm{K}_{2} \mathrm{Cr}_{2} \mathrm{O}_{7} \text { en } \\
\mathrm{HClO}_{4} 0,001 \mathrm{~N}\end{array}$} & 340 & 0,38 & $-1,80$ \\
\cline { 2 - 4 } & 350 & 0,75 & $-2,60$ \\
\hline $\begin{array}{c}\mathrm{Co}\left(\mathrm{NO}_{3}\right)_{2} \text { en } \\
\mathrm{H}_{2} \mathrm{SO}_{4} 0,37 \mathrm{~N}\end{array}$ & 500 & 2,26 & 1,16 \\
\cline { 2 - 4 } & 505 & 2,48 & 0,16 \\
\hline \multirow{2}{*}{$\mathrm{Cianmetahemoglobina}$} & 510 & 2,28 & $-2,30$ \\
\cline { 2 - 4 }$(\mathrm{HiCN})$ & 540 & 1,63 & $-2,50$ \\
\cline { 2 - 4 } & 550 & $\mathrm{ND}$ & $\mathrm{ND}$ \\
\hline
\end{tabular}

*No Determinado.

La Tabla 5-2 muestra la linealidad fotométrica hallada en dos controles realizados al espectrofotómetro Shimadzu 1601. Esta linealidad, expresada como la pendiente de la recta obtenida graficando los valores de las absorbancias halladas en función de las absorbancias de referencia, es óptima pues las pendientes de las rectas se encuentran dentro del límite de aceptabilidad, entre 0,98 y 1,02 (LARESBIC-FBA).

Tabla 5-2: Linealidad fotométrica a distintas longitudes de onda

\begin{tabular}{|c|c|c|c|}
\hline Soluciones de control & $\mathbf{n m}$ & Pendiente (I) & Pendiente (II) \\
\hline $\begin{array}{c}\mathrm{K}_{2} \mathrm{Cr}_{2} \mathrm{O}_{7} \text { en } \\
\mathrm{HClO}_{4} 0,001 \mathrm{~N}\end{array}$ & 340 & 0,9944 & 0,9929 \\
\cline { 2 - 4 } & 350 & 0,9875 & 1,0240 \\
\hline $\begin{array}{c}\mathrm{Co}\left(\mathrm{NO}_{3}\right)_{2} \mathrm{en} \\
\mathrm{H}_{2} \mathrm{SO}_{4} 0,37 \mathrm{~N}\end{array}$ & 500 & 0,9790 & 1,0170 \\
\cline { 2 - 4 } & 505 & 0,9744 & 1,0060 \\
\cline { 2 - 4 } & 510 & 0,9859 & 1,0063 \\
\hline
\end{tabular}

Los dos controles realizados, en dos oportunidades, para evaluar la presencia de luz parásita, arrojaron valores dentro de los límites de aceptabilidad (T\% menor del 0,5\%) 


\subsubsection{Control de calidad del Analizador automático Random Access BioSystems A15}

Se realizaron numerosos controles previos, pero el resultado del último control de calidad (Anexo III) simultáneo con la realización de este estudio, indicó una inexactitud fotométrica $=-2,38 \%$ a $540 \mathrm{~nm}$ (intervalo aceptable $\leq \pm 3,00 \%$ ).

\subsection{Puesta a punto del Método Recomendado - MR (CLSI)}

\subsubsection{Calibración utilizando hierro marca Anedra}

Como ensayo preliminar de la metodología recomendada se realizaron calibraciones con soluciones estándares preparadas con hierro marca Anedra.

En la Tabla 5-3 se muestran los puntos obtenidos para cada concentración de hierro y en la Figura 5-1 se muestra la gráfica obtenida, la regresión lineal y la ecuación de una de las curvas de calibración efectuadas, tomada como ejemplo.

Tabla 5-3: Datos para la obtención de la curva de calibración

\begin{tabular}{|c|c|c|c|}
\hline $\begin{array}{c}\text { Solución de } \\
\text { Fe Anedra } \\
(\mathbf{m g} / \mathbf{L})\end{array}$ & \multicolumn{3}{|c|}{ Repetición } \\
\cline { 2 - 4 } & $\mathbf{1}^{*}$ & $\mathbf{2}^{*}$ & $3^{*}$ \\
\hline 0 & 0 & 0 & 0 \\
\hline 0,25 & 0,070 & 0,064 & 0,067 \\
\hline 0,50 & 0,120 & 0,112 & 0,110 \\
\hline 1,00 & 0,220 & 0,204 & 0,199 \\
\hline 1,50 & 0,327 & 0,318 & 0,325 \\
\hline 2,00 & 0,435 & 0,424 & 0,445 \\
\hline 3,00 & 0,654 & 0,644 & 0,643 \\
\hline
\end{tabular}

*Expresadas en absorbancias a $593 \mathrm{~nm}$. 


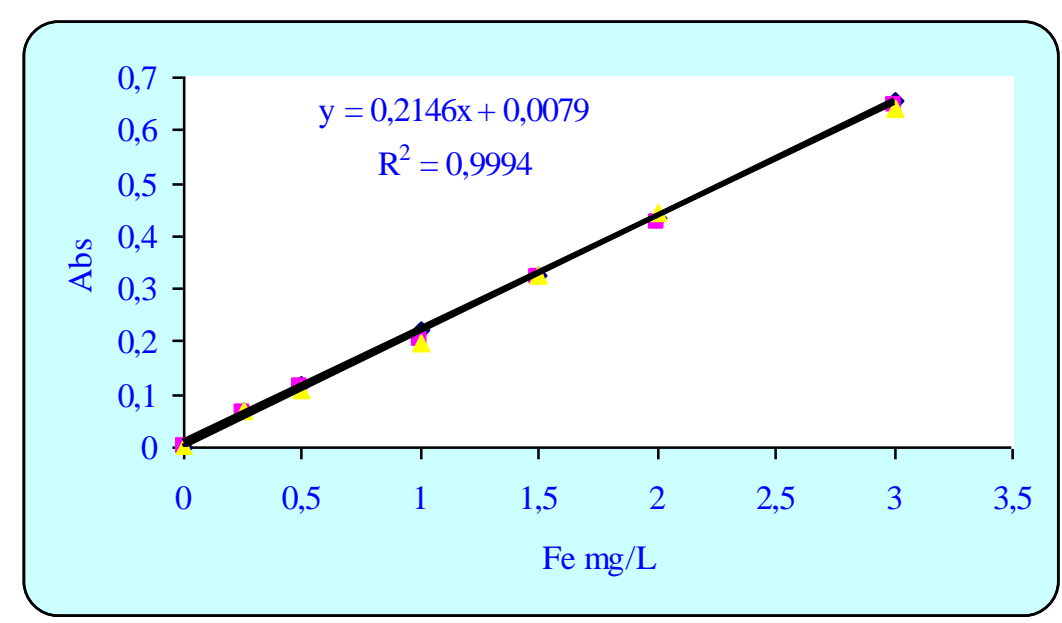

Figura 5-1: Línea de regresión lineal obtenida en uno de 8 ensayos

El promedio de los coeficientes de correlación $(r=0,9991)$ obtenido de las curvas de calibración realizadas con hierro marca Anedra, indica una asociación fuerte y directa entre las variables dependiente e independiente $(n=8 ; p<0,001)$. 


\subsubsection{Calibración con hierro patrón del NIST}

Se realizaron calibraciones con las soluciones estándares preparadas con hierro SRM 937 del NIST (> 99,9 \% de pureza) de acuerdo al método recomendado por el estándar H17-A del CLSI (Van Assendelft et al., 1998).

En la Tabla 5-4 se muestra la concentración y la absorbancia de las muestras estándares de hierro SRM 937 del NIST y en la Figura 5-2 se muestra la gráfica de estos puntos, así como la regresión lineal y la recta obtenida.

Tabla 5-4: Datos para la obtención de la curva de calibración

\begin{tabular}{|c|c|c|c|}
\hline $\begin{array}{c}\text { Solución de } \\
\text { Fe NIST } \\
(\mathbf{m g} / \mathbf{L})\end{array}$ & \multicolumn{3}{|c|}{ Repetición } \\
\cline { 2 - 4 } & $\mathbf{1}^{*}$ & $\mathbf{2}^{*}$ & $\mathbf{3}^{*}$ \\
\hline 0 & 0 & 0 & 0 \\
\hline 0,25 & 0,079 & 0,076 & 0,058 \\
\hline 0,50 & 0,110 & 0,102 & 0,103 \\
\hline 1,00 & 0,215 & 0,215 & 0,217 \\
\hline 1,50 & 0,300 & 0,307 & 0,200 \\
\hline 2,00 & 0,396 & 0,395 & 0,403 \\
\hline 3,00 & 0,598 & 0,660 & 0,611 \\
\hline
\end{tabular}

*Expresadas en absorbancias a $593 \mathrm{~nm}$.

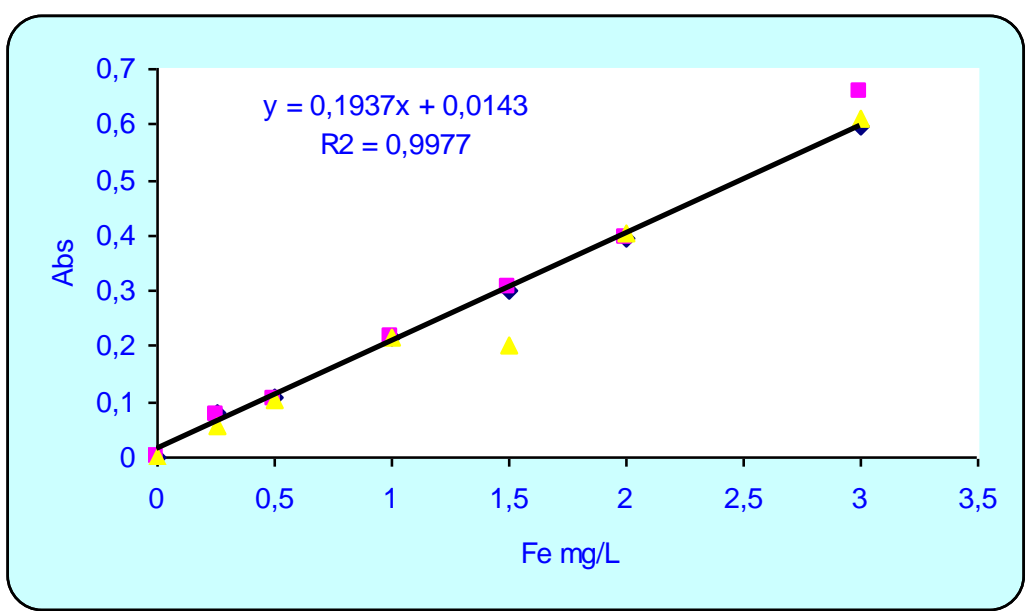

Figura 5-2: Línea de regresión lineal obtenida en uno de 15 ensayos 
El promedio de los coeficientes de correlación $(r=0,9877)$ obtenido de las curvas de calibración realizadas con hierro patrón del NIST, indica una asociación fuerte y directa entre las variables dependiente e independiente $(n=15 ; p<0,001)$.

En ambas calibraciones, mencionadas en los ítems 5.2.1 y 5.2.2, se obtuvieron buenos coeficientes de correlación (r) con valores muy próximos a 1, que indica que el rango de concentraciones empleadas es lo suficientemente amplio para proveer estimaciones confiables de la pendiente y la ordenada al origen.

\subsubsection{Calibración con solución concentrada Merck Titrisol®}

En la Tabla 5-5 se muestra el coeficiente de correlación (r) calculado en cada calibración y la inexactitud de cada punto de las curvas obtenidas con las soluciones de trabajo de Titrisol en relación a los estándares del MR (CLSI), dentro del rango de concentraciones entre 0,25 y $3,00 \mathrm{mg} / \mathrm{L}$ de hierro.

Tabla 5-5: Coeficiente de correlación (r) e inexactitud de los cuatro ensayos realizados

\begin{tabular}{|c|c|c|c|c|}
\hline Estándares & $\begin{array}{c}\text { Valor de referencia* } \\
\text { Fe } \mathbf{~ m g / L ~}\end{array}$ & $\begin{array}{c}\text { Valor obtenido** } \\
\text { Fe mg/L }\end{array}$ & $\begin{array}{c}\text { Inexactitud } \\
\text { \% }\end{array}$ & r \\
\hline \multirow{3}{*}{ Titrisol@1 } & 0,25 & 0,30 & 20,0 & \\
\cline { 2 - 4 } & 0,50 & 0,49 & $-2,0$ & \\
\cline { 2 - 4 } & 1,00 & 1,02 & 2,0 & \multirow{2}{*}{0,9982} \\
\cline { 2 - 4 } & 1,50 & 1,53 & 2,0 & \\
\cline { 2 - 4 } & 2,00 & 1,97 & $-1,5$ & \\
\cline { 2 - 5 } & 3,00 & 2,96 & $-1,3$ & \\
\hline
\end{tabular}




\begin{tabular}{|c|c|c|c|c|}
\hline \multirow{6}{*}{ Titrisol@2 } & 0,25 & 0,30 & 20,0 & \multirow{6}{*}{0,9770} \\
\hline & 0,50 & 0,52 & 4,0 & \\
\hline & 1,00 & 0,96 & $-4,0$ & \\
\hline & 1,50 & 1,40 & $-6,7$ & \\
\hline & 2,00 & 2,18 & 9,0 & \\
\hline & 3,00 & 2,75 & $-8,3$ & \\
\hline \multirow{6}{*}{ Fe NIST 1} & 0,25 & 0,29 & 16,0 & \multirow{6}{*}{0,9986} \\
\hline & 0,50 & 0,51 & 2,0 & \\
\hline & 1,00 & 1,08 & 8,0 & \\
\hline & 1,50 & 1,50 & 0,0 & \\
\hline & 2,00 & 2,02 & 1,0 & \\
\hline & 3,00 & 2,93 & $-2,3$ & \\
\hline \multirow{6}{*}{ Fe NIST 2} & 0,25 & 0,29 & 16,0 & \multirow{6}{*}{0,9985} \\
\hline & 0,50 & 0,50 & 0,0 & \\
\hline & 1,00 & 1,03 & 3,0 & \\
\hline & 1,50 & 1,54 & 2,7 & \\
\hline & 2,00 & 1.99 & $-0,5$ & \\
\hline & 3,00 & 2,93 & $-2,3$ & \\
\hline
\end{tabular}

* Empleando el estándar hierro SRM 937 (NIST).

** Empleando el patrón comercial Titrisol (Merck). 


\subsubsection{Ensayos de prevalidación del MR (CLSI)}

\subsubsection{Linealidad}

Con la intención de conocer el rango analítico del método, es decir, establecer el máximo o mínimo resultado que puede ser considerado confiable, se procesaron diluciones preparadas a partir de la solución estándar intermedia de $50 \mathrm{mg} / \mathrm{L}$ de hierro, obteniéndose concentraciones de: 0,10- 0,50- 1,00- 5,00-10,00 mg/L.

En la Tabla 5-6, se muestran las concentraciones y las absorbancias correspondientes, obtenidas con las soluciones de hierro SRM 937 del NIST y en la Figura 5-3 se muestra la gráfica de estos puntos y la recta obtenida. Se comprobó que la reacción es lineal hasta $10 \mathrm{mg} / \mathrm{L}$.

Tabla 5-6: Datos para la obtención del gráfico de linealidad

\begin{tabular}{|c|c|c|}
\hline \multirow{2}{*}{ Hierro $\mathbf{~ m g / L ~}$} & \multicolumn{2}{|c|}{ Repetición } \\
\cline { 2 - 3 } & $\mathbf{1}^{*}$ & $\mathbf{2}^{*}$ \\
\hline 0 & 0 & 0 \\
\hline 0,10 & 0,031 & 0,030 \\
\hline 0,50 & 0,110 & 0,119 \\
\hline 1,00 & 0,211 & 0,212 \\
\hline 5,00 & 0,962 & 0,984 \\
\hline 10,0 & 1,860 & 1,868 \\
\hline
\end{tabular}

*Expresadas en absorbancias a $593 \mathrm{~nm}$.

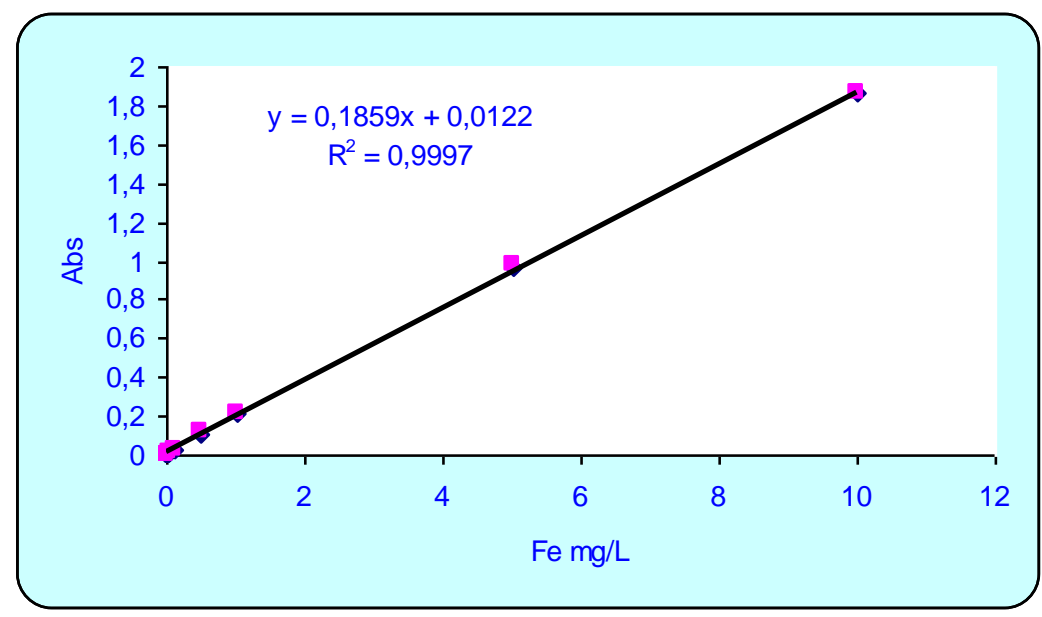

Figura 5-3: Gráfico de regresión simple para la evaluación de la linealidad del MR (CLSI) 


\subsubsection{Recuperación}

El ensayo de recuperación I, se muestra en la Tabla 5-8, donde se observa el porcentaje de recuperación de hierro agregado a muestras de pool de sueros de tres niveles de concentración de hierro y a muestras de sueros controles liofilizados comerciales. El rango obtenido está comprendido entre 70,3 a 97,5\%.

Tabla 5-8: Porcentaje de recuperación de hierro

\begin{tabular}{|l|c|}
\hline \multicolumn{1}{|c|}{ Muestra } & \% recuperación \\
\hline Pool sueros nivel normal & 73,8 \\
\hline Pool sueros nivel normal & 84,6 \\
\hline Pool sueros nivel normal & 97,5 \\
\hline Pool sueros nivel bajo & 71,3 \\
\hline Pool sueros nivel alto & 70,3 \\
\hline Standatrol-Wiener nivel 1 & 90,8 \\
\hline Standatrol-Wiener nivel 2 & 88,6 \\
\hline
\end{tabular}

En el ensayo de recuperación II, se obtuvo un porcentaje promedio de $65,8 \%$ de hierro agregado a un pool de sueros de nivel bajo de concentración.

En el ensayo de recuperación III, se obtuvo un promedio de 93,2\% de recuperación de hierro agregado a un lote de suero provisto por el PEEC-FBA.

\subsubsection{Imprecisión intraensayo}

Para conocer el error aleatorio del MR (CLSI), se realizaron 45 replicaciones de la medida de hierro sérico en una solución de $1 \mathrm{mg} / \mathrm{L}$ de hierro estándar SRM 937 del NIST, y se obtuvo un $\mathrm{CV}=2,02 \%$.

Asimismo, con el objeto de estimar la imprecisión en sueros comerciales se midió el hierro en 24 lotes de sueros liofilizados del PEEC-FBA y se calcularon los valores de la Media, la Desviación Estándar (DE) y el Coeficiente de Variación porcentual (Tabla 59) según las siguientes ecuaciones: 
Media $=\frac{\sum \mathrm{n}}{\mathrm{n}} \quad ; \quad \mathrm{DE}=\left[\frac{\sum \mathrm{n}\left(\mathrm{x}_{\mathrm{i}}-\text { Media }\right)^{2}}{\mathrm{n}-1}\right]^{1 / 2} \quad ; \quad \mathrm{CV}=\frac{\mathrm{DE}}{\text { Media }} \times 100$

donde: $\mathrm{n}=$ número de determinaciones $\quad \mathrm{y} \quad \mathrm{x}_{\mathrm{i}}=$ valor individual

Tabla 5-9: Estimación de la imprecisión en sueros control del PEEC-FBA

\begin{tabular}{|c|c|c|}
\hline Lote $\mathbf{N}^{\circ}$ & $X_{\text {media Fe mg/L }} \pm \mathrm{DE}$ & CV\% \\
\hline 173 & $2,13 \pm 0,06$ & 2,7 \\
\hline 178 & $1,18 \pm 0,08$ & 5,6 \\
\hline 182 & $1,88 \pm 0,06$ & 3,3 \\
\hline 185 & $1,13 \pm 0,06$ & 4,3 \\
\hline 187 & $1,81 \pm 0,04$ & 2,5 \\
\hline 190 & $0,76 \pm 0,06$ & 7,9 \\
\hline 194 & $2,61 \pm 0,05$ & 1,8 \\
\hline 197 & $2,02 \pm 0,06$ & 3,2 \\
\hline 199 & $0,86 \pm 0,02$ & 2,3 \\
\hline 202 & $1,45 \pm 0,09$ & 2,1 \\
\hline 204 & $0,95 \pm 0,09$ & 9,2 \\
\hline 206 & $1,02 \pm 0,12$ & 6,0 \\
\hline 207 & $1,77 \pm 0,07$ & 5,3 \\
\hline 208 & $0,89 \pm 0,12$ & 6,6 \\
\hline 211 & $1,95 \pm 0,02$ & 0,9 \\
\hline 213 & $2,06 \pm 0,10$ & 4,7 \\
\hline 215 & $1,89 \pm 0,01$ & 0,7 \\
\hline 220 & $1,72 \pm 0,04$ & 2,5 \\
\hline 221 & $0,96 \pm 0,07$ & 7,5 \\
\hline 222 & $1,76 \pm 0,05$ & 2,6 \\
\hline 223 & $0,8 \pm 0,03$ & 4,1 \\
\hline 224 & $2,03 \pm 0,11$ & 5,4 \\
\hline 225 & $0,87 \pm 0,03$ & 3,9 \\
\hline 226 & $2,11 \pm 0,03$ & 3,1 \\
\hline
\end{tabular}




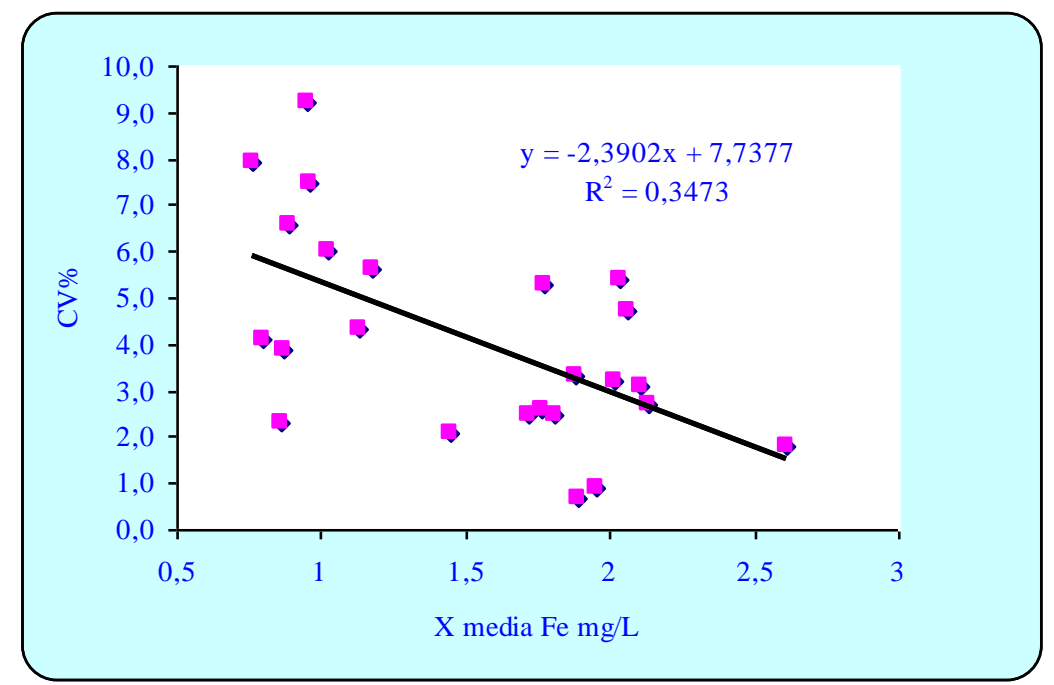

Figura 5-4: Gráfico de dispersión entre Xmedia y CV\% de los valores obtenidos en sueros control del PEEC-FBA

La Figura 5.4 muestra la relación Xmedia - CV\% entre los pares de valores de la Tabla 5-9 donde el CV representa el número de veces que la desviación típica contiene a la media aritmética y por lo tanto, cuanto mayor es el CV mayor es la dispersión y menor la representatividad de la media. Asimismo se observan dos grupos de puntos que corresponden a los dos niveles de concentración de los lotes de sueros del PEECFBA. En esta correlación el valor de $r=0,5893(\mathrm{p}<0,01)$ es significante para 24 pares de valores.

\subsubsection{Inexactitud}

Para conocer el error total (estimador de los componentes aleatorio y sistemático) del MR (CLSI), se calculó la inexactitud, en la serie de las 45 replicaciones de la medida de hierro de la solución de hierro estándar SRM 937 del NIST y se obtuvo una inexactitud promedio $=-1,8 \%$.

A su vez, se calculó la inexactitud en los 24 sueros comerciales liofilizados del PEECFBA evaluados en el item 5.2.4.3. 
Tabla 5-10: Estimación de la inexactitud en sueros control del PEEC-FBA

\begin{tabular}{|c|c|}
\hline Lote $\mathbf{N}^{\circ}$ & Inexactitud \% \\
\hline 173 & 33,3 \\
\hline 178 & $-0,85$ \\
\hline 182 & 24,5 \\
\hline 185 & 2,65 \\
\hline 187 & 26,5 \\
\hline 190 & 30,3 \\
\hline 194 & $-14,2$ \\
\hline 197 & $-6,9$ \\
\hline 199 & 46,5 \\
\hline 202 & 43,4 \\
\hline 204 & 35,8 \\
\hline 206 & 25,5 \\
\hline 207 & 35,0 \\
\hline 208 & 20,2 \\
\hline 211 & 34,9 \\
\hline 213 & 19,9 \\
\hline 215 & 21,2 \\
\hline 220 & 29,6 \\
\hline 221 & 13,5 \\
\hline 222 & 27,8 \\
\hline 223 & 35,0 \\
\hline 224 & 16,7 \\
\hline 225 & 28,7 \\
\hline 226 & 18,0 \\
\hline
\end{tabular}

En la Tabla 5-10 se observan los valores de inexactitud de las medias obtenidas en los mismos lotes de sueros cuyos datos de imprecisión se describen en 5.2.4.3. El rango de inexactitud encontrado estuvo comprendido entre $-14,2$ y $46,5 \%$, considerando que la comparación se hace con los valores informados por una red de laboratorios, donde la variabilidad interlaboratorio es una de los factores de mayor incidencia sobre los valores consenso. 


\subsection{Aplicación del Método Recomendado para la asignación de valores de hierro en diferentes materiales: comerciales, de evaluación externa y de preparación propia}

\subsubsection{Estándares comerciales de hierro}

A - Se realizaron mediciones de hierro por el MR (CLSI) incorporando sueros calibradores de BS y de W en las corridas.

Los resultados obtenidos se observan en las Tabla 5-11, que además muestra la inexactitud, expresada como porcentaje de error y calculada según la siguiente ecuación:

$$
\mathrm{ES}=\frac{\mathrm{X}_{\text {media }}}{\mathrm{VR}} \frac{-\mathrm{VR}}{\mathrm{VR}} 100
$$

donde $\mathrm{X}_{\text {media }}$ es el valor promedio obtenido de las repeticiones efectuadas, $\mathrm{y}$ VR, considerado como valor de referencia, corresponde al valor obtenido con el MR(CLSI).

Tabla 5-11: Evaluación de la inexactitud en materiales de calibración comerciales usando el MR (CLSI)

\begin{tabular}{|c|c|c|c|c|c|c|}
\hline \multirow{2}{*}{ Calibrador } & \multicolumn{3}{|c|}{ Repetición } & & Valor asignado \\
\cline { 2 - 4 } & $\mathbf{1}^{*}$ & $\mathbf{2}^{*}$ & $\mathbf{3}^{*}$ & $\begin{array}{c}\text { por fabricante } \\
\text { Fe mg/L }\end{array}$ & $\begin{array}{c}\text { Valor obtenido con } \\
\text { MR (CLSI) } \\
\text { Fe mg/L }\end{array}$ & $\begin{array}{c}\text { Inexactitud } \\
\%\end{array}$ \\
\hline BS & 0,383 & 0,389 & 0,385 & 1,79 & 1,73 & 3,45 \\
\hline W & 0,335 & 0,352 & 0,349 & 1,71 & 1,54 & 11,0 \\
\hline
\end{tabular}

*Expresadas en absorbancias a $560 \mathrm{~nm}$ para BS y a $600 \mathrm{~nm}$ para W, según lo indicado por el fabricante en los respectivos insertos.

B - Se realizaron mediciones de hierro por el MR (CLSI) incorporando sueros controles de BS y de W en las corridas. 
Los resultados obtenidos se observan en las Tabla 5-12, que además muestra la inexactitud calculada según la ecuación del ítem 5.3.1, tomando como valor de referencia el valor obtenido con el MR (CLSI) y como $\mathrm{X}_{\text {media }}$ el valor medio del rango de concentración de hierro de cada nivel, proporcionado por el fabricante.

Tabla 5-12: Evaluación de la Inexactitud en materiales de control comerciales usando el MR (CLSI)

\begin{tabular}{|c|c|c|c|c|c|c|}
\hline \multirow{2}{*}{$\begin{array}{l}\text { Material } \\
\text { de } \\
\text { Control }\end{array}$} & \multicolumn{3}{|c|}{ Repetición } & \multirow{2}{*}{$\begin{array}{c}\text { Rango } \\
\text { asignado por } \\
\text { fabricante } \\
\text { Fe mg/L }\end{array}$} & \multirow{2}{*}{$\begin{array}{c}\text { Valor } \\
\text { obtenido } \\
\text { con } \\
\text { MR(CLSI) } \\
\text { Fe mg/L }\end{array}$} & \multirow{2}{*}{$\begin{array}{c}\text { Inexactitud } \\
\%\end{array}$} \\
\hline & $1 *$ & $2 *$ & $3^{*}$ & & & \\
\hline $\begin{array}{c}\text { BS - } \\
\text { Nivel I }\end{array}$ & 0,302 & 0,310 & 0,290 & $0,97-1,38$ & 1,32 & $-10,9$ \\
\hline $\begin{array}{c}\text { BS - } \\
\text { Nivel II }\end{array}$ & 0,531 & 0,544 & 0,507 & $1,97-2,81$ & 2,43 & $-1,64$ \\
\hline $\begin{array}{c}\text { W - } \\
\text { Nivel I }\end{array}$ & 0,570 & 0,546 & 0,566 & $1,66-2,70$ & 2,59 & $-15,8$ \\
\hline $\begin{array}{c}\text { W - } \\
\text { Nivel II }\end{array}$ & 0,130 & 0,117 & 0,122 & $0,41-0,77$ & 0,45 & 31,1 \\
\hline
\end{tabular}

*Expresadas en absorbancias a $560 \mathrm{~nm}$ para BS y a $600 \mathrm{~nm}$ para $\mathrm{W}$, según lo indicado por el fabricante en los respectivos insertos.

\subsubsection{Estudio comparativo de la medida de hierro en Sueros control del Programa de Evaluación Externa de Calidad del Reino Unido (UK NEQAS)}

Se efectuaron determinaciones de hierro por el método recomendado en ocho sueros provistos por el Programa de evaluación externa de calidad del Reino Unido (UK NEQAS) cuyas concentraciones abarcan un amplio rango de medición analítica, entre 0,58 y $2,03 \mathrm{mg} / \mathrm{L}$.

En la Tabla 5-13, se observan los valores obtenidos y la inexactitud de los valores de consenso proporcionados por el informe del Programa UK NEQAS, calculada en 
relación al MR (CLSI), y en la Figura 5-5 se muestra, mediante un gráfico de dispersión, la correlación entre los valores obtenidos, con un coeficiente de correlación (r) de $0,9930(\mathrm{p}<0,001)$.

Tabla 5-13: Evaluación de la inexactitud de los valores consenso del UK NEQAS con respecto al MR (CLSI)

\begin{tabular}{|c|c|c|c|}
\hline $\begin{array}{c}\text { Sueros } \\
\text { Lote }\end{array}$ & $\begin{array}{c}\text { Valores consenso del } \\
\text { UK NEQAS } \\
\text { Fe mg/L }\end{array}$ & $\begin{array}{c}\text { Val. obtenidos con } \\
\text { MR(CLSI) } \\
\text { Fe mg/L }\end{array}$ & $\begin{array}{c}\text { Inexactitud } \\
\%\end{array}$ \\
\hline 676 & 1,535 & 1,558 & $-1,47$ \\
\hline 677 & 1,023 & 0,970 & 5,46 \\
\hline 678 & 2,026 & 2,161 & $-6,24$ \\
\hline 679 & 1,540 & 1,529 & 0,72 \\
\hline 680 & 1,773 & 1,695 & 4,60 \\
\hline 681 & 0,584 & 0,576 & 1,39 \\
\hline 682 & 1,903 & 1,901 & 0,10 \\
\hline 683 & 1,695 & 1,754 & $-3,36$ \\
\hline
\end{tabular}

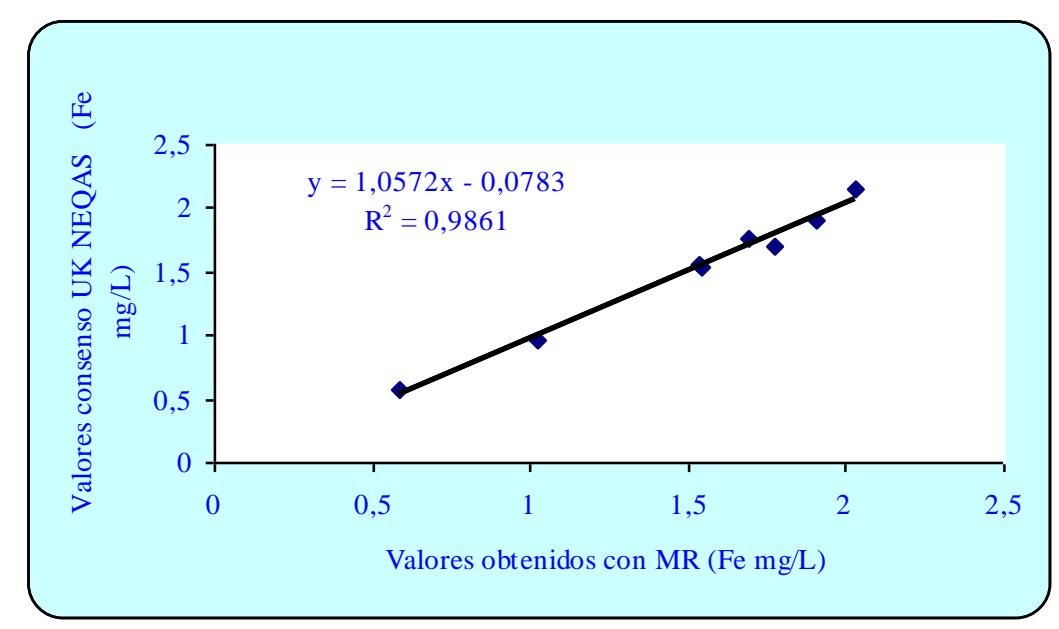

Figura 5-5: Gráfico de correlación entre valores del UK NEQAS y el MR (CLSI) 
En la Figura 5-6, mediante un gráfico de columnas, se comparan también ambos grupos de valores teniendo en cuenta que los participantes del Programa UK NEQAS utilizan el método directo (sin desproteinización) para la medición de hierro.

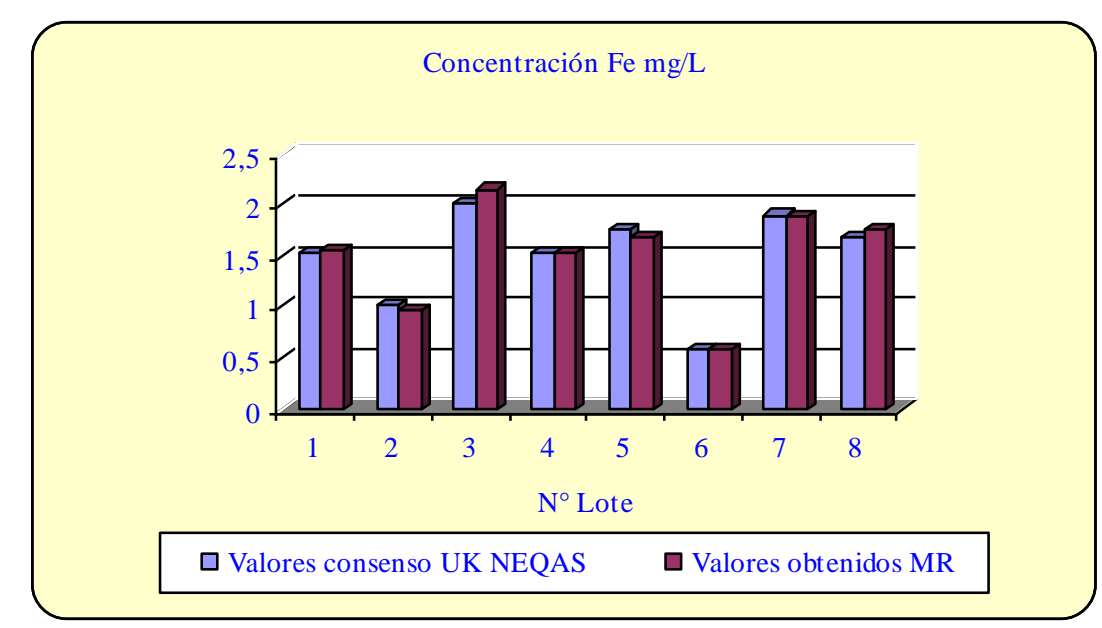

Figura 5-6: Gráfico de columnas de resultados obtenidos entre UK NEQAS y el MR (CLSI)

\subsubsection{Estudio comparativo de la medida de hierro en Sueros control del Programa de Evaluación Externa de Calidad del Centro Wadsworth, Departamento de Salud del Estado de New York (WCDHNY)}

Se efectuaron determinaciones de hierro por el método recomendado en cinco sueros proporcionados por el WCDHNY cuyas concentraciones abarcan un rango de medición analítica mas acotado que los valores de los sueros control provistos por el UK NEQAS y que se encuentra dentro de los valores considerados normales $(0,81$ a $1,16 \mathrm{mg} / \mathrm{L})$.

En la Tabla 5-14, se observan los valores obtenidos y la inexactitud de los valores de consenso proporcionados por el informe del WCDHNY calculada en relación al MR (CLSI), y en la Figura 5-7 se muestra, mediante un gráfico de dispersión, la correlación entre los valores obtenidos por ambas metodologías, con un coeficiente de correlación de $0,9586(\mathrm{p}<0,001)$. 
Tabla 5-14: Evaluación de la inexactitud de los valores de consenso del WCDHNY con respecto al MR (CLSI)

\begin{tabular}{|l|c|c|c|}
\hline $\begin{array}{c}\text { Sueros } \\
\text { Lote }\end{array}$ & $\begin{array}{c}\text { Valores consenso del } \\
\text { WCDHNY } \\
\text { Fe mg/L }\end{array}$ & $\begin{array}{c}\text { Val. obtenidos con } \\
\text { MR (CLSI) } \\
\text { Fe mg/L }\end{array}$ & $\begin{array}{c}\text { Inexactitud } \\
\%\end{array}$ \\
\hline Lote C41 & 0,81 & 0,98 & $-17,3$ \\
\hline Lote C42 & 0,83 & 0,95 & $-12,6$ \\
\hline Lote C43 & 0,66 & 0,72 & $-8,33$ \\
\hline Lote $\mathrm{C} 44$ & 1,16 & 1,19 & $-2,52$ \\
\hline Lote $\mathrm{C} 45$ & 1,03 & 1,08 & $-4,62$ \\
\hline
\end{tabular}

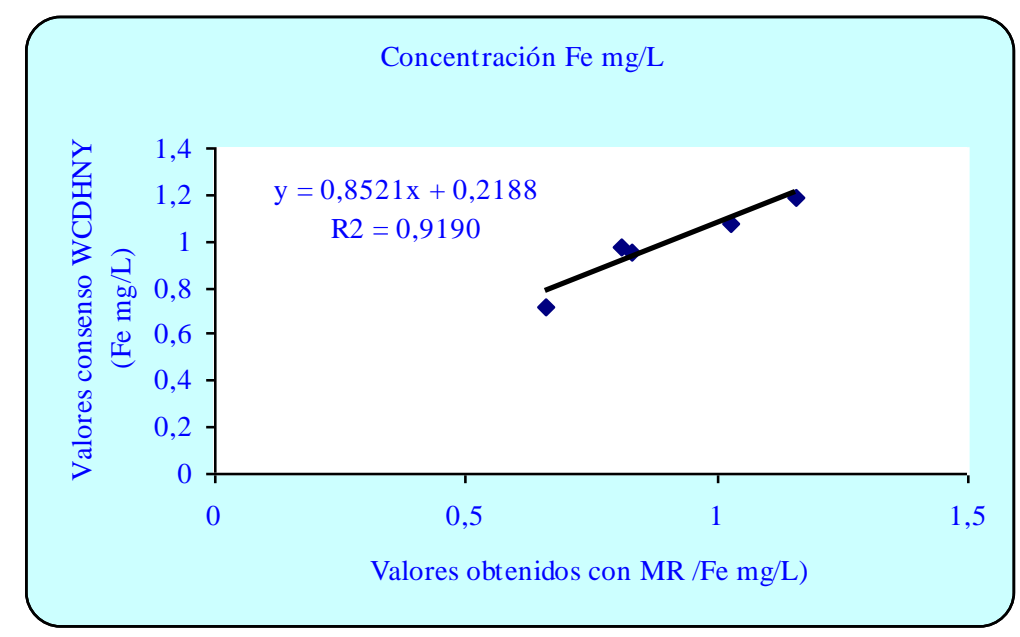

Figura 5-7: Gráfico de correlación entre valores del WCDHNY y el MR (CLSI)

A su vez, en la Figura 5-8, mediante un gráfico de columnas se comparan ambos grupos de valores, teniendo en cuenta que, también en este caso, el WCDHNY utiliza el método directo para la medición de hierro. 


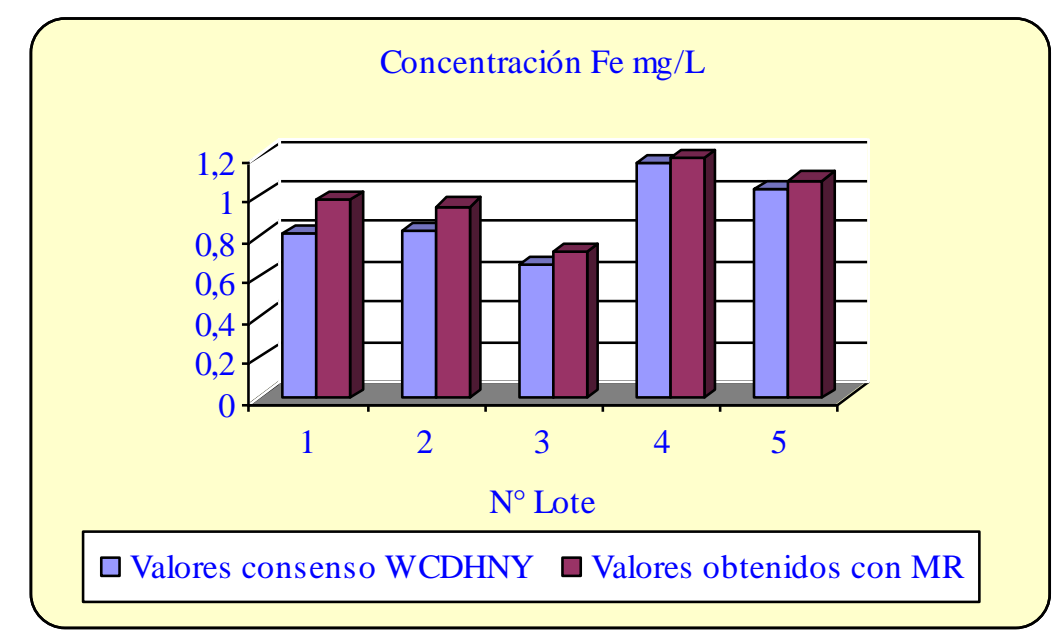

Figura 5-8: Gráfico de columnas de resultados obtenidos entre el WCDHNY y MR (CLSI)

\subsubsection{Estudio comparativo de la medida de hierro en Sueros control del Programa de Evaluación Externa de Calidad de la Fundación Bioquímica Argentina (PEEC-FBA)}

Se realizó la medición de hierro por el método recomendado, en varios sueros reconstituidos del PEEC-FBA, teniendo en cuenta que hay un predominio de laboratorios pertenecientes a la red de este Programa que utilizan el método directo. En las 24 encuestas de los lotes en estudio, el número de laboratorios participantes varió entre 454 y 807 , de los cuales el 91,1\% utilizó el método de colorimetría directa (Cailliat et al., 2007), mientras que el 8,9\% restante indicó el empleo de métodos con desproteinización previa y colorimetría con ferrozina o con ferene y métodos directos usando batofenantrolina o cromazurol B como cromógenos.

La Tabla 5-15 muestra los valores consenso de las medias, la DE y los CV\% del PEEC-FBA y los valores medios, la DE y los CV\% obtenidos, para los mismos lotes de sueros, empleando el MR (CLSI). Se observa que los CV\% de los valores consenso del PEEC-FBA arrojan valores que superan en más del 50 al 100\% a los CV\% obtenidos con el MR (CLSI). 
Tabla 5-15: Comparación de Xmedia, DE y CV entre valores del PEEC y del MR

(CLSI)

\begin{tabular}{|c|c|c|c|c|c|c|}
\hline \multirow[b]{2}{*}{$\begin{array}{c}\text { Encuesta } \\
\text { PEEC } \\
\mathbf{N}^{\circ}\end{array}$} & \multirow[b]{2}{*}{$\begin{array}{c}\text { Laboratorios } \\
\text { participantes } \\
\text { aceptados }\end{array}$} & \multirow{2}{*}{$\begin{array}{l}\text { Laboratorios que } \\
\text { utilizan } \\
\text { colorimetría } \\
\text { directa } \\
\text { n }(\%)\end{array}$} & \multicolumn{2}{|c|}{$\begin{array}{c}\text { Valores consenso del } \\
\text { PEEC }\end{array}$} & \multicolumn{2}{|c|}{$\begin{array}{l}\text { Valores obtenidos } \\
\text { con MR (CLSI) }\end{array}$} \\
\hline & & & $\mathrm{X}_{\text {media }} \pm \mathrm{DE}$ & CV\% & $X_{\text {media }} \pm$ DE & CV\% \\
\hline 173 & 600 & $539(89,8)$ & $2,84 \pm 1,02$ & 35,9 & $2,13 \pm 0,06$ & 2,7 \\
\hline 178 & 546 & $509(93,2)$ & $1,17 \pm 0,22$ & 17,1 & $1,18 \pm 0,08$ & 5,6 \\
\hline 182 & 478 & $450(94,1)$ & $2,34 \pm 0,61$ & 26,1 & $1,88 \pm 0,06$ & 3,3 \\
\hline 185 & 454 & $430(94,7)$ & $1,16 \pm 0,48$ & 41,4 & $1,13 \pm 0,06$ & 4,3 \\
\hline 187 & 636 & $603(94,8)$ & $2,29 \pm 0,59$ & 25,8 & $1,81 \pm 0,04$ & 2,5 \\
\hline 190 & 643 & $610(94,8)$ & $0,99 \pm 0,35$ & 35,3 & $0,76 \pm 0,06$ & 7,9 \\
\hline 194 & 566 & $520(91,9)$ & $2,24 \pm 0,60$ & 26,8 & $2,61 \pm 0,05$ & 1,8 \\
\hline 197 & 559 & $534(95,5)$ & $1,88 \pm 0,48$ & 25,5 & $2,02 \pm 0,06$ & 3,2 \\
\hline 199 & 602 & $575(95,5)$ & $1,26 \pm 0,29$ & 15,9 & $0,86 \pm 0,02$ & 2,3 \\
\hline 202 & 610 & $587(96,2)$ & $2,08 \pm 0,53$ & 25,5 & $1,45 \pm 0,09$ & 2,1 \\
\hline 204 & 616 & $587(95,3)$ & $1,29 \pm 0,20$ & 15,5 & $0,95 \pm 0,09$ & 9,2 \\
\hline 206 & 465 & $414(89,0)$ & $1,28 \pm 0,22$ & 17,2 & $1,02 \pm 0,12$ & 6,0 \\
\hline 207 & 500 & $455(91,0)$ & $2,39 \pm 0,43$ & 18,0 & $1,77 \pm 0,07$ & 5,3 \\
\hline 208 & 504 & $459(91,1)$ & $1,07 \pm 0,19$ & 17,8 & $0,89 \pm 0,12$ & 6,6 \\
\hline 211 & 681 & $613(90,0)$ & $2,63 \pm 0,36$ & 13,7 & $1,95 \pm 0,02$ & 0,9 \\
\hline 213 & 696 & $607(87,2)$ & $2,47 \pm 0,33$ & 13,4 & $2,06 \pm 0,10$ & 4,7 \\
\hline 215 & 740 & $644(87,0)$ & $2,29 \pm 0,33$ & 14,4 & $1,89 \pm 0,01$ & 0,7 \\
\hline 220 & 682 & $604(88,6)$ & $2,23 \pm 0,29$ & 13,0 & $1,72 \pm 0,04$ & 2,5 \\
\hline 221 & 740 & $654(88,4)$ & $1,09 \pm 0,15$ & 13,8 & $0,96 \pm 0,07$ & 7,5 \\
\hline 222 & 721 & $629(87,2)$ & $2,25 \pm 0,24$ & 10,7 & $1,76 \pm 0,05$ & 2,6 \\
\hline 223 & 771 & $682(88,5)$ & $1,08 \pm 0,14$ & 13,0 & $0,8 \pm 0,03$ & 4,1 \\
\hline 224 & 778 & $679(87,3)$ & $2,37 \pm 0,29$ & 12,2 & $2,03 \pm 0,11$ & 5,4 \\
\hline 225 & 747 & $654(87,6)$ & $1,12 \pm 0,13$ & 11,6 & $0,87 \pm 0,03$ & 3,9 \\
\hline 226 & 807 & $703(87,1)$ & $2,49 \pm 0,35$ & 14,6 & $2,11 \pm 0,03$ & 3,1 \\
\hline
\end{tabular}

Asimismo en la Figura 5-9, mediante un gráfico de dispersión, se muestra la correlación entre los valores obtenidos en todas las mediciones, con un coeficiente de correlación de 0,9107 ( $\mathrm{p}<0,001) \mathrm{y}$, en la Figura 5-10 mediante un gráfico de columnas se comparan los grupos de valores, teniendo en cuenta que, los valores consenso del PEEC-FBA provienen del grupo de participantes del Programa que 
utilizan como método de medición de hierro la colorimetría directa y como cromógeno ferrozina o ferene.

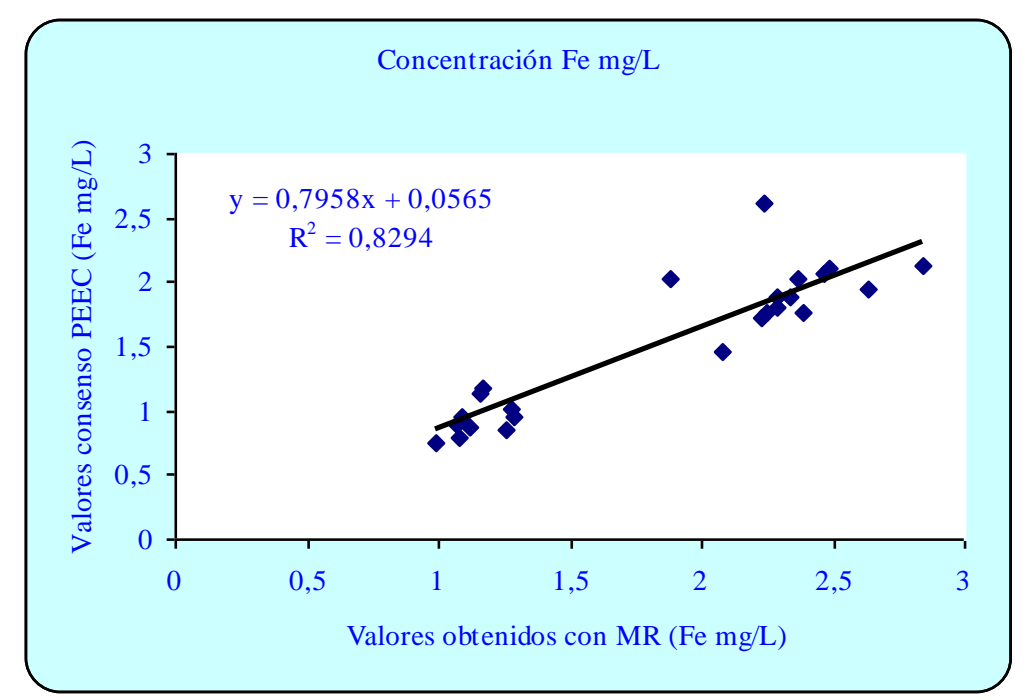

Figura 5-9: Gráfico de correlación entre valores del PEEC-FBA y el MR (CLSI)

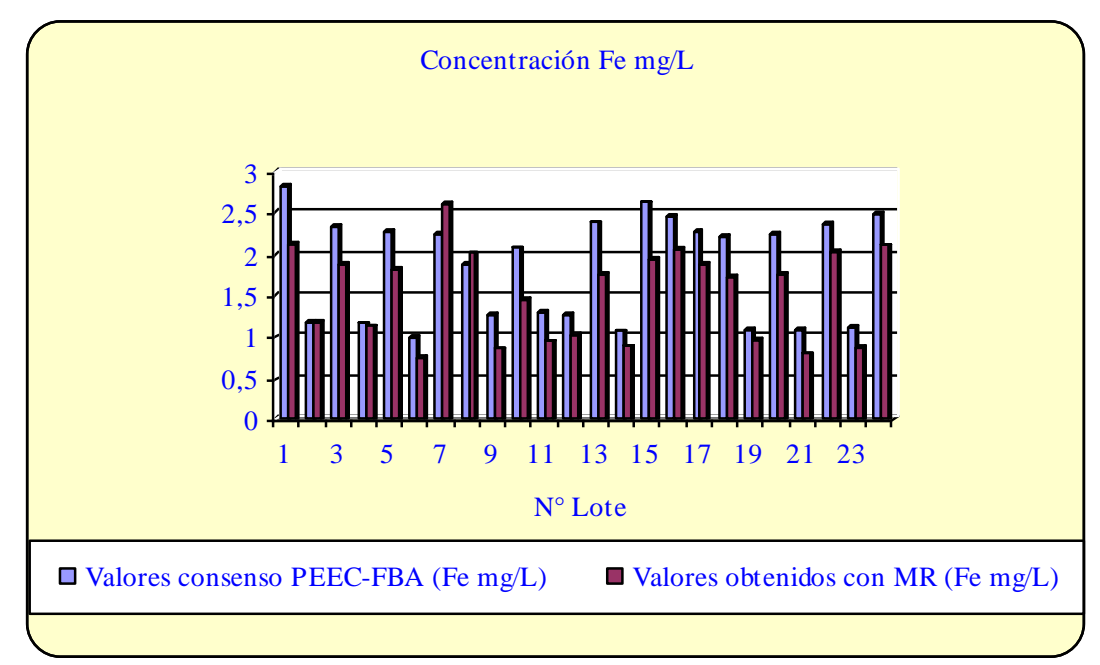

Figura 5-10: Gráfico de columnas obtenido entre valores consenso del PEEC-FBA y MR (CLSI)

5.3.5 Comparación de los valores de las medias, desviación estándar y coeficiente de variación obtenidos con el MR (CLSI), utilizando la calibración realizada con Titrisol@ - Merck 
Aquí, con el objeto de conocer si existen diferencias significativas entre las calibraciones con hierro NIST y con la solución patrón Titrisol, se realizó el cálculo de las concentraciones respectivas de hierro obtenidas en la serie de 24 lotes del PEEC FBA, en base a la calibración obtenida con Titrisol de Merck.

La Tabla 5- 16 muestra los valores obtenidos en ambos casos.

Tabla 5-16: Medias, DE y CV\% entre valores del PEEC-FBA según el MR (CLSI) y su relación con los valores calculados según la calibración realizada con Titrisol

\begin{tabular}{|c|c|c|c|c|}
\hline $\begin{array}{c}\text { PEEC } \\
\text { Lote } \mathbf{N}^{\circ}\end{array}$ & $\begin{array}{c}\text { X }_{\text {media MR (CLSI) }} \pm \\
\text { DE } \\
\text { Fe mg/L }\end{array}$ & CV\% & $\begin{array}{c}\mathrm{X}_{\text {media MRT }} \pm \mathrm{DE} \\
\text { Fe mg } / \mathrm{L}\end{array}$ & CV\% \\
\hline 173 & $2,13 \pm 0,06$ & 2,7 & $2,24 \pm 0,09$ & 4,0 \\
\hline 178 & $1,18 \pm 0,08$ & 5,6 & $1,27 \pm 0,11$ & 8,6 \\
\hline 182 & $1,88 \pm 0,06$ & 3,3 & $1,81 \pm 0,01$ & 0,5 \\
\hline 185 & $1,13 \pm 0,06$ & 4,3 & $1,23 \pm 0,01$ & 0,8 \\
\hline 187 & $1,81 \pm 0,04$ & 2,5 & $1,78 \pm 0,01$ & 0,6 \\
\hline 190 & $0,76 \pm 0,06$ & 7,9 & $0,99 \pm 0,16$ & 16,2 \\
\hline 194 & $2,61 \pm 0,05$ & 1,8 & $2,67 \pm 0,04$ & 1,5 \\
\hline 197 & $2,02 \pm 0,06$ & 3,2 & $1,99 \pm 0,12$ & 6,0 \\
\hline 199 & $0,86 \pm 0,02$ & 2,3 & $1,13 \pm 0,03$ & 2,6 \\
\hline 202 & $1,45 \pm 0,09$ & 2,1 & $2,10 \pm 0,01$ & 0,48 \\
\hline 204 & $0,95 \pm 0,09$ & 9,2 & $1,22 \pm 0,13$ & 10,6 \\
\hline 206 & $1,02 \pm 0,12$ & 6,0 & $1,27 \pm 0,08$ & 6,3 \\
\hline 207 & $1,77 \pm 0,07$ & 5,3 & $1,92 \pm 0,08$ & 4,2 \\
\hline 208 & $0,89 \pm 0,12$ & 6,6 & $1,14 \pm 0,08$ & 7,0 \\
\hline 211 & $1,95 \pm 0,02$ & 0,9 & $2,03 \pm 0,23$ & 11,3 \\
\hline 213 & $2,06 \pm 0,10$ & 4,7 & $2,45 \pm 0,21$ & 8,6 \\
\hline 215 & $1,89 \pm 0,01$ & 0,7 & $2,19 \pm 0,18$ & 8,2 \\
\hline 220 & $1,72 \pm 0,04$ & 2,5 & $2,01 \pm 0,07$ & 3,5 \\
\hline 221 & $0,96 \pm 0,07$ & 7,5 & $1,18 \pm 0,16$ & 13,6 \\
\hline 222 & $1,76 \pm 0,05$ & 2,6 & $2,44 \pm 0,06$ & 2,4 \\
\hline 223 & $0,8 \pm 0,03$ & 4,1 & $1,05 \pm 0,06$ & 5,7 \\
\hline 224 & $2,03 \pm 0,11$ & 5,4 & $1,79 \pm 0,09$ & 5,0 \\
\hline 225 & $0,87 \pm 0,03$ & 3,9 & $1,15 \pm 0,06$ & 5,2 \\
\hline 226 & $2,11 \pm 0,03$ & 3,1 & $2,11 \pm 0,04$ & 1,9 \\
\hline
\end{tabular}


Asimismo, la Figura 5-11 muestra la relación entre la Media (Xmedia) y el CV\% entre los pares de valores de la Tabla 5-16, donde el CV representa el número de veces que la desviación típica contiene a la media aritmética y por lo tanto, cuanto mayor es el CV mayor es la dispersión y menor la representatividad de la media. Asimismo se observan dos grupos de puntos que corresponden a los dos niveles de concentración de los lotes de sueros del PEEC-FBA. En esta correlación el valor de $r=0,3824$ ( $p<0,05$ ) es significante para 24 pares de valores y el rango de CV\% es mas amplio $(0,5$ a 16,2) que el obtenido cuando relacionamos los valores obtenidos con el MR (CLSI).

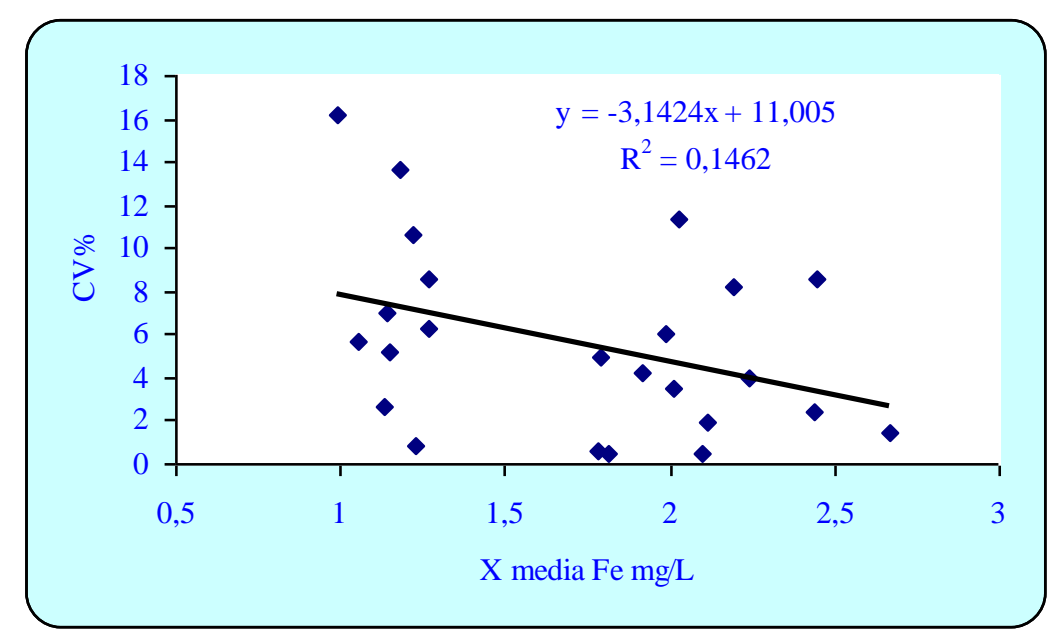

Figura 5-11: Gráfico de dispersión entre Xmedia y CV\% de los valores obtenidos en sueros control del PEEC-FBA calculados en base a la calibración con Titrisol 


\subsubsection{Ensayos con pool de sueros humanos de preparación propia}

\subsubsection{A - Medición de hierro con el MR (CLSI)}

De acuerdo al procedimiento descripto en el item 4.2.1.5 inciso II de Materiales y Métodos, se realizaron 50 repeticiones (durante 5 días se corrieron diez muestras de cada nivel de concentración) de la medida de hierro por el método recomendado en cada lote de pool de sueros de los tres niveles de concentración y se midieron las absorbancias a $593 \mathrm{~nm}$ en el espectrofotómetro Shimadzu. Asimismo, a manera de comparación, las absorbancias de las mezclas reactivas también se leyeron en el Analizador automático Random Access BioSystems A15 a $600 \mathrm{~nm}$, considerando la posibilidad de transferir etapas del MR (CLSI) a una metodología automatizada como veremos en el item 5.3.6.1 B.

En la Tabla 5-17 se muestran los valores de la Medias, DE y CV\% obtenidos en las corridas medidas en el espectrofotómetro Shimadzu, y en la Tabla 5-18 se muestran los valores de los mismos parámetros, obtenidos a partir de la lectura de las mismas series de mezclas reactivas, en el Autonalizador A15.

Tabla 5-17: Parámetros obtenidos en tres niveles de concentración de Fe con MR (CLSI) medidos en el espectrofotómetro Shimadzu

\begin{tabular}{|c|c|c|c|c|}
\hline Día & Parámetros $^{*}$ & Nivel bajo Fe mg/L & Nivel mediano Fe mg/L & Nivel alto Fe mg/L \\
\hline \multirow{3}{*}{1} & Xmedia & 0,52 & 1,09 & 2,00 \\
& DE & 0,03 & 0,05 & 0,06 \\
& CV & 5,61 & 4,26 & 2,83 \\
\hline \multirow{3}{*}{2} & Xmedia & 0,51 & 1,07 & 2,04 \\
& DE & 0,03 & 0,05 & 0,08 \\
& CV & 5,96 & 4,79 & 3,74 \\
\hline \multirow{3}{*}{3} & Xmedia & 0,55 & 1,13 & 2,01 \\
& DE & 0,03 & 0,03 & 0,05 \\
& CV & 4,84 & 2,45 & 2,29 \\
\hline \multirow{3}{*}{4} & Xmedia & 0,55 & 1,11 & 2,03 \\
& DE & 0,03 & 0,03 & 0,06 \\
& CV & 5,38 & 3,08 & 2,93 \\
\hline
\end{tabular}




\begin{tabular}{|c|c|c|c|c|}
\hline \multirow{3}{*}{5} & Xmedia & 0,56 & 1,04 & 2,02 \\
& $\mathrm{DE}$ & 0,02 & 0,03 & 0,03 \\
& $\mathrm{CV}$ & 3,50 & 2,59 & 1,55 \\
\hline
\end{tabular}

* Calculados mediante el programa Microsoft Excel 2003

Tabla 5-18: Parámetros obtenidos en tres niveles de concentración de Fe con MR (CLSI) medidos en el Autonalizador A15

\begin{tabular}{|c|c|c|c|c|}
\hline Día & Parámetros ${ }^{*}$ & Nivel bajo Fe mg/L & Nivel mediano Fe mg/L & Nivel alto Fe mg/L \\
\hline 1 & $\begin{array}{c}\text { Xmedia } \\
\text { DE } \\
\text { CV }\end{array}$ & ND** & ND** & $\mathrm{ND} * *$ \\
\hline 2 & $\begin{array}{c}\text { Xmedia } \\
\text { DE } \\
\text { CV }\end{array}$ & $\begin{array}{l}0,43 \\
0,01 \\
1,91\end{array}$ & $\begin{array}{l}1,05 \\
0,02 \\
1,78\end{array}$ & $\begin{array}{l}2,13 \\
0,05 \\
2,26\end{array}$ \\
\hline 3 & $\begin{array}{c}\text { Xmedia } \\
\text { DE } \\
\text { CV }\end{array}$ & $\begin{array}{l}0,45 \\
0,01 \\
2,06\end{array}$ & $\begin{array}{l}1,04 \\
0,01 \\
1,14\end{array}$ & $\begin{array}{l}2,14 \\
0,02 \\
0,79\end{array}$ \\
\hline 4 & $\begin{array}{c}\text { Xmedia } \\
\text { DE } \\
\text { CV }\end{array}$ & $\begin{array}{l}0,51 \\
0,02 \\
3,95\end{array}$ & $\begin{array}{l}1,02 \\
0,04 \\
3,42\end{array}$ & $\begin{array}{l}2,02 \\
0,05 \\
2,55\end{array}$ \\
\hline 5 & $\begin{array}{c}\text { Xmedia } \\
\text { DE } \\
\text { CV }\end{array}$ & $\begin{array}{l}0,53 \\
0,02 \\
4,11\end{array}$ & $\begin{array}{l}1,02 \\
0,02 \\
1,96\end{array}$ & $\begin{array}{l}2,00 \\
0,03 \\
1,61\end{array}$ \\
\hline
\end{tabular}

* Calculados mediante el programa Microsoft Excel 2003

** No Determinado

Se observa que los valores obtenidos de las lecturas de las corridas realizadas en el Autonalizador A15, tanto para las Medias como para los CV\%, si bien son menores a las obtenidas con el espectrofotómetro Shimadzu en el $67 \%$ y $83 \%$ respectivamente, considerando los tres niveles de concentración de hierro, esta diferencia es preponderante en los niveles bajo y mediano. 


\subsection{B - Medición de hierro por el MR semiautomatizado (CLSI Se Au)}

Paralelamente se realizaron 50 repeticiones (durante 5 días se corrieron diez muestras de cada nivel de concentración) de la determinación de hierro en el sobrenadante obtenido de acuerdo al procedimiento descripto en el item 4.2.1.5 II, de cada lote de pooles de los tres niveles de concentración y se leyeron las absorbancias a $600 \mathrm{~nm}$ en el autoanalizador A15. En la Tabla 5-19 se muestran los valores de la Medias, DE y CV\% obtenidos en éstas últimas corridas.

Tabla 5-19: Parámetros obtenidos en tres niveles de concentración de hierro con CLSI Se Au

\begin{tabular}{|c|c|c|c|c|}
\hline Día & Parámetros $^{*}$ & Nivel bajo Fe mg/L & Nivel mediano Fe mg/L & Nivel alto Fe mg/L \\
\hline \multirow{3}{*}{1} & Xmedia & 0,50 & 1,04 & 1,79 \\
& DE & 0,02 & 0,05 & 0,12 \\
& CV & 3,51 & 4,51 & 6,58 \\
\hline \multirow{2}{*}{2} & Xmedia & 0,50 & 1,00 & 1,91 \\
& DE & 0,04 & 0,04 & 0,10 \\
& CV & 8,72 & 4,31 & 5,24 \\
\hline \multirow{3}{*}{3} & Xmedia & 0,49 & 0,99 & 1,95 \\
& DE & 0,03 & 0,04 & 0,07 \\
& CV & 5,32 & 4,27 & 3,58 \\
\hline \multirow{3}{*}{4} & Xmedia & 0,48 & 1,00 & 1,96 \\
& DE & 0,03 & 0,06 & 0,07 \\
& CV & 7,17 & 5,85 & 3,43 \\
\hline \multirow{2}{*}{5} & Xmedia & 0,50 & 0,99 & 1,96 \\
& DE & 0,03 & 0,04 & 0,06 \\
& CV & 6,88 & 4,42 & 3,16 \\
\hline
\end{tabular}

* Calculados mediante el programa Microsoft Excel 2003

Se observa que los valores de las Medias obtenidos de las lecturas de las corridas realizadas en el Autonalizador A15, en esta modificación del MR (CLSI), son menores en un $100 \%$, mientras que los $\mathrm{CV} \%$ en un $87 \%$ presentan valores mayores cuando se comparan con los del MR (CLSI), en los tres niveles de concentración de hierro. 
5.3.6.2 Medición de hierro con el método comercial de BS manual y automatizado

\section{A - Calibración}

Se efectuó la calibración del método comercial de BS, según el protocolo indicado en el item 4.2.2.1, utilizando diluciones del suero calibrador proporcionado por BS e incluyendo en la corrida, el patrón de 1,02 mg/L de $\mathrm{Fe}$ y tres de las soluciones estándares del MR (CLSI). Las mediciones se efectuaron por triplicado (Tabla 5-20 y la curva de calibración obtenida se graficó en la Figura 5-12.

Tabla 5-20: Datos para la obtención de la curva de calibración del método manual de BS

\begin{tabular}{|c|c|c|c|}
\hline \multirow{2}{*}{$\begin{array}{c}\text { Calibrador } \\
\text { Fe mg/L }\end{array}$} & \multicolumn{3}{|c|}{ Repetición } \\
\cline { 2 - 4 } & $\mathbf{1}^{*}$ & $\mathbf{2}^{*}$ & $\mathbf{3}^{*}$ \\
\hline 0 & 0 & 0 & 0 \\
\hline 0,45 & 0,144 & 0,150 & 0,147 \\
\hline 0,89 & 0,221 & 0,250 & 0,230 \\
\hline 1,79 & 0,401 & 0,397 & 0,396 \\
\hline
\end{tabular}

*Expresadas en absorbancias a $560 \mathrm{~nm}$.

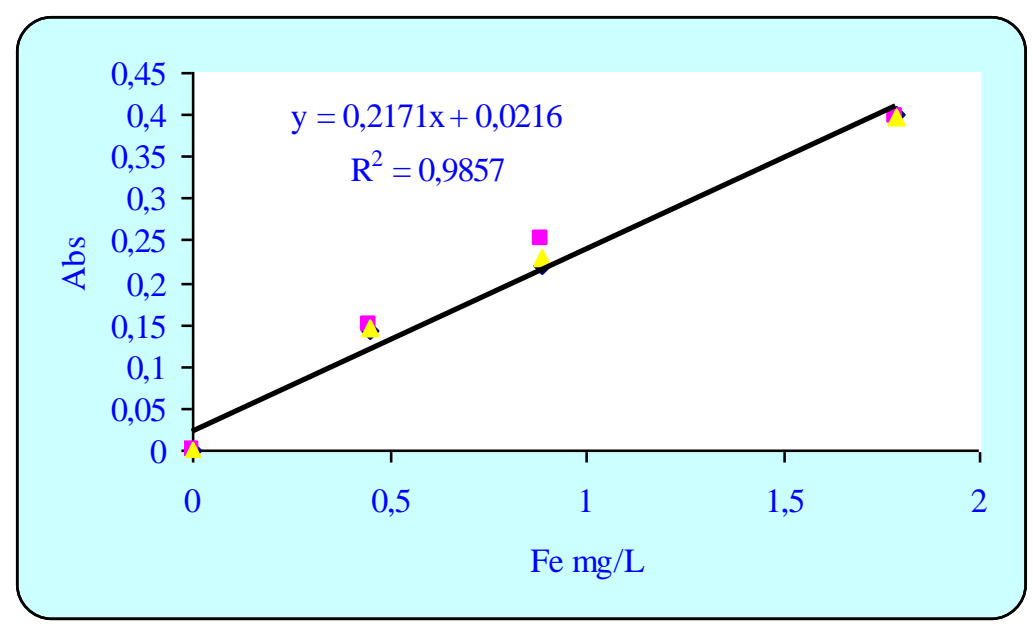

Figura 5-12: Curva de calibración obtenida con el método manual de BS 


\section{B - Procedimiento}

Se realizaron 50 repeticiones (durante 5 días se corrieron diez muestras de cada nivel de concentración) de la medida de hierro con el equipo comercial de BS en cada lote de pooles de los tres niveles de concentración y se midieron las absorbancias en forma manual en el espectrofotómetro Shimadzu y, en forma paralela, se efectuaron las determinaciones por método automático en el Autoanalizador A15.

En la Tabla 5-21 se muestran los valores de la Medias, DE y CV\% obtenidos en las corridas cuyas lecturas de absorbancia se realizaron en el espectrofotómetro Shimadzu (BS Ma), en comparación con los valores de los mismos parámetros, obtenidos a partir de las determinaciones efectuadas en el Autonalizador A15 (BS Au).

Tabla 5-21: Parámetros obtenidos con el equipo BS por método manual y por método automatizado

\begin{tabular}{|c|c|c|c|c|c|c|c|}
\hline \multirow[b]{2}{*}{ Día } & \multirow{2}{*}{ Parámetros* } & \multicolumn{2}{|c|}{ Nivel bajo Fe mg/L } & \multicolumn{2}{|c|}{ Nivel mediano Fe mg/L } & \multicolumn{2}{|c|}{ Nivel alto Fe mg/L } \\
\hline & & BS Ma & BS Au & BS Ma & BS Au & BS Ma & BS Au \\
\hline \multirow{3}{*}{1} & Xmedia & 0,55 & 0,51 & 1,01 & 1,01 & 2,1 & 2,03 \\
\hline & $\mathrm{DE}$ & 0,03 & 0,01 & 0,03 & 0,03 & 0,02 & 0,02 \\
\hline & $\mathrm{CV}$ & 5,52 & 2,09 & 3,46 & 3,32 & 1,13 & 0,80 \\
\hline \multirow{3}{*}{2} & Xmedia & 0,49 & 0,52 & 0,94 & 0,91 & 2,12 & 1,98 \\
\hline & $\mathrm{DE}$ & 0,03 & 0,01 & 0,04 & 0,04 & 0,05 & 0,03 \\
\hline & $\mathrm{CV}$ & 5,27 & 2,85 & 3,87 & 4,37 & 2,56 & 1,44 \\
\hline \multirow{3}{*}{3} & Xmedia & 0,51 & 0,52 & 1,04 & 0,99 & 2,09 & 1,99 \\
\hline & $\mathrm{DE}$ & 0,02 & 0,02 & 0,04 & 0,01 & 0,04 & 0,01 \\
\hline & $\mathrm{CV}$ & 4,87 & 4,19 & 3,85 & 1,19 & 1,67 & 0,57 \\
\hline \multirow{3}{*}{4} & Xmedia & 0,52 & 0,54 & 1,03 & 0,99 & 2,08 & 1,91 \\
\hline & $\mathrm{DE}$ & 0,02 & 0,02 & 0,01 & 0,03 & 0,02 & 0,03 \\
\hline & $\mathrm{CV}$ & 3,70 & 4,33 & 1,29 & 3,49 & 0,93 & 1,36 \\
\hline \multirow{3}{*}{5} & Xmedia & 0,51 & 0,51 & 1,02 & 1,01 & 2,06 & 2,00 \\
\hline & $\mathrm{DE}$ & 0,02 & 0,02 & 0,03 & 0,03 & 0,02 & 0,03 \\
\hline & $\mathrm{CV}$ & 3,49 & 4,13 & 2,60 & 2,83 & 0,75 & 1,33 \\
\hline
\end{tabular}

* Calculados mediante el programa Microsoft Excel 2003 
5.3.6.3 Medición de hierro con el equipo comercial de W manual y automatizado

\section{A - Calibración}

Se efectuó la calibración del método comercial de W, según el protocolo indicado en el item 4.2.2.2, utilizando diluciones del suero calibrador proporcionado por $\mathrm{W}$ e incluyendo en la corrida, el patrón de 1,00 mg/L de Fe y tres de las soluciones estándares del MR (CLSI). Las mediciones se efectuaron por triplicado (Tabla 5-22) y la curva obtenida se graficó en la Figura 5-13.

Tabla 5-22: Datos para la obtención de la curva de calibración del método manual de $\mathrm{W}$

\begin{tabular}{|c|c|c|c|}
\hline $\begin{array}{c}\text { Calibrador } \\
\text { Fe mg/L }\end{array}$ & \multicolumn{3}{|c|}{ Repetición } \\
\cline { 2 - 4 } & $\mathbf{1}^{*}$ & $\mathbf{2}^{*}$ & $\mathbf{3}^{*}$ \\
\hline 0 & 0 & 0 & 0 \\
\hline 0,43 & 0,136 & 0,144 & 0,146 \\
\hline 0,86 & 0,267 & 0,261 & 0,271 \\
\hline 1,71 & 0,377 & 0,379 & 0,385 \\
\hline
\end{tabular}

*Expresadas en absorbancias a $600 \mathrm{~nm}$.

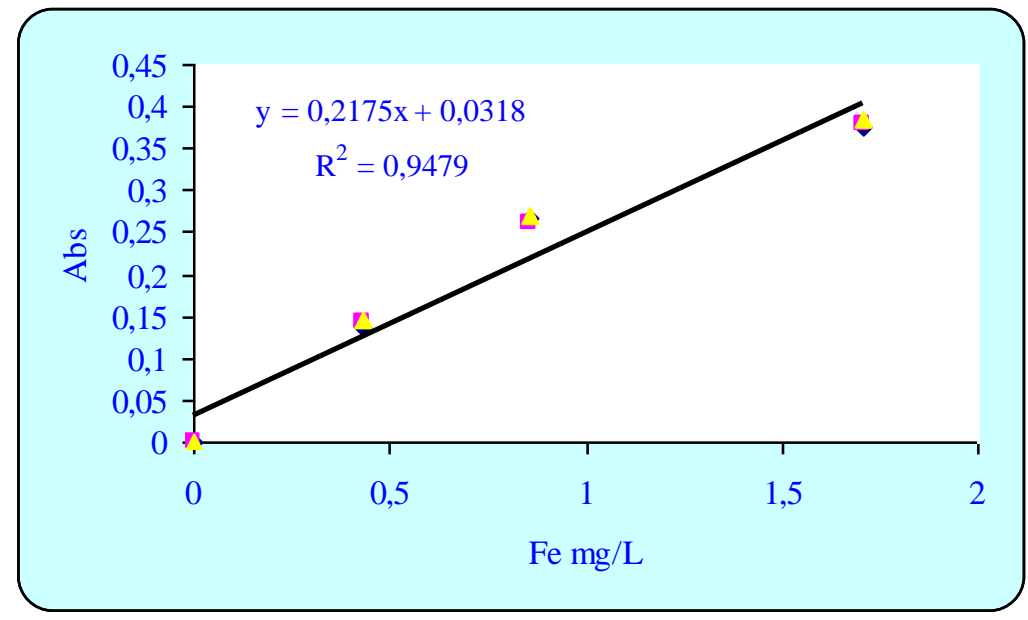

Figura 5-13: Curva de calibración obtenida con el equipo de W 


\section{B - Procedimiento}

Se realizaron 50 repeticiones (durante 5 días se corrieron diez muestras de cada nivel de concentración) de la medida de hierro con el equipo comercial de $\mathrm{W}$ en cada lote de pooles de los tres niveles de concentración y se midieron las absorbancias en forma manual en el espectrofotómetro Shimadzu y, en forma paralela, se efectuaron las determinaciones por método automático en el Autoanalizador A15.

En la Tabla 5-23 se muestran los valores de la Medias, DE y CV\% obtenidos en las corridas cuyas lecturas de absorbancia se realizaron en el espectrofotómetro Shimadzu (W Ma), en comparación con los valores de los mismos parámetros, obtenidos a partir de las determinaciones efectuadas en el Autonalizador A15 (W Au).

Tabla 5-23: Parámetros obtenidos con el equipo $\mathrm{W}$ por método manual y por método automatizado

\begin{tabular}{|c|c|c|c|c|c|c|c|}
\hline \multirow{2}{*}{ Día } & \multirow{2}{*}{ Parámetros* } & \multicolumn{2}{|c|}{ Nivel bajo Fe mg/L } & \multicolumn{2}{c|}{ Nivel mediano Fe mg/L } & \multicolumn{2}{c|}{ Nivel alto Fe mg/L } \\
\cline { 3 - 8 } & & W Ma & W Au & W Ma & W Au & W Ma & W Au \\
\hline \multirow{3}{*}{1} & Xmedia & 0,56 & 0,51 & 0,93 & 0,98 & 2,07 & 1,99 \\
& DE & 0,04 & 0,03 & 0,04 & 0,03 & 0,09 & 0,03 \\
& CV & 6,72 & 5,47 & 4,30 & 2,78 & 4,56 & 1,61 \\
\hline \multirow{3}{*}{2} & Xmedia & 0,52 & 0,50 & 1,01 & 0,99 & 2,11 & 2,00 \\
& DE & 0,02 & 0,02 & 0,03 & 0,03 & 0,09 & 0,03 \\
& CV & 4,29 & 3,05 & 3,02 & 3,03 & 4,14 & 1,73 \\
\hline \multirow{3}{*}{3} & Xmedia & 0,52 & 0,50 & 0,93 & 1,05 & 1,99 & 2,00 \\
& DE & 0,02 & 0,02 & 0,04 & 0,03 & 0,08 & 0,06 \\
& CV & 4,64 & 3,27 & 4,21 & 3,18 & 4,26 & 3,12 \\
\hline \multirow{3}{*}{4} & Xmedia & 0,53 & 0,49 & 1,02 & 0,95 & 1,95 & 1,96 \\
& DE & 0,04 & 0,01 & 0,04 & 0,01 & 0,01 & 0,01 \\
& CV & 7,54 & 2,89 & 4,31 & 0,92 & 0,26 & 0,75 \\
\hline \multirow{3}{*}{5} & Xmedia & 0,51 & 0,50 & 1,00 & 0,96 & 1,96 & 1,98 \\
& DE & 0,02 & 0,02 & 0,02 & 0,02 & 0,01 & 0,03 \\
& CV & 4,32 & 4,05 & 2,05 & 2,24 & 0,38 & 1,27 \\
\hline
\end{tabular}

* Calculados mediante el programa Microsoft Excel 2003 


\subsection{Análisis Estadístico de los datos obtenidos en pooles de sueros con el MR (CLSI) y con equipos comerciales}

Como primer paso a la evaluación estadística, se realizó el test de Dixon a todas las series de determinaciones y no se detectaron valores marginales.

\subsubsection{Comparación de Medias}

Utilizando como herramienta estadística el Statgraphics® Plus V5.1, con un $n=50$ para cada nivel, se calcularon los valores de las Medias, la DE y el CV\% obtenidos de las seis metodologías desarrolladas para los niveles bajo, mediano y alto de concentración de hierro (Tabla 5-24).

Se observa que, a excepción del método CLSI Se Au, en el cual el CV\% del pool de nivel mediano es menor que el CV\% del pool del nivel alto, y en el método BS $\mathrm{Au}$ donde el CV\% del pool del nivel bajo es menor que el CV\% del nivel mediano, en los demás métodos se observa que, a mayor concentración de hierro, el CV\% disminuye, mientras que el rango total está comprendido entre 1,93 a 6,46.

Asimismo, los métodos W Au y BS Au, presentan CV\% más bajos (mejor performance) que los métodos manuales. 
Tabla 5-24: Comparación de parámetros para tres niveles de concentración de hierro sérico

\begin{tabular}{|c|c|c|c|c|c|}
\hline Método & Nivel & $\mathbf{n}$ & X media Fe mg/L & DE & $\mathrm{CV} \%$ \\
\hline \multirow{3}{*}{ CLSI } & bajo & 50 & 0,5356 & 0,0336 & 6,28 \\
\hline & mediano & 50 & 1,0880 & 0,0491 & 4,51 \\
\hline & alto & 50 & 2,0206 & 0,0551 & 2,73 \\
\hline \multirow{3}{*}{ CLSI Se Au } & bajo & 50 & 0,4934 & 0,0318 & 6,46 \\
\hline & mediano & 50 & 1,0056 & 0,0485 & 4,82 \\
\hline & alto & 50 & 1,9136 & 0,1056 & 5,52 \\
\hline \multirow{3}{*}{ BS Ma } & bajo & 50 & 0,5176 & 0,0312 & 6,03 \\
\hline & mediano & 50 & 1,0054 & 0,0459 & 4,56 \\
\hline & alto & 50 & 2,0818 & 0,0403 & 1,93 \\
\hline \multirow{3}{*}{$\mathrm{BS} \mathrm{Au}$} & bajo & 50 & 0,5198 & 0,0202 & 3,90 \\
\hline & mediano & 50 & 0,9830 & 0,0483 & 4,91 \\
\hline & alto & 50 & 1,9816 & 0,0471 & 2,38 \\
\hline \multirow{3}{*}{ W Ma } & bajo & 50 & 0,5300 & 0,0330 & 6,23 \\
\hline & mediano & 50 & 0,9790 & 0,0510 & 5,21 \\
\hline & alto & 50 & 2,0158 & 0,0938 & 4,65 \\
\hline \multirow{3}{*}{$\mathrm{W} \mathrm{Au}$} & bajo & 50 & 0,4984 & 0,0193 & 3,87 \\
\hline & mediano & 50 & 0,9730 & 0,0298 & 3,07 \\
\hline & alto & 50 & 1,9874 & 0,0387 & 1,95 \\
\hline
\end{tabular}

Paralelamente, mediante la prueba t de Student, para la determinación de las diferencias entre las medias y para la construcción de los intervalos de confianza, se compararon las medias de los dos métodos comerciales tanto manual como automatizado y del método semiautomatizado del MR (CLSI Se Au) con el MR (CLSI), para cada uno de los niveles de concentración de hierro (Tablas 5-25, 5-26, 5-27, 5-28 y 5-29).

En los tres niveles de concentración del analito, se encontró que el intervalo de $95 \%$ de confianza para la diferencia de medias es aceptable para el rango esperado de decisión clínica. 
Tabla 5-25: Comparación entre el método de BS manual (BS Ma) y el MR (CLSI)

\begin{tabular}{|c|c|c|c|c|c|c|}
\hline \multirow[t]{2}{*}{$\begin{array}{l}\text { Concentración } \\
\text { de Fe ( mg/L) }\end{array}$} & \multirow[t]{2}{*}{$\begin{array}{l}X_{\text {media }} \\
\text { BS Ma }\end{array}$} & \multirow[t]{2}{*}{$\begin{array}{l}\mathbf{X}_{\text {media }} \\
\text { CLSI }\end{array}$} & \multirow[t]{2}{*}{ p - valor } & \multicolumn{2}{|c|}{$\begin{array}{l}95 \% \text { Intervalo de } \\
\text { confianza para la } \\
\text { diferencia }\end{array}$} & \multirow[t]{2}{*}{$\begin{array}{c}\text { Inexactitud } \\
\%\end{array}$} \\
\hline & & & & inferior & superior & \\
\hline Nivel bajo & 0,5176 & 0,5356 & $0,008^{*}$ & 0,0050 & 0,0310 & $-3,36$ \\
\hline Nivel medio & 1,0054 & 1,0880 & $0,000^{*}$ & 0,0652 & 0,1000 & $-7,59$ \\
\hline Nivel alto & 2,0818 & 2,0206 & $0,000^{*}$ & $\begin{array}{l}-0,0769 \\
\end{array}$ & $-0,0455$ & 3,01 \\
\hline
\end{tabular}

* Con significancia estadística

Tabla 5-26: Comparación entre el método de W manual (W Ma) y el MR (CLSI)

\begin{tabular}{|c|c|c|c|c|c|c|}
\hline \multirow[t]{2}{*}{$\begin{array}{l}\text { Concentración } \\
\text { de } \mathrm{Fe}(\mathrm{mg} / \mathrm{L})\end{array}$} & \multirow[t]{2}{*}{$\begin{array}{l}X_{\text {media }} \\
\text { W Ma }\end{array}$} & \multirow[t]{2}{*}{$\begin{array}{l}\mathbf{X}_{\text {media }} \\
\text { CLSI }\end{array}$} & \multirow[t]{2}{*}{ p - valor } & \multicolumn{2}{|c|}{$\begin{array}{c}95 \% \text { Intervalo de } \\
\text { confianza para la } \\
\text { diferencia }\end{array}$} & \multirow[t]{2}{*}{$\begin{array}{c}\text { Inexactitud } \\
\%\end{array}$} \\
\hline & & & & inferior & superior & \\
\hline Nivel bajo & 0,5300 & 0,5356 & 0,372 & $-0,0069$ & 0,0181 & $-1,05$ \\
\hline Nivel medio & 0,9790 & 1,0880 & $0,000 *$ & 0,0863 & 0,1317 & $-10,02$ \\
\hline Nivel alto & 2,0158 & 2,0206 & 0,771 & $-0,0282$ & 0,0378 & $-0,24$ \\
\hline
\end{tabular}

* Con significancia estadística

Tabla 5-27: Comparación entre el método de CLSI semiautomatizado (CLSI Se Au) y el MR (CLSI)

\begin{tabular}{|c|c|c|c|c|c|c|}
\hline \multirow{2}{*}{$\begin{array}{c}\text { Concentración } \\
\text { de Fe ( mg/L) }\end{array}$} & CLSI SeAu & CLSI & & \multicolumn{2}{|c|}{$\begin{array}{c}\text { 95\% Intervalo de } \\
\text { confianza para la } \\
\text { diferencia }\end{array}$} & \multirow{2}{*}{$\begin{array}{c}\text { Inexactitud } \\
\%\end{array}$} \\
\cline { 5 - 6 } & & & & $\mathbf{X}_{\text {media }}$ & $\mathbf{p}$ - valor & \multicolumn{2}{|c|}{$\begin{array}{c}\text { inferior } \\
\text { Nivel bajo }\end{array}$} & 0,4934 & 0,5356 & $0,000^{*}$ & 0,0288 & 0,0556 & $-7,88$ \\
\hline Nivel medio & 1,0056 & 1,0880 & $0,000^{*}$ & 0,0635 & 0,1013 & $-7,57$ \\
\hline Nivel alto & 1,9136 & 2,0206 & $0,000^{*}$ & 0,0733 & 0,1407 & $-5,29$ \\
\hline
\end{tabular}

* Con significancia estadística 
Tabla 5-28: Comparación entre el método de BS automatizado (BS Au) y el MR (CLSI)

\begin{tabular}{|c|c|c|c|c|c|c|}
\hline \multirow[t]{2}{*}{$\begin{array}{c}\text { Concentración } \\
\text { de Fe (mg/L) }\end{array}$} & \multirow[t]{2}{*}{$\begin{array}{l}\mathbf{X}_{\text {media }} \\
\text { BS Au }\end{array}$} & \multirow[t]{2}{*}{$\begin{array}{l}X_{\text {media }} \\
\text { CLSI }\end{array}$} & \multirow[t]{2}{*}{ p - valor } & \multicolumn{2}{|c|}{$\begin{array}{l}\text { 95\% Intervalo de } \\
\text { confianza para la } \\
\text { diferencia }\end{array}$} & \multirow[t]{2}{*}{$\begin{array}{c}\text { Inexactitud } \\
\%\end{array}$} \\
\hline & & & & inferior & superior & \\
\hline Nivel bajo & 0,5198 & 0,5356 & $0,007 *$ & 0,0045 & 0,0271 & 8,25 \\
\hline Nivel medio & 0,9830 & 1,0880 & $0,000 *$ & 0,0852 & 0,1248 & $-9,65$ \\
\hline Nivel alto & 1,9816 & 2,0206 & $0,001^{*}$ & 0,0174 & 0,0606 & $-1,93$ \\
\hline
\end{tabular}

* Con significancia estadística

Tabla 5-29: Comparación entre el método de W automatizado (W Au) y el MR (CLSI)

\begin{tabular}{|c|c|c|c|c|c|c|}
\hline \multirow[t]{2}{*}{$\begin{array}{l}\text { Concentración } \\
\text { de } \mathrm{Fe}(\mathrm{mg} / \mathrm{L})\end{array}$} & \multirow[t]{2}{*}{$\begin{array}{l}\mathbf{X}_{\text {media }} \\
\mathbf{W} \text { Au }\end{array}$} & \multirow[t]{2}{*}{$\begin{array}{l}\mathbf{X}_{\text {media }} \\
\text { CLSI }\end{array}$} & \multirow[t]{2}{*}{ p - valor } & \multicolumn{2}{|c|}{$\begin{array}{c}95 \% \text { Intervalo de } \\
\text { confianza para la } \\
\text { diferencia }\end{array}$} & \multirow[t]{2}{*}{$\begin{array}{c}\text { Inexactitud } \\
\%\end{array}$} \\
\hline & & & & inferior & superior & \\
\hline Nivel bajo & 0,4984 & 0,5356 & $0,000 *$ & 0,0251 & 0,0493 & $-6,94$ \\
\hline Nivel medio & 1,0054 & 1,0880 & $0,000 *$ & 0,0988 & 0,1248 & $-7,59$ \\
\hline Nivel alto & 1,9874 & 2,0206 & $0,001 *$ & 0,0148 & 0,0516 & $-1,64$ \\
\hline
\end{tabular}

*Con significancia estadística

5.4.2 Correlación de los datos obtenidos por: análisis de regresión lineal, histogramas de distribución y gráficos de Bland - Altman

La dispersión de las diferencias observadas entre las medidas pareadas de los métodos fue evaluada aplicando procedimientos estadísticos, recomendados por Linnet K. y Boyd J. (2008), para comparación de métodos. 
Por estudios de regresión lineal se determinaron los valores de la recta de regresión y del coeficiente de correlación (r) entre pares de métodos, como se muestra en la Tabla 5-30, donde el rango de $r=0,9878$ a 0,9942 , indica una relación relativamente fuerte entre las variables, mientras que los valores de p-valor inferiores a 0,01 , demuestra que existe una relación lineal estadísticamente significativa, en las comparaciones de los siete pares de métodos, para un nivel de confianza del $99 \%$.

Tabla 5-30: Líneas de regresión y coeficiente de correlación entre siete pares de métodos $(*)$

\begin{tabular}{|c|c|c|}
\hline $\begin{array}{c}\text { Pares de Métodos } \\
\text { comparados }\end{array}$ & Recta de regresión & $\begin{array}{c}\text { Coef. de } \\
\text { correlación } \\
\text { (r) }\end{array}$ \\
\hline CLSI - BS Ma & $\mathrm{BS} \mathrm{Ma}=-0,0847+1,0589 *$ CLSI & 0,9941 \\
\hline CLSI - W Ma & $\mathrm{W} \mathrm{Ma}=-0,0462+1,0053 * \mathrm{CLSI}$ & 0,9878 \\
\hline CLSI - BS Au & $\mathrm{BS} \mathrm{Au}=-0,0381+0,9875 * \mathrm{CLSI}$ & 0,9928 \\
\hline $\mathrm{CLSI}-\mathrm{W} \mathrm{Au}$ & $\mathrm{W} \mathrm{Au}=-0,0689+1,0059 *$ CLSI & 0,9942 \\
\hline CLSI - CLSI Se $\mathrm{Au}$ & CLSI Se $\mathrm{Au}=-0,0199+0,9529 *$ CLSI & 0,9905 \\
\hline CLSI Se $\mathrm{Au}-\mathrm{BS} \mathrm{Au}$ & $\mathrm{BS} \mathrm{Au}=-0,0044+1,0214 *$ CLSI Se Au & 0,9880 \\
\hline CLSI Se $\mathrm{Au}-\mathrm{W} \mathrm{Au}$ & $\mathrm{W} \mathrm{Au}=-0,0319+1,0416^{*}$ CLSI Se $\mathrm{Au}$ & 0,9905 \\
\hline
\end{tabular}

(*) $\mathrm{n}=150$ para cada método

Los histogramas de distribución de las diferencias entre los valores obtenidos con el MR (CLSI) y los otros métodos, indican las variaciones en las frecuencias de datos de las variables para los diferentes métodos, y los gráficos de Bland - Altman, muestran las diferencias como una función del promedio de las mediciones.

Las gráficas de correlación obtenidas por comparación de los métodos se observan a continuación: 


\section{Gráficos de Regresión Lineal}

1 - Comparación entre los valores obtenidos por el MR (CLSI) y los valores obtenidos con los métodos manuales ( $\left.\begin{array}{lll}\text { y } & \text { B }\end{array}\right)$ y automatizados (C y D) de los equipos comerciales, y con la modificación semiautomatizada del MR (E).

A

Comparación métodos CLSI/BS Ma

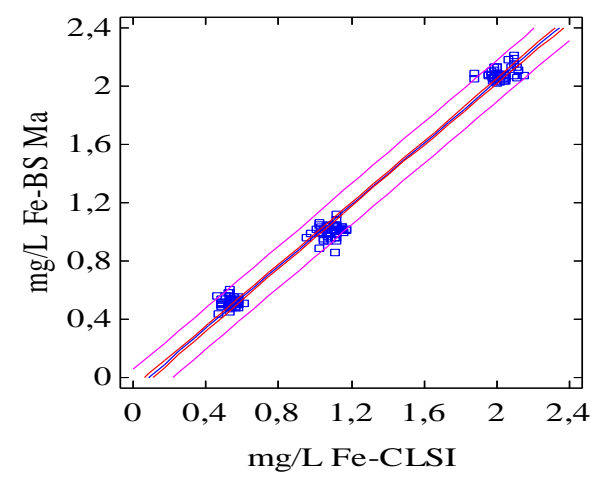

C

Comparación métodos CLSI/BS Au

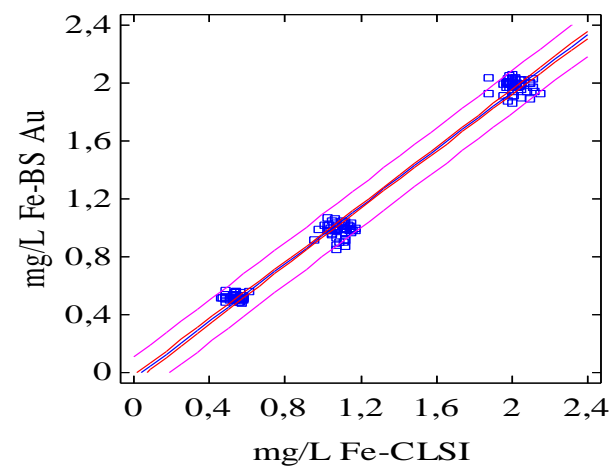

B
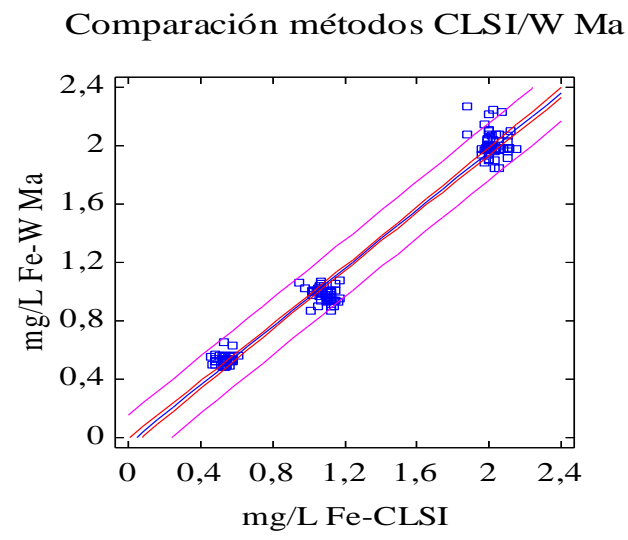

D

Comparación métodos CLSI/W Au

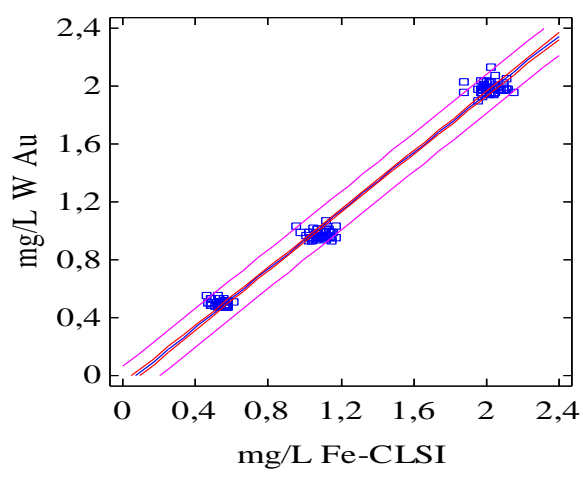

$\mathbf{E}$

Comparación métodos CLSI/CLSI SeAu

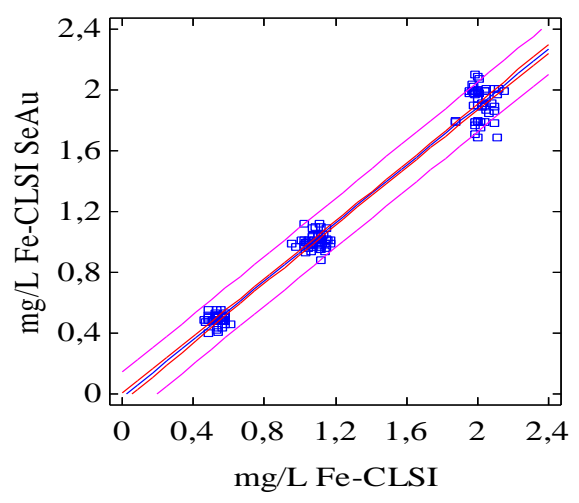


2 -Comparación entre los valores obtenidos con la modificación semiautomatizada (CLSI Se Au) y los valores obtenidos con los métodos automatizados de los equipos comerciales de BS (F) y de W (G).

$\mathbf{F}$

Comparación CLSI SeAu/BS Au

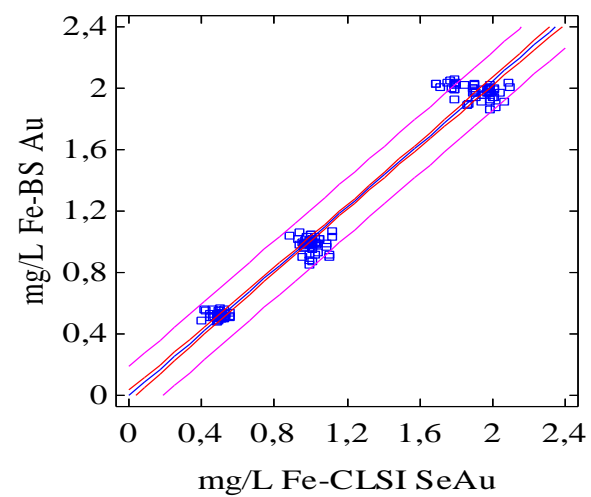

G

Comparación CLSI SeAu/W Au

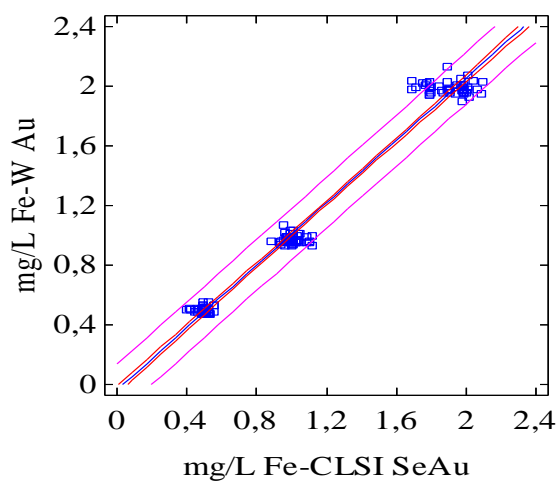

De la observación de los esquemas gráficos tanto en $\mathbf{1}$ como en $\mathbf{2}$ se detecta una mayor dispersión de valores en los pooles del nivel alto de concentración de hierro.

Los parámetros de la recta de regresión (ver Tabla 5-30) que mejor se ajusta a los puntos, en todos los casos muestra, para la ordenada al origen, valores negativos próximos a $0 \mathrm{y}$, para las pendientes, valores de 1 ó próximos a 1 , que nos dan una estimación del bajo error sistemático. 


\section{Histogramas}

1 - Comparación entre los valores obtenidos por el MR (CLSI) y los valores obtenidos con los métodos manuales (H e I) y automatizados ( $\mathrm{J}$ y $\mathrm{K}$ ) de los equipos comerciales.

$\mathbf{H}$

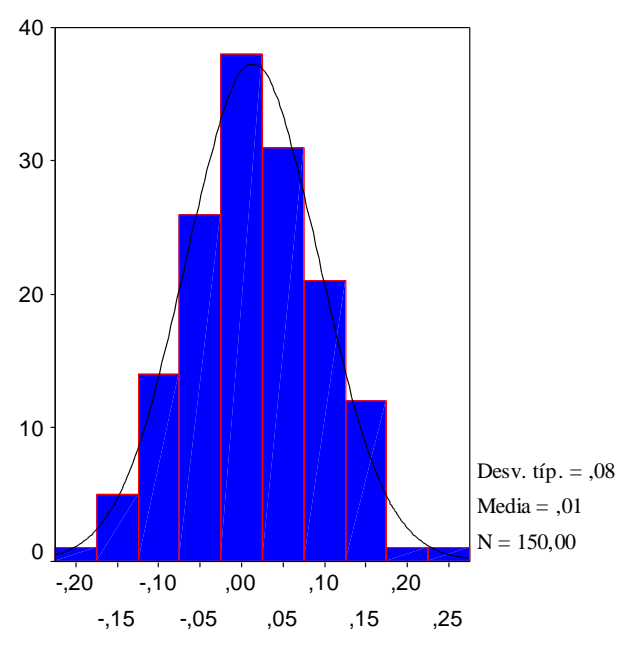

CLSI - BS Ma

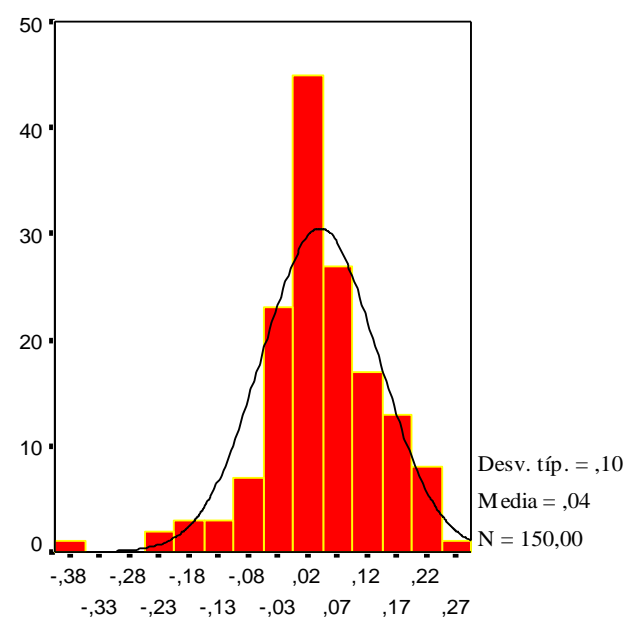

CLSI - W Ma
$\mathbf{K}$

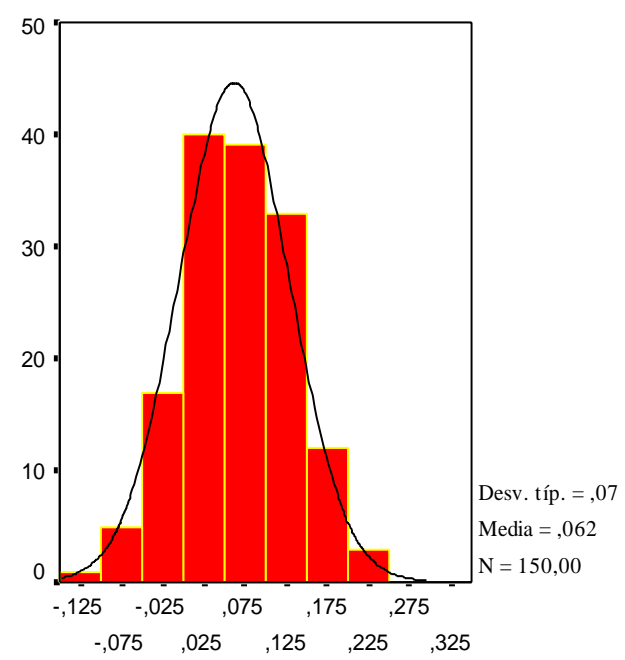

CLSI - W Au 
2 - Comparación entre los valores obtenidos con el MR (CLSI) y los valores obtenidos con la modificación semiautomatizada del MR (CLSI)=CLSI Se Au* (L) y entre este último y los métodos automatizados de los equipos comerciales de BS (M) y de W (N).

$\mathrm{L}$

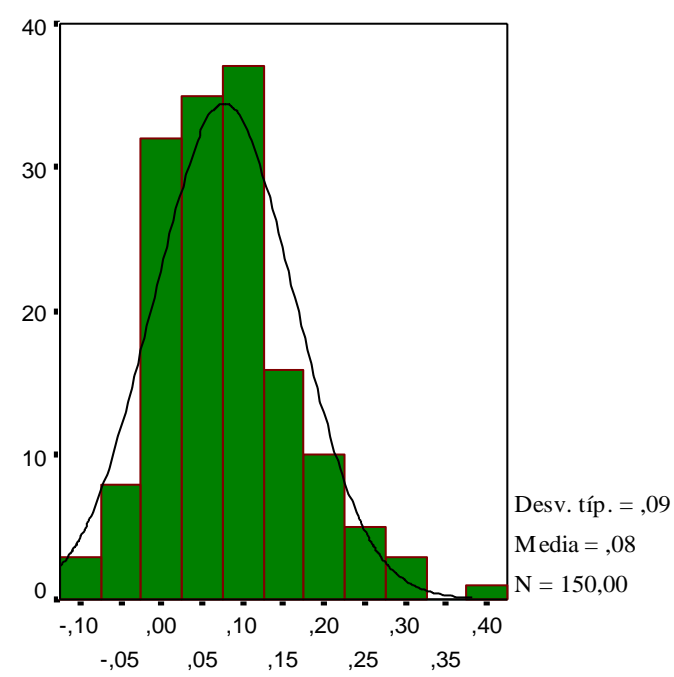

CLSI - CLSI SeAu

M

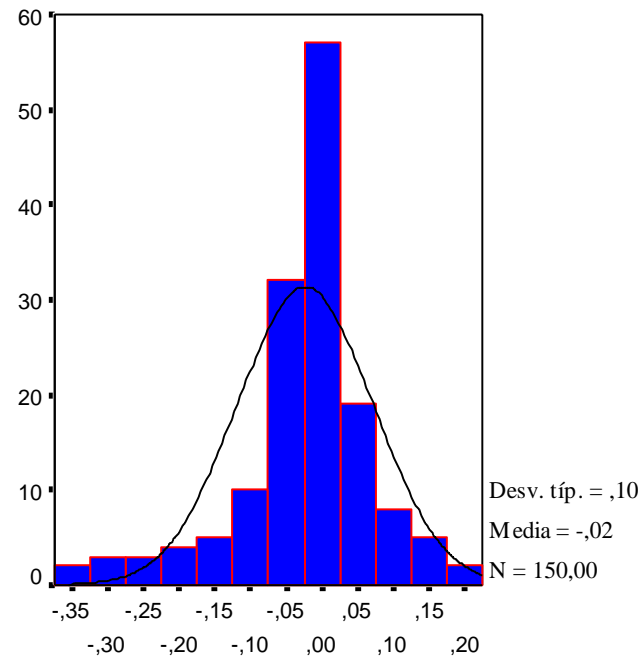

CSA - BSAu
$\mathbf{N}$

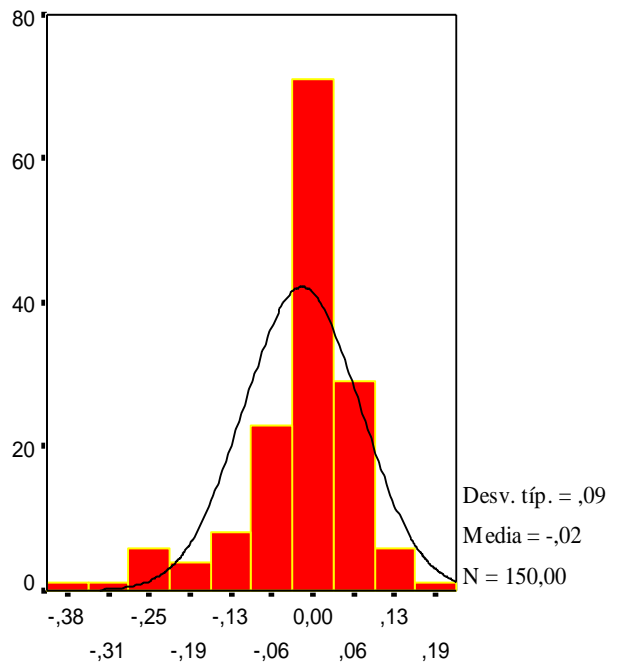

CSA -Wau

$*$ CLSI Se Au = CSA 
Los histogramas representan la distribución de las diferencias entre los valores obtenidos con el MR (CLSI) y los otros métodos, agrupados en intervalos; y en el eje vertical se observan las frecuencias de dichos intervalos.

En ellos se observó una mayor concordancia entre los valores obtenidos con el MR (CLSI) y con los métodos, tanto manual como automatizado de BS, y también, el MR (CLSI) presentó buena correlación con los valores obtenidos por el método W Au. 


\section{Gráficos de Bland-Altman}

1 - Diferencias entre los valores obtenidos por el MR (CLSI) y los valores obtenidos con los métodos manuales de los equipos comerciales versus el valor medio
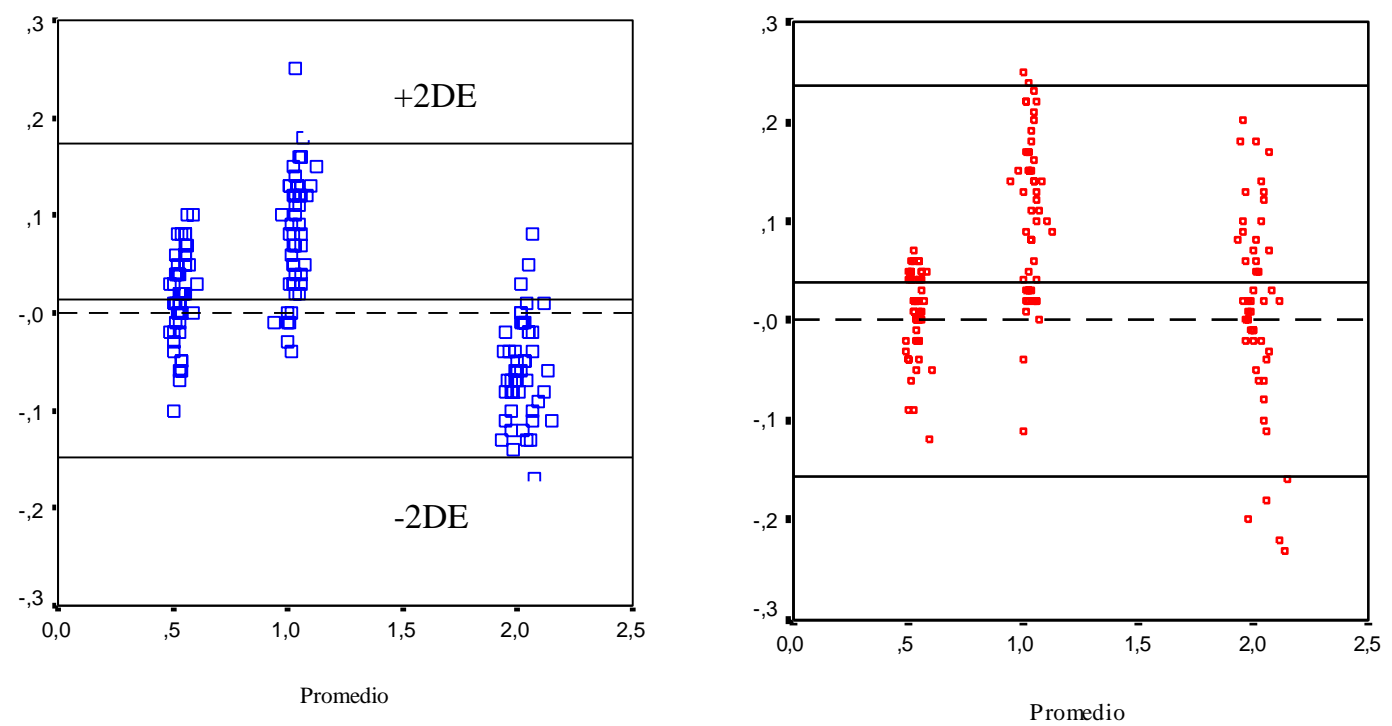

2 - Diferencias entre los valores obtenidos por el MR (CLSI) y los valores obtenidos con los métodos automatizados de los equipos comerciales versus el valor medio
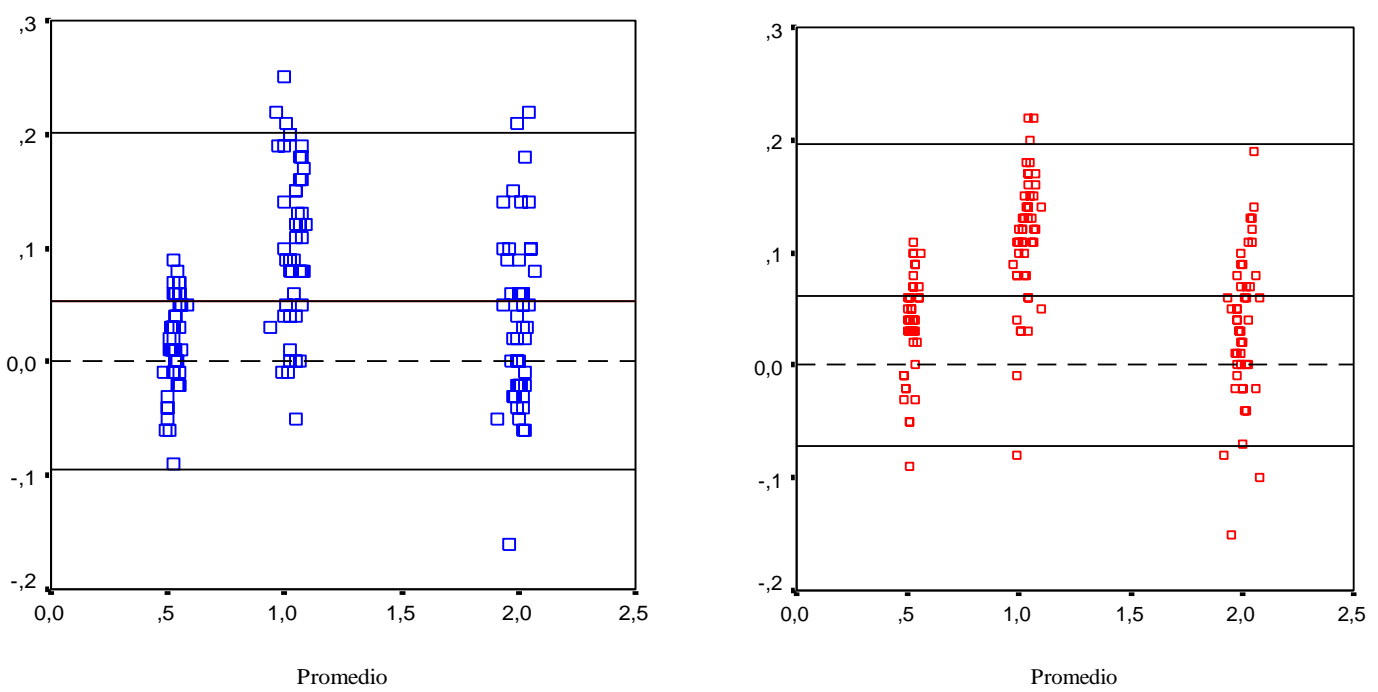
3 - Diferencia entre los valores obtenidos por el MR (CLSI) y los valores obtenidos con la modificación semiautomatizada (CLSI Se Au) versus el valor medio

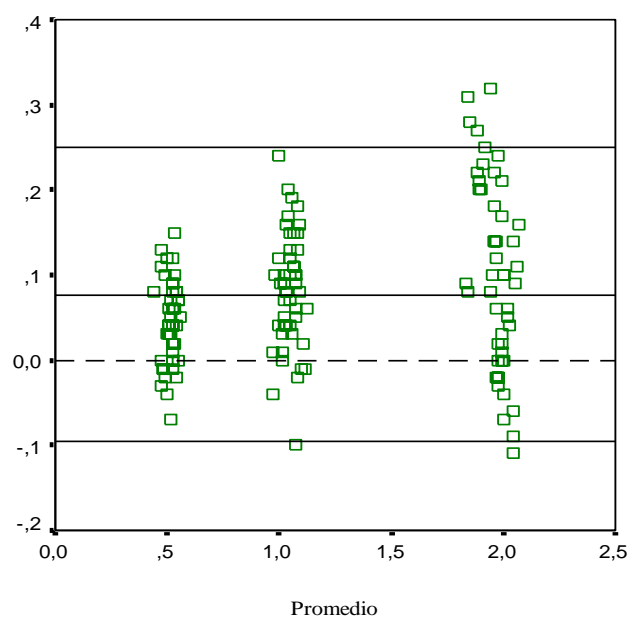

4 - Diferencias entre los valores obtenidos por CLSI Se Au* y los valores obtenidos con los métodos automatizados de los equipos comerciales versus el valor medio
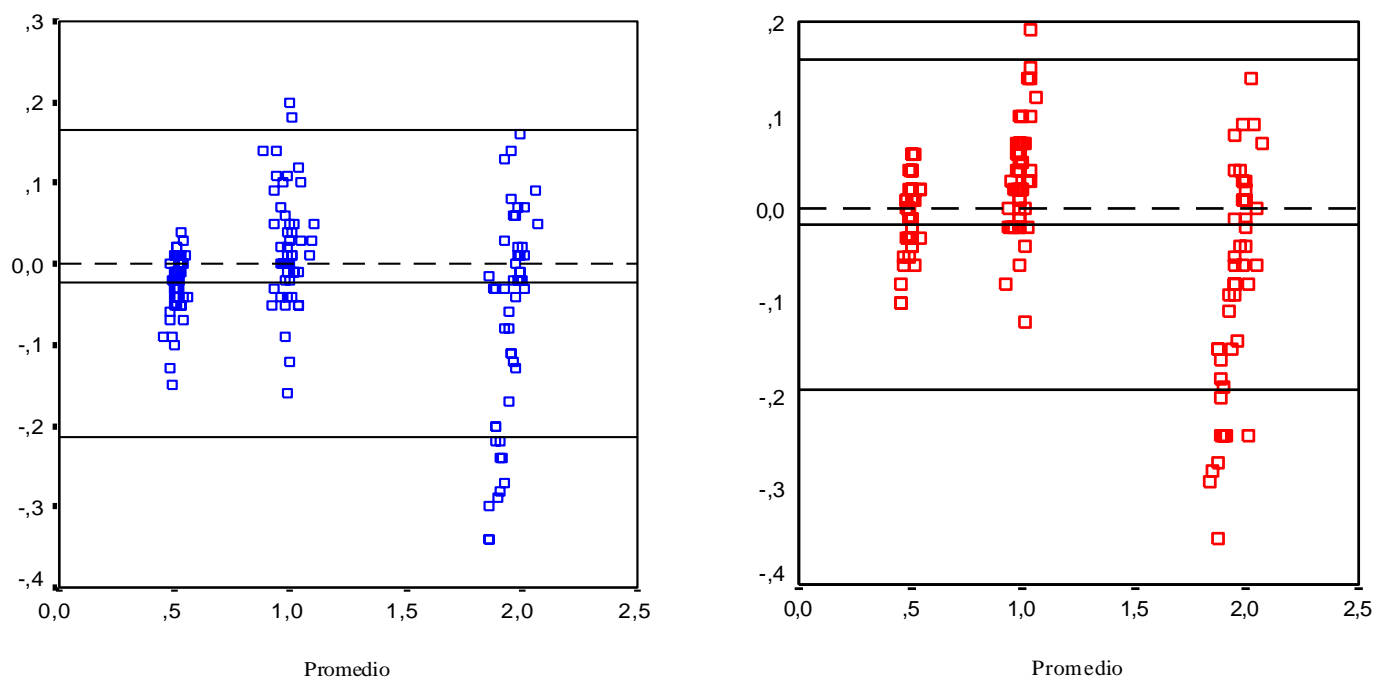

*CLSI Se Au = CSA 
Mediante los gráficos de Bland - Altman evaluamos la concordancia entre los métodos y la dispersión de los resultados obtenidos, a partir de la representación de la diferencia entre cada par de valores frente a la media de cada par de valores.

En la comparación del MR (CLSI) con los métodos comerciales manuales, en el caso del método de BS Ma, se observó que para la concentración mas baja de hierro ambos métodos coinciden, para el nivel medio los resultados con BS Ma son inferiores a los del MR (CLSI), y para la concentración más alta ocurre lo contrario.

A su vez, en la comparación del MR (CLSI) con el método comercial de W Ma, se observó que para la concentración mas baja ambos métodos coinciden, para el nivel medio los resultados de $\mathrm{W}$ Ma son inferiores a los del MR (CLSI), y para la concentración más alta hay mayor dispersión.

Con respecto a la comparación del MR (CLSI) con los métodos automatizados, se observó que para el método de BS Au no hay diferencias para el nivel bajo, mientras que para el nivel medio los valores de BS Au son inferiores a los del MR (CLSI), y algo muy parecido ocurre para el nivel más alto de hierro, mientras que para el método de W Au, en los tres niveles de concentración los valores del W Au son inferiores a los del CLSI, especialmente en el nivel medio de concentración de hierro.

Cuando se comparó el MR (CLSI) con la modificación semiautomatizada (CLSI Se Au) se observó que este último presenta valores inferiores al MR (CLSI) en todas las concentraciones de hierro, con una mayor dispersión de datos en el nivel alto.

En relación a la comparación del CLSI $\mathrm{Se} \mathrm{Au}$ con los métodos comerciales automatizados, se observó que para el nivel bajo, los valores del CLSI Se Au son menores a los valores obtenidos con el método de BS Au, no hay diferencia para el nivel medio, y en el nivel alto el CLSI Se Au presenta valores inferiores al BS Au, con una marcada dispersión de los mismos. En la comparación del CLSI Se Au con el W $\mathrm{Au}$, en el nivel bajo los valores obtenidos muestran concordancia, en el nivel medio el CLSI Se Au muestra valores mayores que el W Au y en el nivel alto los valores del CLSI Se Au son menores que los del W Au con mayor dispersión. 
Adicionalmente, se realizó la comparación, según Bland - Altman, entre los valores obtenidos con los dos métodos automatizados de los equipos comerciales (BS Au y W Au) y según muestra la Figura 5-14, ambos métodos coinciden bastante bien en los tres niveles de concentración de hierro.

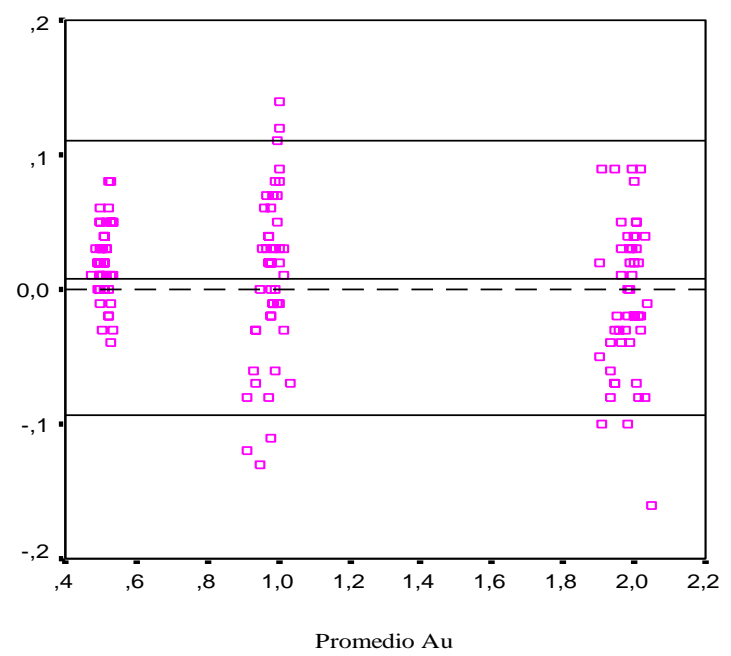

Figura 5-14: Gráfico de Bland-Altman entre las diferencias entre los dos métodos automatizados de los equipos comerciales versus el valor medio 


\subsection{Evaluación de la presentación de los equipos de reactivos comerciales utilizados en este trabajo}

Antes de proceder a la fase analítica de este trabajo se realizó el examen de la rotulación y del inserto de los equipos comerciales de reactivos, de acuerdo a las recomendaciones de la IFCC/OMS (Logan J.E. et al., 1985a), sobre la evaluación de juegos de reactivos para diagnóstico utilizados en los laboratorios de salud con recursos limitados, según lo descripto en el item 1-6.

\section{A - Examen de la rotulación del equipo: TABLA I}

B - Examen del inserto: TABLA II 


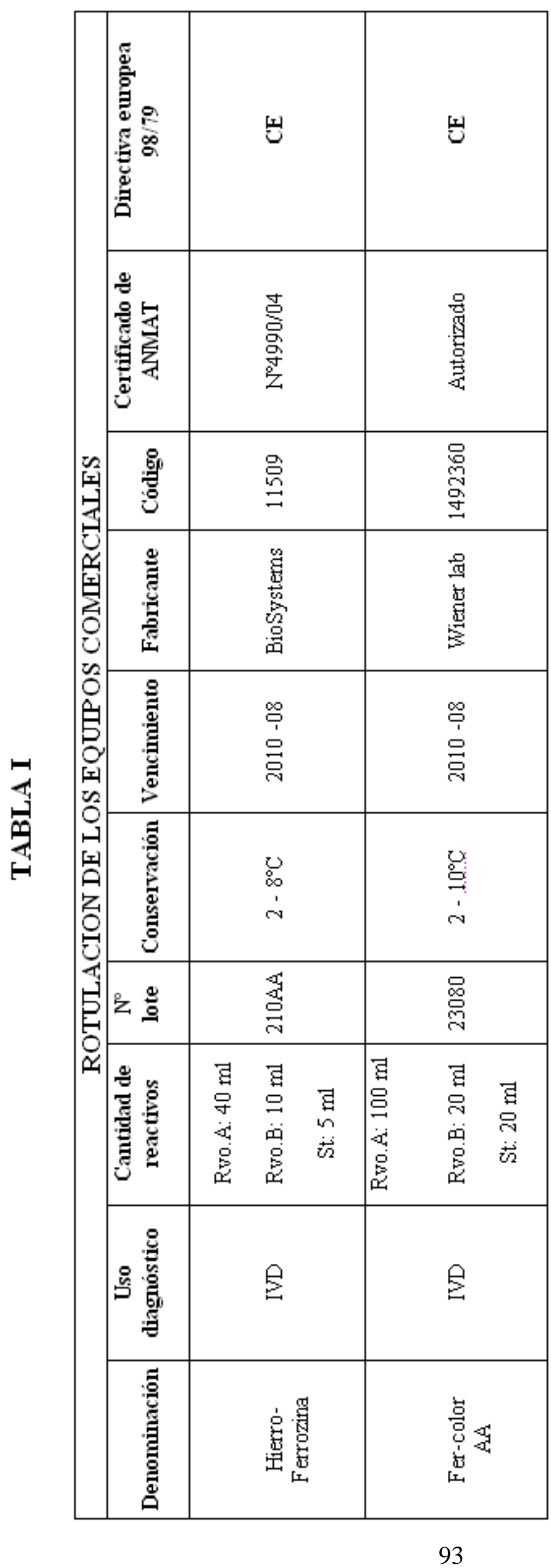




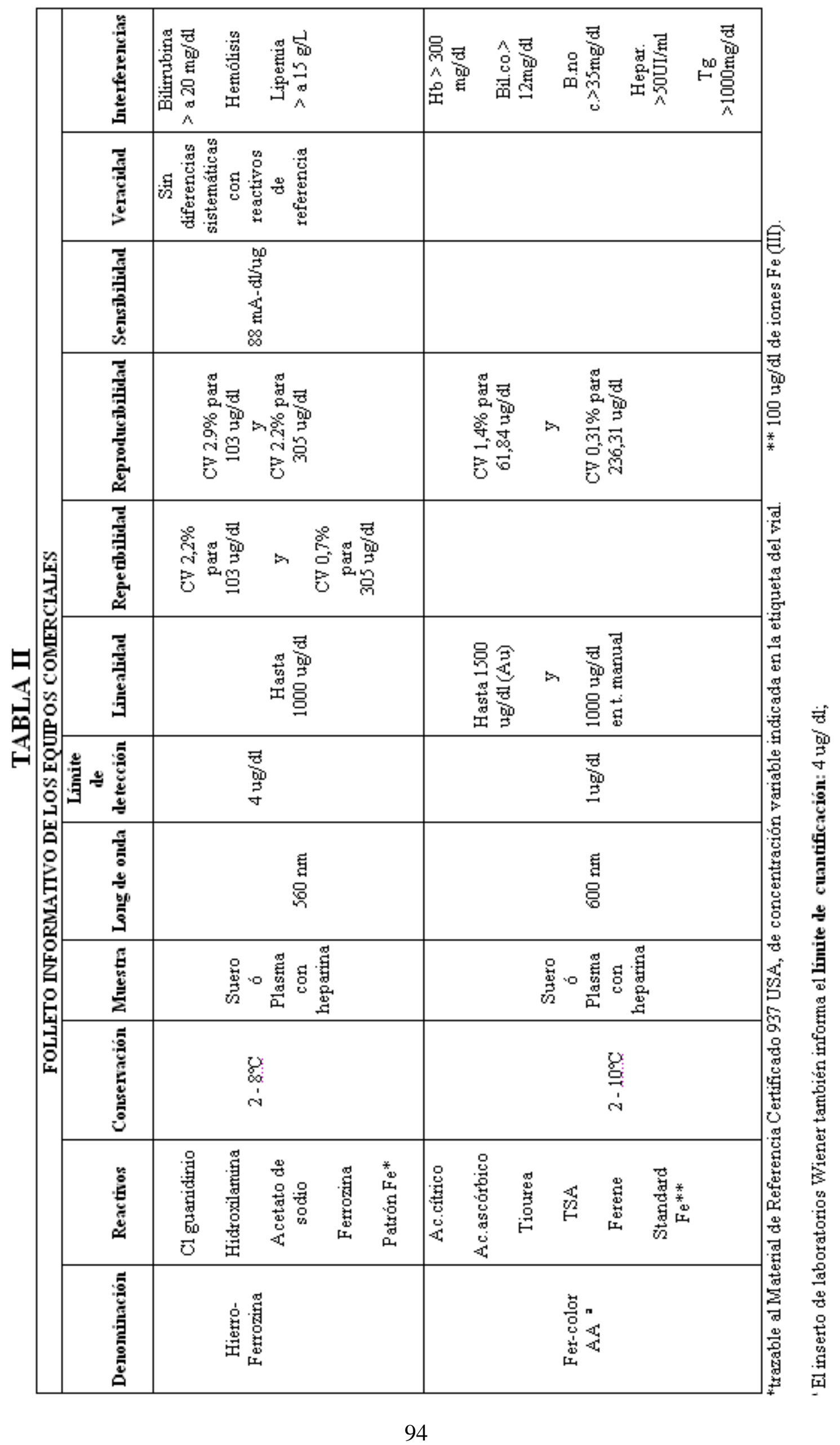




\section{Discusión y Conclusiones}


Como objetivo primordial de este trabajo, nos propusimos transferir las recomendaciones surgidas de la evaluación de la metodología recomendada para la determinación de hierro sérico a la red de laboratorios públicos y privados, para el mejoramiento de la calidad analítica de la determinación de ferremia. Para ello, se llevó a cabo el estudio del comportamiento de los equipos comerciales de mayor frecuencia de uso en los laboratorios bioquímicos para la cuantificación de este parámetro, que miden este analito directamente en el suero, en comparación con el método recomendado (MR) por el estándar H17-A del CLSI que usa desproteinización previa a la colorimetría, sobre la base de varias características. Las mismas incluyeron: puesta a punto del MR (CLSI), ensayos de validación del mismo (linealidad, recuperación, imprecisión, inexactitud) y la aplicación del MR (CLSI) para la asignación de valores en diferentes materiales de control: comerciales, de programas de evaluación externa nacionales e internacionales y de preparación propia.

En relación a la puesta a punto del MR (CLSI), en la primera etapa analítica, se realizaron calibraciones con hierro Anedra y con el material de referencia del NIST obteniéndose buenos coeficientes de correlación ( 0,9997 y 0,9988, respectivamente). El estudio de comparación con la solución patrón concentrada Titrisol de Merck arrojó valores disímiles solo en los rangos bajos de concentración de hierro (16 a 20\%), mientras que para rangos medios y altos los valores fueron mas coincidentes con los valores del MR (CLSI) con porcentajes de inexactitud de -6,7 a 8\% para el rango medio y -2 a 9\% para el rango alto. Este hallazgo, ya había sido reportado hace casi dos décadas por Blijenberg B.G. et al. (1993) que reportó datos de inexactitud para valores bajos de $45,8 \%$ y para valores altos de 4,15\%, y por Tietz N.W. et al. (1994) que obtuvo valores de inexactitud para $0,47 \mathrm{mg} / \mathrm{L}$ de $58,5 \%$ y para $1,98 \mathrm{mg} / \mathrm{L}$ de $1 \%$, quienes atribuían esta variación a diversas fuentes de error. Entre ellas, debemos mencionar: incompleta disociación del hierro de su unión con proteínas y pérdidas de hierro durante la precipitación de proteínas (Bunting P. S.y Aggarwal M., 1983; Tietz N.W. y Rinker A.D., 1994; Mori L. et al., 1981), reducción incompleta del ión férrico a ferroso (Schlosnagle D. C., 1982), interferencias como el cobre que puede formar complejos con el cromógeno (Eckfeldt J.H.y Witte D.L., 1994; Mori L. et al.,1981), la hemoglobina que como trazas, puede sumar hierro y así podrían elevar el valor real, e interferencias espectrofotométricas por otros componentes de la matriz sérica como bilirrubina y lípidos (Valcour A.A. et al.,1990). 
Entre los ensayos de prevalidación, comprobamos que la reacción es lineal hasta 10 $\mathrm{mg} / \mathrm{L}$ y el rango total de recuperación del hierro agregado estuvo comprendido entre 65,8 a $97,5 \%$, en todos los materiales de matriz proteica empleados. En la bibliografía, los porcentajes de recuperación mencionados en métodos con desproteinización son algo mayores: 95,3 a 100,6\% (Barkan G. y Walker B.S., 1940) y 99,5 a 102\% (Trinder P., 1956), mientras que para un método directo automatizado se ha descripto un rango de valores menores y mas amplio: 43 a 88\% (Zak B., y Epstein E., 1965). En nuestra experiencia el rango porcentual de recuperación, según el nivel de concentración de hierro, fue mayor al descripto por Zak y Epstein.

En los estudios de comparación del MR (CLSI) realizados con sueros de programas internacionales (UK NEQAS y WCDHNY) y nacionales (PEEC-FBA) se encontraron algunas diferencias. A modo de ejemplo, para el UK NEQAS el rango de inexactitud estuvo comprendido entre $-6,24$ a 5,66\% y para el WCDHNY el rango fue entre - 17,3 a -2,52\%, mientras que los coeficientes de correlación mostraron valores aceptables: 0,9930 y 0,9586 respectivamente, teniendo en cuenta que ambos programas miden el hierro por métodos directos.

Asimismo, se observó que el MR (CLSI) arroja siempre valores más altos que los valores de consenso del WCDHNY, mientras que solo el 37,5\% de los valores obtenidos por el MR (CLSI) en los sueros del UK NEQAS mostró valores más elevados que los valores de consenso del mismo; en este caso el $100 \%$ de los sesgos calculados mostraron valores menores que los descriptos por Ricos et al., 1999, mientras que, los sesgos calculados para el WCDHNY, solo en un 60\% fueron menores que los descriptos por Ricos et al.(1999).

En relación a la imprecisión y a la inexactitud del MR (CLSI) se evaluaron sobre una solución de $1 \mathrm{mg} / \mathrm{L}$ de hierro estándar SRM 937 del NIST, y se obtuvo un CV = 2,02\%, y la inexactitud promedio $=-1,8 \%$. A su vez, la imprecisión calculada sobre 24 sueros del PEEC-FBA mostró un CV entre 0,7 y 9,2\% (menor que el sugerido por Ricos et al, 1999, de 26,5\%) mientras que la inexactitud arrojó un rango del orden de -14,2 a 46,5\%, que guarda relación con la gran variabilidad del MR (CLSI). Teniendo en cuenta que la comparación se hace con valores consenso informados en una red de laboratorios, como era previsible, obtuvimos valores considerablemente más grandes que los informados por Ricos et al (1999), que para el analito hierro describe un error total permitido de $30,7 \%$. 
Igualmente, de los estudios sobre 24 sueros del PEEC-FBA se observó que el 88\% (21 de 24) de los valores de las medias obtenidas utilizando el MR (CLSI) para medir hierro, arrojó valores levemente inferiores que las medias de los valores consenso tanto en valores bajos o medianos como en valores más altos. Atribuimos esta diferencia a la desproteinización previa en el MR (CLSI) y nos preguntamos si en estos casos también se cumplían las aseveraciones que motivó a algunos investigadores a proponer y realizar diversas modificaciones al método para la determinacióm de hierro sérico según lo descripto en la Tabla 1-1. Los primeros investigadores que reportaron los porcentajes de recuperación como Trinder P. informó un 99,5 a $102 \%$ de recuperación de hierro en sus ensayos, y Zak B. et al. (1965) comunicaron la obtención de 88\% de recuperación. Mas adelante, otros investigadores, documentaron los CV\% de las diferentes metodologías según puede verse en la Tabla 6-2., en la cual también se muestran los $\mathrm{CV} \%$ (intracorrida y totales) encontrados para los tres niveles de concentración de hierro evaluados en el presente trabajo.

Aquí es importante recordar que un mismo procedimiento analítico implementado en distintos laboratorios no necesariamente se comporta del mismo modo en cada uno de ellos, pues su desempeño está influenciado por la existencia de errores sistemáticos y aleatorios, ya sea individualmente o combinados. Lo ideal es eliminar el error sistemático y reducir la variabilidad aleatoria a valores aceptables y así, las diferencias del valor obtenido con respecto al verdadero estarán originadas por la variabilidad inherente al método, la cual, en una red de laboratorios va a resultar de la sumatoria de varios factores especialmente errores en la fase analítica y en la fase post analítica (Mazziotta D., 1995). 
Tabla 6-2: Coeficientes de variación para diferentes métodos que miden hierro sérico

\begin{tabular}{|c|c|c|}
\hline \multicolumn{2}{|l|}{ Método } & CV\% reportado \\
\hline \multicolumn{2}{|c|}{$\begin{array}{l}\text { Levy A.L.y Vitacca P. } \\
\qquad(1961)\end{array}$} & $28,27 \%$ \\
\hline \multicolumn{2}{|c|}{$\begin{array}{c}\text { Caraway W.T. } \\
\text { (1963) }\end{array}$} & $\begin{array}{l}2,4 \% \text { (macrotécnica) } \\
3,06 \% \text { (microtécnica) }\end{array}$ \\
\hline \multicolumn{2}{|c|}{$\begin{array}{l}\text { Young D.S.y Hicks J.M. } \\
\qquad(1965)\end{array}$} & $2,3 \%$ \\
\hline \multicolumn{2}{|c|}{$\begin{array}{c}\text { Giovanniello T.J. et al. } \\
\text { (1968) }\end{array}$} & $8,33 \%$ \\
\hline \multicolumn{2}{|c|}{$\begin{array}{l}\text { Giovanniello T.J. et al. } \\
\qquad(1979)\end{array}$} & $\begin{array}{l}4,4 \% \text { (intracorrida) } \\
5,5 \% \text { (intercorrida) }\end{array}$ \\
\hline \multicolumn{2}{|c|}{$\begin{array}{l}\text { Ceriotti F.y Ceriotti G. } \\
\qquad(1980)\end{array}$} & $\begin{array}{l}2,6 \% \text { (intracorrida) } \\
4,6 \% \text { (intercorrida) }\end{array}$ \\
\hline \multicolumn{2}{|c|}{$\begin{array}{l}\text { Levinson S.S. } \\
\text { (1980) }\end{array}$} & 2,4 a $3,4 \%$ \\
\hline \multicolumn{2}{|c|}{$\begin{array}{l}\text { Mori L. et al. } \\
\text { (1981) }\end{array}$} & $2,4 \%$ \\
\hline \multicolumn{2}{|c|}{$\begin{array}{l}\text { Schlosnagle D.C. et al. } \\
\qquad(1982)\end{array}$} & 0,4 a $1,4 \%$ \\
\hline \multirow{3}{*}{ Presente trabajo } & $\begin{array}{l}\text { Nivel } \\
\text { bajo }\end{array}$ & $\begin{array}{c}5,06 \text { (intracorrida) } \\
6,28 \text { (total) }\end{array}$ \\
\hline & $\begin{array}{l}\text { Nivel } \\
\text { medio }\end{array}$ & $\begin{array}{c}3,43 \text { (intracorrida) } \\
4,51 \text { (total) }\end{array}$ \\
\hline & $\begin{array}{l}\text { Nivel } \\
\text { alto }\end{array}$ & $\begin{array}{c}2,67 \text { (intracorrida) } \\
2,73 \text { (total) }\end{array}$ \\
\hline
\end{tabular}

Los CV\% intracorrida y totales, como indicadores de la precisión obtenida en este trabajo, para los tres niveles de concentración de hierro muestran valores dentro del rango propuesto como deseable por el CLSI. 
Adicionalmente, se estimó la concordancia entre ambos grupos de valores recalculando los datos asignados por el MR (CLSI) a los lotes del PEEC-FBA, en base a la calibración con Titrisol. La gran dispersión obtenida se tradujo en un mayor rango de CV\% (0,5 a $16,2 \%)$.

A la par se confirmó que en general en laboratorios de distintos países, y en particular en el ámbito local, prácticamente el MR (CLSI) no está en uso y ha sido reemplazado por métodos que determinan hierro directamente en el suero, debido en parte a los requerimientos de la automatización a lo que se suma, con seguridad, la tediosa tarea de desproteinización previa del MR (CLSI). Incluso actualmente no existe ningún equipo comercial que permita realizar la desproteinización previa al dosaje de hierro en el sobrenadante, si bien hace algunos años, había disponible en el mercado un equipo para determinar hierro con/sin desproteinización previa a la colorimetría con batofenantrolina (Iron Merckotest, 2001).

Las evaluaciones con el MR (CLSI) de los sueros calibradores de los equipos comerciales mostraron también algunas diferencias: $3,45 \%$ de inexactitud para el suero calibrador de BS y 11,0\% para el suero calibrador de W. Aquí los sesgos son mas pequeños teniendo en cuenta que las condiciones experimentales fueron mucho mas controladas. En los materiales de control comerciales se observan valores de inexactitud mayores de $\mathrm{W}$ con respecto a $\mathrm{BS}$.

Teniendo en cuenta los antecedentes antes mencionados y dada la dificultad de disponer de un método de referencia aceptado internacionalmente, las comparaciones relativas son válidas. Por ello se procedió a realizar la segunda etapa de este trabajo con el propósito de conocer y evaluar las posibles concordancias y desvíos de dos de los métodos comerciales mas utilizados por la red de laboratorios en nuestro medio (Fernández Alberti M.A. et al., 2002) en relación al MR (CLSI). Paralelamente se comparó la modificación semiautomatizada del MR (CLSI Se Au) con el mismo MR (CLSI) y con ambos métodos comerciales automatizados (BS Au y W Au).

En las comparaciones de los dos métodos comerciales manuales y automatizados con el MR (CLSI) se observó que los CV\% obtenidos fueron moderadamente superiores a los considerados aceptables por la normas del CLSI, principalmente para valores bajos de hierro.

En los análisis de regresión lineal del MR (CLSI) comparando con los dos métodos manuales y automatizados comerciales (BS y W), y con CLSI Se Au, y a su vez, de este último con los métodos automatizados de BS y de W, los coeficientes de correlación (r) 
obtenidos indicaron una relación relativamente fuerte entre las variables (Tabla 5-30). Dado que el p-valor es inferior a 0,01, existe relación estadísticamente significativa entre los métodos comerciales y el MR (CLSI) para un nivel de confianza del $99 \%$. Estudios similares realizados por otros autores ((Tietz. N.W. et al., 1994) cuando compararon el método de referencia del ICSH (método con desproteinización) con varios métodos automatizados: DuPont aca, Abbott TDx, Kodak Ektachem con Gen.14 y con Gen.18, BM/Hitachi 717 y el reactivo de Synermed Iron-600 en el BM/Hitachi 717 , reportaron valores que en promedio son mas bajos que los obtenidos con el método del ICSH de 1990, especialmente en el rango bajo, y todos mostraron una intercepción negativa para la ordenada al origen con valores de pendientes cercanos a la unidad. También los estudios de precisión del método del ICSH y estos métodos automatizados mostraron, en el rango normal o alto, valores aceptables para todos los métodos, pero esta precisión disminuía en el rango bajo. Para el método del ICSH obtuvieron CV\% entre 4,7 a 5,1, y para los métodos automatizados un rango mas amplio, CV\% entre 0,6 y $10,0 \%$.

Empleando otras formas de análisis mediante histogramas de distribución de las diferencias y gráficos de Bland-Altman se observó que los histogramas de distribución de las diferencias entre los valores obtenidos con el MR (CLSI) y los otros métodos, mostraron una mayor concordancia del MR (CLSI) con los métodos de BS, tanto manual como automatizado, y con el método de W Au. En tanto en los gráficos de Bland - Altman pudimos apreciar la dispersión de valores en los tres niveles de concentración de hierro, que resultó ser mayor en el nivel más alto.

Si bien la mayor concordancia se observó al contrastar el MR (CLSI) con los métodos comerciales automatizados, estos métodos mostraron en general valores inferiores a los del MR (CLSI), mientras que la comparación con la modificación del MR (CLSI Se $\mathrm{Au}$ ) mostró una gran dispersión de datos y cuando este último se relacionó con los métodos comerciales automatizados la mejor coincidencia se dio en niveles bajos de concentración de hierro. Los intervalos de confianza al 95\% para las diferencias entre el MR (CLSI) y los otros métodos, muestran que estas diferencias son suficientemente pequeñas dentro del rango de concentración de hierro útil para propósitos de diagnóstico clínico. Desde el punto de vista de los estudios estadísticos se concluye que solamente para el método W Ma y puntualmente para los niveles bajo y alto de concentración, no hay diferencia significativa con los valores obtenidos por el MR (CLSI). Esta 
observación está directamente vinculada a los valores de inexactitud que se muestran en las Tablas 5-25 a 5-29.

Por otra parte, el análisis de imprecisión de los métodos efectuado sobre los pooles de sueros demostró: para el pool de sueros de nivel bajo de concentración ensayado, los CV\% no superaron el 6,4\%; para el pool de sueros de nivel medio no sobrepasaron el $\mathrm{CV}=5 \%$, a excepción del método manual de $\mathrm{W}(\mathrm{CV}=5,2 \%)$ y, para el pool de sueros de nivel alto se obtuvieron CV\% entre 1,9 a 2,7\% cuando comparamos el MR (CLSI) con los métodos comerciales de BS y de $\mathrm{W}$ automatizados. Por último, los métodos comerciales automatizados mostraron buena correlación entre sí, en relación a la dispersión observada (Figura 5-14).

Con respecto a la modificación semiautomatizada del MR (CLSI Se Au), si bien el coeficiente de correlación resultó igual a 0,9905, indicando una relación relativamente fuerte entre las variables, los CV\% obtenidos, para los tres niveles de concentración ensayados, fueron mayores que los valores obtenidos con el MR (CLSI). Esta característica, que revela una gran imprecisión, la hace poco apropiada para detectar especialmente, un balance negativo de hierro.

A partir de ésta performance y considerando la gran laboriosidad del método recomendado - que en este trabajo fue nuestra referencia- teniendo en cuenta que dentro de la química hematológica el analito hierro es uno de los parámetros que presenta gran variabilidad biológica: $30,7 \%$ de especificidad deseable para el error total permitido (Ricos et al., 1999) y que todos los métodos de medición de hierro sérico con o sin precipitación, es decir MR (CLSI) ó métodos de campo, dependen de las condiciones ácidas del medio para liberar el hierro de su unión con las proteínas del suero y su conversión a la forma ferrosa, del coeficiente de extinción molar del cromógeno empleado y de la posible interferencia de otros iones metálicos, como las principales características a mejorar en toda medición de la ferremia, se reafirma que la automatización de la metodología es una alternativa útil para el laboratorio bioquímico.

En el caso de los dos métodos comerciales ensayados, presentan ventajas sobre el MR (CLSI) pues emplean menos volumen de muestra y menor tiempo total de procesamiento.

Con respecto al examen de la presentación de los juegos o equipos comerciales de reactivos considerados en este trabajo, en primer término, se evaluó la información presentada en la rotulación de los mismos (TABLA I) y se constató que presentan una sola diferencia en relación a la reglamentación solicitada por el ANMAT, pues el equipo 
de BS indica el número de certificado otorgado por esta Institución y el equipo de W solo aclara que es un producto autorizado por el ANMAT, sin especificación del número de certificación.

Si bien ambos equipos comerciales de reactivos cumplen con los requerimientos previstos por la Dirección Europea 98/79 CE de productos sanitarios para el diagnóstico IVD, se observó que hay algunas variaciones en el criterio de elección en cuanto al informe de las características generales y metrológicas de cada equipo (TABLA II).

El folleto informativo de los dos equipos comerciales aclara, desde ya, el nombre del mismo, los reactivos que contienen, la temperatura de almacenamiento para su perfecta conservación, la longitud de onda empleada en el ensayo, el límite de linealidad, la reproducibilidad interserie expresada como $\mathrm{CV} \%$, y las interferencias conocidas. De mismo modo, el inserto del equipo de BS agrega el informe sobre la sensibilidad del método, la repetibilidad intraserie expresada como CV\% y menciona que el patrón de hierro incluido tiene una concentración indicada en la etiqueta del vial que es trazable al Material de Referencia Certificado 937 del NIST, USA. Con respecto a la veracidad del mismo apunta que los resultados obtenidos con estos reactivos, no muestran diferencias sistemáticas al ser comparados con reactivos de referencia puntualizando que la calibración con el patrón acuoso puede causar sesgos, especialmente en algunos analizadores, en cuyos casos, recomienda calibrar usando un patrón de base sérica (Calibrador de Bioquímica, cód.18011) según lo descripto en el inserto de Biosystems (2006).

A su vez, el inserto del equipo de $\mathrm{W}$ informa el límite de cuantificación $\mathrm{y}$, con respecto al estándar de hierro, que es una solución de iones hierro (III) equivalente a $100 \mathrm{ug} / \mathrm{dl}$, aclara que el mismo no es provisto en todas las presentaciones.

En función de los resultados obtenidos en este trabajo, sería de interés que el mismo contribuya al mejoramiento de la calidad en la determinación de hierro sérico, ya sea en los Laboratorios de Bioquímica Clínica como también, en las revisiones periódicas llevadas a cabo por la Industria responsable del funcionamiento de los equipos comerciales empleados.

A modo de síntesis es importante destacar:

- En la puesta a punto del MR (CLSI) las calibraciones realizadas con diferentes materiales (hierro Anedra, hierro SRM 937, Titrisol) mostraron buenos coeficientes de correlación con un rango general comprendido entre 0,9770 y 0,9997 . 
- En los ensayos de prevalidación del MR (CLSI) se observó que la reacción es lineal hasta $10 \mathrm{mg} / \mathrm{L}$, las pruebas de recuperación arrojaron valores comprendidos entre 65,8 a 97,5\%, la imprecisión intraensayo promedio mostró un $\mathrm{CV}=2,02 \%$ y la inexactitud promedio $=-1,8 \%$.

- En relación a la asignación de valores a diversos materiales comerciales y de programas de evaluación externa, los ensayos realizados mostraron diversos datos de inexactitud: 3,4\% para el calibrador de BS y 11,0\% para el de W, un rango de $-15,8$ a $31,1 \%$ para los materiales control de $\mathrm{W}$ y un rango menor para el de BS (-10,9 a -1,6). Con respecto a la comparación de los valores obtenidos con el MR (CLSI) en sueros del UK NEQAS y del WCDHNY la inexactitud hallada estuvo comprendida entre $-6,24$ a $5,66 \%$ y entre $-17,3$ a $-2,52 \%$ respectivamente.

- Con respecto a la asignación de valores en los lotes de sueros del PEEC-FBA, se observó que el $88 \%$ de los valores de las medias obtenidas utilizando el MR (CLSI) para medir hierro, fueron levemente inferiores que las medias de los valores consenso tanto en valores bajos o medianos como en valores más altos.

- De los resultados mostrados en todos estos estudios, y sobre la base de que la determinación de la ferremia, en prácticamente todos los laboratorios de bioquímica clínica, se realiza por métodos directos, se dedujo la necesidad de evaluar el desempeño de los métodos manuales y automatizados de los equipos mas frecuentemente empleados en la red de laboratorios participantes del Subprograma Hematología del PEEC-FBA. Para ello se realizaron evaluaciones estadísticas de los datos obtenidos a partir de las series de determinaciones de hierro sérico efectuadas en forma comparativa entre el MR (CLSI) y las metodologías de los equipos comerciales BS y W, utilizando pooles de sueros de tres niveles de concentración del analito.

- Los CV\% intracorrida y totales obtenidos con el MR (CLSI) en los tres niveles de concentración de hierro mostraron valores bajos dentro del rango propuesto como deseable por el CLSI ( Nivel bajo: $\mathrm{CVi}=5,06 \%$; $\mathrm{CVt}=6,28 \%$ ) (Nivel medio: $\mathrm{CVi}=3,43 \% ; \mathrm{CVt}=4,51 \%)($ Nivel alto $=\mathrm{CVi}=2,67 \% ; \mathrm{CVt}=2,73 \%)$.

- Los estudios de las concordancias, con el objeto de evaluar si los métodos comerciales son intercambiables con el MR (CLSI) y considerando a este último como nuestro "método de referencia", se realizaron por estudios de: 
regresión lineal, por distribución de la frecuencia de las variables y por el procedimiento desagregado de Bland-Altman, a los que se sumó la prueba $t$ de Student. Los estudios de regresión, ajustados al modelo de regresión lineal simple $y=a+b x$, presentaron una relación relativamente fuerte entre las variables $(r=0,9878-0,9942)$; los histogramas de distribución de frecuencias mostraron una mejor correlación del MR(CLSI) con los métodos de BS, tanto manual como automatizado y con el método automatizado de $\mathrm{W}$; y en los gráficos de Bland - Altman se observó la dispersión de valores en cada concentración de hierro, la cual resultó ser mayor en el nivel mas alto, y también, los límites de concordancia del 95\% como $\pm 2 \mathrm{DE}$ indican entre que diferencias oscilan la mayor parte de las mediciones tomadas con los pares de métodos comparados.

- En relación a la modificación semiautomatizada del MR (CLSI) se obtuvieron CV\% más elevados que los del MR (CLSI), y esta mayor imprecisión la hace poco apropiada para detectar en especial un balance negativo de hierro.

Como conclusión, debemos reconocer que la verdadera cuestión es si la mejora analítica en los métodos para evaluar hierro sérico, mejoran sustancialmente la utilidad clínica de este analito. Creemos que un dosaje único y aislado de hierro sérico no tiene valor desde el punto de vista del tratamiento clínico de un paciente. Su medida, en conjunto con el estudio del hemograma completo, que incluya la evaluación de los Índices hematimétricos y la observación criteriosa de la morfología sanguínea, la medida de la CTFH y la saturación de Tf, es imprescindible como base de estudios posteriores para la detección y seguimiento de anemias y sobrecargas de hierro, en todos los laboratorios de países en desarrollo.

En el caso particular de la determinación de la ferremia, es necesario garantizar no solo desde la toma de muestra, incluyendo el interrogatorio al paciente, sino también profundizar en las medidas de descontaminación del material utilizado en todas las fases analíticas, realizar calibraciones periódicas con estándares o calibradores de reconocida trazabilidad y con valores asignados por metodologías de orden metrológico superior, con el objeto de minimizar en lo posible todo error aleatorio y eliminar el error sistemático.

Finalmente, si bien es importante contar con un método definitivo o de referencia para la evaluación de hierro sérico, en estos momentos, la participación de todo laboratorio 
en programas de evaluación externa de la calidad y la realización del control de calidad interno diariamente, no solo para la medida de hierro sino para toda la batería de análisis que procesa, brinda credibilidad de los resultados en beneficio del paciente y en el del propio Laboratorio de Análisis Bioquímicos. 


\section{Bibliografía}


- Barkan G., Walker B.S. Determination of serum iron and pseudohemoglobin with o-phenanthroline. J.Biol.Chem. 1940; 135: 37- 42.

- Beard J.L., Piñero D.J. Deficiencia de hierro. Centro de Estudios Sobre Nutrición Infantil (CESNI), 1997.

- Bennington J. L. Diccionario enciclopédico del laboratorio clínico. Madrid: Editorial Médica Panamericana S. A.; 1991.

- Beutler E., Lichtman M.A., Coller B.S., Kipps T.J., Seligson U. Williams Hematología. 6 ed. Madrid: Marbán; 2005.

- Blijenberg B.G., Roetering h.A., Brouwer H.J. Serum iron and proficiency testing: A dilema. Eur.J.Clin.Chem.Clin.Biochem. 1993; 31(4): 233-237.

- Boccio J., Páez M.C., Zubillaga M., Salgueiro J., Goldman C., Barrado D., et al. Causas y consecuencias de la deficiencia de hierro sobre la salud humana. Arch. Latinoam. Nutr. 2004; 54 (2): 165-173.

- Boccio J., Salgueiro J., Lysionek A., Zubillaga M., Goldman C., Weill R., Caro R. Metabolismo del hierro: conceptos actuales sobre un micronutriente esencial. Arch.Latinoam.Nutr. 2003; 53 (2):119-32.

- Bothwell T.H., Conrad M.E., Cook J.D., Fielding J., Hallberg L., Izak G., et al. Recomendations for measurement of serum iron in human blood. Br. J. of Haematol.1978; 38(2): 291-294.

- Britos S. Transición nutricional, obesidad y desafíos de las políticas públicas y los agronegocios. [Internet] Buenos Aires: Unidad de Salud y Agronegocios del Programa de Agronegocios y Alimentos. 2008. Disponible en: http://www.nutrinfo.com/pagina/info/papersaludyagronegocios2008.pdf 
- Brugnara C. A hematologic "Gold standard "for iron-deficient states? Clin. Chem. 2002; 48 (7): 981-982.

- Bunting P.S., Aggarwal M. Interference from renal dialysis patients' specimen on a direct method for serum iron. Clin. Chem. 1983; 29(6): 11061108.

- Büttner J., Borth R., Boutwell J.H., Broughton P.M.G., Bowyer, R.C. International Federation of Clinical Chemistry, Approved recommendation (1978) on quality control in clinical chemistry: Part 2. Assessment of analytical methods for routine use. Clin. Chim. Acta. 1979; 98: 145F $162 \mathrm{~F}$.

- Cailliat M.C., Fernandez Alberti A., Mazziotta D., Fink N. E. Inexactitud de la medición de hierro sérico por el método directo, evaluada mediante la evaluación externa. Manual de resúmenes, Calilab 2007- número 94.

- Calvo E.B., Gnazzo N. Prevalence of iron deficiency in children aged 9-24 mo from a large urban area of Argentina. Am. J. Clin. Nutr. 1990; 52: 534540.

- Caraway W.T. Macro and micro methods for the determination of serum iron and iron-binding capacity. Clin. Chem. 1963; 9: 188-99.

- Ceriotti F., Ceriotti G. Improved direct specific determination of serum iron and total iron-binding capacity. Clin. Chem. 1980; 26(2): 327-331.

- Coy G.A. Estandarización de métodos analíticos. Instituto de Hidrología, Meteorología y Estudios Ambientales. Ministerio de Ambiente, Vivienda y Desarrollo Territorial. República de Colombia. 2006.

- de Duve, C. Prelude to a cell. The Sciences. 1990; 30: 22-8. 
- Del Castillo Rueda A., López-Herce Cid J.A., De Portugal Álvarez J.

Hemocromatosis hereditaria. Diagnóstico clínico: manifestaciones precoces, procesos relacionados y formas atípicas. An Med Interna - Madrid. 2002; 19 : $251-256$.

- Donato H., Cedola A., Rapetti M., Buys M., Gutiérrez M., Parias Nucci R., et al. Anemia ferropénica. Guía de diagnóstico y tratamiento. Arch. Argent. Pediatr.2009; 107(4): 353 - 361.

- Donato H., Rapetti C., Crisp R. Anemias carenciales. Anemias en pediatría. Buenos Aires: Fundasap; 2005.

- Eckfeldt J.H., Witte D.L. Serum iron: Would analytical improvement enhance patient outcome? Clin. Chem. 1994; 40(4): 505 - 507.

- Encuesta Nacional de Nutrición y Salud (ENNyS). Documento de resultados. [Internet]. Buenos Aires: Ministerio de Salud - Presidencia de la Nación. 2007. Disponible en:

http://www.msal.gov.ar/htm/site/ennys/pdf/ENNyS_Documento-deresultados-2007-II.pdf

- Estandarización en Química Clínica. Boletín Mensual editado por el Programa de Evaluación Externa de Calidad. Fundación Bioquímica Argentina; febrero 1997.

- Fernández Alberti M.A., Cailliat M.C., Ventimiglia F., Mazziotta D., Fink N.E. Evaluación externa de calidad de hierro sérico y de la capacidad de fijación del hierro. Manual de resúmenes, Calilab 2002 - número 26.

- Floering D.A. College of American Pathologist experience with the linearity surveys, 1987-1991. Arch Pathol Lab Med. 1992; 116 (7): 739 - 745. 
- Forrelat Barrios M., Fernández Delgado N., Hernández Ramírez P. Nuevos conocimientos sobre el metabolismo del hierro. Rev Cubana Hematol Inmunol Hemote. 2005; 21(3).

- Forrellat Barrios M., Gautier du Défaix Gómez H., Fernández Delgado N. Metabolismo del hierro. Rev. Cubana Hematol. Inmunol. Hemoter. 2000; 16(3):149-60.

- Fraser C.G., Biological variation: from principles to practice. AACC Press Washington. 2001.

- Fuentes Arderiú X. Glossary of ISO metrological and related terms and definitions relevant to clinical laboratory sciences. Madison WI: Westgard QC, 1999.

- Fuentes Arderiú X. Trueness and uncertainty. Madison WI: Westgard QC, 2000.

- Ganz T. Hepcidin, a key regulator of iron metabolism and mediator of anemia of inflammation. Blood. 2003; 102 (3): 783 - 788.

- Garber C.C., Castañeda Méndez K., Dawson J. M., Johnson G.F., Sharma A Preliminary evaluation of quantitative clinical laboratory methods; Approved guideline. CLSI, 1998, document EP10-A. Villanova, PA: CLSI, 1998

- Garrido L.L., Muñante J.H, Valencia Caballero V., Lozano Miranda Z., Nago Nago A. Hemocromatosis hereditaria. Rev. Gastroenterol. Perú. 2003; $23(4): 302-306$.

- Giovanniello T.J., Dibenedetto G., Palmer D. W., Peters T. Fully and semiautomated determination of serum iron and total iron-binding capacity. J. Lab. \& Med. 1968; 71(5); 874 - 83. 
- Giovanniello T.J., Pecci J.,Garry P.J. Iron and total iron binding capacity. Working Group of the AACC Committee on Standards, 1979.

- Hallberg L., Scrimshaw N., Viteri F., Yip R., Bailey K., Underwood B. Iron Deficiency Anaemia. Assesment. Prevention and Control. A guide for a programme managers. World Health Organization, 2001, p15

- Henry J.B., Davey F.R,, Herman C.J,, McPherson R.A., Pincus M.R., Threatte G.A., et al. El laboratorio en el diagnóstico clínico. 20 ed. Madrid: Marban; 2005.

- Herbert V. Iron disorders can mimic anything, so always test for them. Blood Rev.1992; 6(3): 125 - 32.

- Inserto del equipo Fer-Color de Wiener (ver ANEXO II).

- Inserto del equipo Hierro-Ferrozina de Biosystems (ver ANEXO I).

- Instruction manual operation. Guide UV-1601 Shimadzu recording Spectrophotometer (P/N 206-67001). Shimadzu Corporation. 1994.

- Iron Panel of the International Committee for Standardization in Haematology (ICSH). Revised recommendations for the measurements of the serum iron in human blood. Br. J. Haematol. 1990; 75(4): 615 - 616.

- Izquierdo Alvarez S. Desarrollo e implementación de un sistema de gestión de la calidad en un laboratorio de referencia "Unidad de metales". Acreditación según la UNE-en ISO 15.189. [Tesis doctoral]. Universidad de Zaragoza; 2007.

- Jhang J.S., Chang C.C., Fink D.J., Kroll M.H. Evaluation of linearity in the laboratory. Arch Pathol Lab Med. 2004; 128(1): 44 - 8. 
- Lafay M. Exploración de una anemia. Acta Bioquím. Clín. Latinoam. 2003; 37 (2): $203-28$.

- Leal M. J. Y., Romero A.T.B., Ortega P., Chávez C. J. Interleucina-10 e interferón gamma en adolescentes de sexo femenino anémicas con depósitos de hierro depletados. Rev. Chil. Nutr. 2008; 35 (2): 101 - 108.

- Levinson S.S. Manul ferrozine kit method for iron and total iron-capacity adapted an evaluated for use with discrete mechanized analyzers. Clin. Chem. 1980; 26(5): 671 - 672.

- Levy A.L., Vitacca P. Direct determination and binding capacity of serum iron. Clin.Chem. 1961; 7(3): 241 - 248.

- Linnet K., Boyd J. Selection and analytical evaluation of methods - with statistical techniques. En: Burtis C., Ashwood E., Bruns D. Tietz Fundamentals of clinical chemistry. 6 ed. Philadelphia: W.B. Saunders Co.; 2008; 14: 353 - 407.

- Lodish H., Berk A., Zipursky S.L., Matsudaira P., Baltimore D., Darnell J. Biología celular y molecular. 4 ed. Buenos Aires: Médica Panamericana; 2002.

- Logan J.E., Bayse D.D., Koedam J.C., Mather A., Wilding P. Principios y recomendaciones de la Federación Internacional de Química Clínica/Organización Mundial de la Salud sobre evaluación de los juegos de reactivos para diagnóstico utilizados en los laboratorios de salud con recursos limitados. Acta Bioquím.Clín. Latinoam. 1985a; 19 (1): 133 - 144.

- Logan J.E., Bayse D.D., Koedam J.C., Mather A., Wilding P. Principios y recomendaciones de la Federación Internacional de Química Clínica/Organización Mundial de la Salud sobre evaluación de los juegos de reactivos para diagnóstico utilizados en los laboratorios de salud con recursos limitados. Acta Bioquím. Clín. Latinoam. 1985b; 19 (2): 259 - 288. 
- Mazziotta D. Materiales de control en Química Clínica: Preparación en el laboratorio. PEEC Noticias; julio 1995.

- Mazziotta D. Trazabilidad en el laboratorio clínico. V Congreso Cubano de Patología Clínica - La Habana, 2004.

- McCay, CM. Notes on the history of nutrition research. Bern: H. Huber; 1973.

- McCord J.M., Iron, free radicals, and oxidative injury. Semin. Hematol. 1998; 35 (1): 5 - 12.

- Morasso M.C., Molero J., Vinocur P., Acosta 1., Pacussi N., Raselli S., et al. Deficiencias de hierro y de vitamina A y prevalencia de anemia en niños y niñas de 6 a 24 meses de edad en Chaco, Argentina. Arch. Latinoam. Nutr. 2003; 53: 21 - 29.

- Mori L., Bekkering A., Traini J., Vanderlinden L. Ferrozine iron and total iron-binding capacity method adapted to the ABA-100 Bichromatic Analyzer. Clin. Chem. 1981; 27(8): 1441- 1444.

- Olivares G.M., Tomás W.K. Consecuencias de la deficiencia de hierro. Rev. Chil. Nutr. 2003; 30(3): 226 - 33.

- Pérez G., Vittori D., Pregi N., Garbossa G., Nesse A. Homeostasis del hierro. Mecanismos de absorción, captación celular y regulación. Acta Bioquím. Clín. Latinoam. 2005, 39 (3): 301 - 14.

- Pietrangelo A. Hereditary hemochromatosis - A new look at an old disease. N. Engl. J.Med. 2004; 350(23): 2383 - 97. 
- Pintado Cros T., Pérez Sánchez I., Escudero Soto A., Mayayo Crespo M. Fisiopatología del metabolismo del hierro. Medicine. 2001; 8(51): 2669 2675.

- Peters T., Giovanniello T.J., Apt L., Ross J.F- A simple improved method for the determination of serum iron. II, J. Lab Clin. Med. 1956; 48(2):280 - 8.

- Ramsay, W.N.M. Plasma Iron. Advances in Clinical Chemistry. New York: Academic Press; 1958; 1: 1 - 38.

- Ricos C., Alvarez V., Cava F., Garcia-Lario J.V., Hernandez A., Jimenez C.V., et al. Current databases on biologic variation: pros, cons and progress. Scand J. Clin. Lab. Invest. 1999; 59: 491 - 500.

- Rubin M., Barnett R.N., Bayse, D.F., Beutler E., Brown S.B., Logan J.E., et al. International Federation of Clinical Chemistry, Provisional recommendation (1978) on evaluation of diagnostic kits: Part 1. Recommendations for specifications on labeling of clinical laboratory materials, Clin. Chim. Acta. 1979; 95: 155F - 162F.

- Sabater Baudet L. Mecanismos moleculares de la tolerancia central. [Tesis doctoral]. Universidad Autónoma de Barcelona; 2007.

- Salonen J.T., Nyyssönen K., Korpela H., Tuomilehto J., Seppänen R., Salonen R. High stored iron levels are associated with excess risk of myocardial infarction in eastern Finnish men. Circulation. 1992; 86(3): 803 11 .

- Schlosnagle D.C., Hutton P. S., Conn R.B. Ferrozine assay of serum iron and total iron-binding capacity adapted to the COBAS BIO Centrifugal Analyzer. Clin. Chem. 1982; 28 (7): 1730 - 1732.

- Schwarcz R., Uranga A., Lomuto C., Martínez I., Galimberti D., García O.M., et al. El cuidado prenatal. Guía para la práctica del cuidado 
preconcepcional y del control prenatal. [Internet] Buenos Aires: Ministerio de Salud - Presidencia de la Nación. 2001. Disponible en:

http://www.msal.gov.ar/htm/Site/promin/UCMISALUD/publicaciones/pdf/01 -PRENATAL.pdf

- Sosa M., Ottolini G., Sánchez M., Amato D., Cardozo A., Camuso M., et al. Estudio comparativo de dos métodos para medición de hierro sérico. Acta Bioquím. Latinoam. 2001; 35(2): 255 - 259.

- Technicon Information Bulletin, N-62P (basado en la modificación del procedimiento de Giovanniello et al. En Automation in analytical chemistry, 1976, p185.

- Tholen D.W., Kroll M., Astles J.R., Caffo A.L., Happe T.M., Krouwer J., Lasky F. Evaluation of the linearity of quantitative measurement procedures: A statistical approach; Approved guideline. CLSI Document EP6-A. Villanova, PA: CLSI, 2003.

- Thomas C., Thomas L. Biochemical markers and hematologic indices in the diagnosis of functional iron deficiency. Clin. Chem. 2002; 48(7): 1066 1076.

- Tietz N. W. Fundamentals of clinical chemistry, 2 ed. Philadelphia: W.B. Saunders Co.; 1976.

- Tietz N.W. Accuracy in clinical chemistry - Dose anybody care? Clin. Chem. 1994; 40(6): 859 - 861.

- Tietz N.W., Rinker A.D. Should accuracy of iron measurements be improved? Clin. Chem. 1994; 40(7): 1347-48. 
- Tietz N.W., Rinker A.D., Morrison S.R. When Is a serum iron really a serum iron? The status of serum iron measurements. Clin. Chem. 1994; 40(4): 546 551.

- Trinder P. The improved determination of iron in serum. J. Clin. Pathol. 1956; 9(2): 170 - 2.

- Valcour A.A., Krzymowaki G., Onoroski M., Bowers G.N., Mc Comb R. B. Proposed reference method for iron in serum used to evaluate two automated iron methods. Clin. Chem. 1990; 36(10): 1789 - 1792.

- Van Assendelft O.W., Doumas B.T., Fairbanks V.F., Gunter E.W., Nealon D.A.Determination of serum iron, total iron-binding capacity and percent transferrin saturation. Approved Standard. CLSI Document H17-A. Villanova, PA: CLSI, 1998

- Van Assendelft O.W., Doumas B.T., Fairbanks V.F., Gunter E.W., Nealon D.A. Determination of serum iron, total iron-binding capacity and percent transferrin saturation. Approved Standard. CLSI Document H17-B. Villanova, PA: CLSI, 1998

- Vreugdenhil G., van Eijk H.G., Swaak A.J.G. Iron and iron chelatore in rheumatoid arthritis. Drugs today. 1992; 28: 157 - 63.

- Young D.S., Hicks J.M. Method for the automatic determination of serum iron. J.Clin. Pathol. 1965; 18: 98 - 102.

- Zak B., Epstein E. Automated determination of serum iron. Clin. Chem. $1965 ; 11: 641-4$.

- Zilva J.F., Pannall P.R. Bioquímica clínica en el diagnóstico y tratamiento. 2 ed. Barcelona: Salvat; 1979. 


\section{Glosario}


En este glosario se definen términos con los que es necesario familiarizarse pues se relacionan con los objetivos específicos de ésta tesis:

\section{Calibración}

Conjunto de operaciones que establece, bajo condiciones especificadas, la relación entre los valores de magnitudes indicados por un instrumento de medición o sistema de medición, o valores representados por un material de referencia y los correspondientes valores obtenidos, según normas, a partir de patrones.

\section{Condiciones de repetibilidad}

Condiciones en las que los resultados de mediciones independientes son obtenidos con el mismo procedimiento de medición en el mismo laboratorio por el mismo operador, usando el mismo equipamiento dentro de intervalos cortos de tiempo.

\section{Condiciones de reproducibilidad}

Condiciones en las que los resultados de las mediciones se obtienen del mismo mensurando en diferentes laboratorios con diferentes condiciones.

\section{Error aleatorio}

Resultado de una medición menos la media que resultaría de un número infinito de mediciones del mismo mensurando llevada a cabo bajo condiciones de repetibilidad. Notas: 1) El error aleatorio es igual a error de medición menos error sistemático. 2) En la práctica, el error aleatorio puede estimarse a partir de 20 o más mediciones repetidas de un mensurando en una única corrida y bajo condiciones especificadas.

\section{Error de medición}

Resultado de una medición menos un valor verdadero del mensurando.

Notas: 1) Cuando es necesario distinguir error de error relativo, el primero a veces es llamado error absoluto de la medición. 2) En muchas instancias, el error de medición es llamado error total. 


\section{Error relativo}

Error de medición dividido por un valor verdadero del mensurando.

\section{Error sistemático}

Media que resultaría de un número infinito de mediciones del mismo mensurando, llevadas a cabo bajo condiciones de repetibilidad, menos un valor verdadero del mensurando.

Notas: 1) El error sistemático es igual a error de medición menos error aleatorio. 2) El error sistemático puede ser constante o proporcional al valor del mensurando. 3) En la práctica, el error sistemático se estima a partir de 20 o más mediciones repetidas de un mensurando, bajo condiciones especificadas. 4) En muchas instancias el error sistemático es llamado sesgo, pero el International vocabulary of basic and general terms in metrology sólo usa este término como característica de un instrumento de medición. 5) El error sistemático es prácticamente equivalente al concepto clásico de la IFCC de inexactitud.

\section{Estándar de trabajo}

Estándar que es utilizado rutinariamente para calibrar o controlar las medidas de material, los instrumentos de medición o los materiales de referencia.

Nota: en las ciencias del laboratorio clínico, el estándar es llamado generalmente material de calibración o simplemente calibrador.

\section{Estándar primario}

Estándar designado o ampliamente reconocido como poseedor de las más altas cualidades metrológicas y cuyo valor es aceptado sin referencia a otros estándares de la misma cantidad.

\section{Estándar secundario}

Estándar cuyo valor es asignado por comparación con un estándar primario de la misma cantidad. 


\section{Exactitud}

El término exactitud en un método analítico se refiere al grado de aproximación de un resultado obtenido y el valor verdadero del mensurando.

Notas: 1) La exactitud es un concepto cualitativo. Su contraparte cuantitativa es error de medición. 2) Se cuantifica la inexactitud. 3) La IFCC ha usado este término con el significado de veracidad, la cual en realidad indica la concordancia entre el valor promedio obtenido y el valor verdadero.

\section{Incertidumbre de medición}

Parámetro, asociado con el resultado de una medición, que caracteriza la dispersión de los valores que razonablemente serían atribuidos al mensurando.

Nota: el parámetro puede ser, por ejemplo, una desviación estándar (o un múltiplo de ella), o el ancho medio de un intervalo que posee un nivel de confianza declarado.

\section{Instrumento de medición}

Dispositivo que intenta ser usado para hacer mediciones, sólo o en conjunto con dispositivo(s) suplementario(s).

\section{Límite de detección}

Cantidad o concentración mínima de sustancia que puede ser detectada con fiabilidad por un método analítico determinado.

\section{Linealidad}

El término linealidad aplicado a un método analítico, se refiere al tramo de concentraciones de analito en el que la respuesta es función lineal de la concentración; la representación gráfica de este tramo (concentraciones frente a respuestas) debe exhibir una buena adherencia de los puntos experimentales a la recta de regresión para que el método analítico en cuestión sea aceptable.

El CLSI en su documento EP6-A recomienda el empleo de cinco muestras con cuatro réplicas de los diferentes niveles de concentración; el empleo de un número menor puede ocasionar que la regresión obtenida no incluya las curvas sigmoideas no lineales que pueden presentar algunos analitos. 
También pueden utilizarse muestras patrones comerciales, como lo hizo el Colegio Americano de Patólogos en la encuesta sobre linealidad realizada entre 1987 y 1991.

\section{Material de control}

Sustancia que tiene una o varias de sus propiedades bien establecidas para ser usada en la calibración de un instrumento, en la validación de un método analítico y en la asignación de valores a otro material.

\section{Material de referencia}

Material o sustancia suficientemente homogénea que posee valores asignados bien conocidos establecidos por organismos acreditados reconocidos, para permitir su empleo en la calibración de instrumentos, la evaluación de un método o la atribución de valores a materiales secundarios.

Nota: algunos materiales de referencia tienen propiedades que, debido a que no pueden correlacionarse con la estructura química establecida o por otras razones, no pueden ser medidos por procedimientos físicos o químicos definidos exactamente. Tales materiales incluyen ciertos materiales de referencia biológicos, para lo cual la OMS ha asignado una unidad arbitraria denominada unidad internacional. Ejemplos: 1) suero humano SRM 909b del NIST. 2) Prolactina humana IS 84/500 de la OMS.

\section{Método definitivo}

Método analítico que ha sido sujeto a una meticulosa investigación y evaluación de fuentes de inexactitud, incluyendo inespecificidad. Los valores obtenidos con estos métodos son considerados los "valores verdaderos". Los materiales cuyos valores son asignados a este nivel se los denomina materiales de referencia primarios y son de utilidad en el desarrollo y puesta en funcionamiento de métodos de referencia.

\section{Método de referencia}

Método analítico que ha sido cuidadosamente investigado en el cual se incluye una descripción exacta y clara de las condiciones y procedimientos necesarios para la determinación de una cantidad. Generalmente son procedimientos muy laboriosos y que requieren ser instalados y mantenidos especialmente con propósitos de estandarización. 
Los materiales cuyos valores se asignan con estos métodos se denominan materiales de referencia secundarios.

\section{Método recomendado}

Procedimiento evaluado por organizaciones oficiales (CLSI; NIST) competentes en el área de normalización de métodos analíticos según determinados criterios de valoración, o bien ha sido adoptado como método aceptado por asociaciones profesionales como la de la UE basados en métodos ampliamente conocidos y evaluados satisfactoriamente por especialistas en este tipo de análisis, y son considerados como métodos referee para identificar el mejor método de referencia.

\section{Muestra control}

Sustancia estable y homogénea con propiedades biológicas y comportamiento igual o muy similar al de las muestras.

\section{Precisión}

El término precisión indica el grado de concordancia entre los resultados obtenidos para un mismo analito en réplicas de una misma muestra, aplicando el mismo procedimiento experimental bajo condiciones prefijadas.

Notas: 1) La precisión es un concepto cualitativo. Su contraparte cuantitativa es la imprecisión, que se computa como el desvío estándar o un coeficiente de variación de los resultados de medición. 2) La imprecisión depende críticamente de las condiciones especificadas. 3) La desviación estándar que expresa la imprecisión puede depender del valor del mensurando; el fenómeno es llamado heteroscedasticidad.

\section{Recuperación}

Es la capacidad que tiene un procedimiento analítico para determinar cuantitativamente una especie química que ha sido adicionada a una muestra. Esta adición debe hacerse en la forma prevista en el diseño de las condiciones de estandarización para que sea reproducible. Se expresa como porcentaje y se calcula según la siguiente fórmula:

$$
\% \mathrm{R}=\frac{\mathrm{C} \mathrm{ob}-\mathrm{C} \mathrm{i}}{\mathrm{C} \mathrm{ad}} \times 100
$$


donde: $\mathrm{Cob}=\mathrm{Concentración} \mathrm{obtenida;} \mathrm{Ci}=$ Concentración inicial y $\mathrm{Cad}=$ concentración adicionada.

\section{Repetibilidad}

Este término indica la precisión bajo condiciones de repetibilidad.

\section{Repetibilidad de resultados de mediciones}

Grado de mayor cercanía al acuerdo entre los resultados de sucesivas mediciones del mismo mensurando, llevadas a cabo bajo las mismas condiciones de medición.

Notas: 1) La repetibilidad es un concepto cualitativo. Su contraparte cuantitativa es la desviación estándar de repetibilidad o el coeficiente de variación de repetibilidad de los resultados de medición. 2) La repetibilidad puede depender del valor del mensurando.

\section{Reproducibilidad}

Este término indica la precisión bajo condiciones de reproducibilidad.

\section{Reproducibilidad de resultados de mediciones}

Grado de mayor cercanía al acuerdo entre los resultados de mediciones del mismo mensurando llevados a cabo bajo condiciones de medición cambiadas.

Notas: 1) Las condiciones cambiadas pueden incluir: principios de medición, métodos de medición, observador, instrumento de medición, estándar de referencia, locación, condiciones de uso, tiempo; este conjunto de condiciones especificadas se denomina condiciones de reproducibilidad. 2) La reproducibilidad es un concepto cualitativo. Su contraparte cuantitativa es la desviación estándar de reproducibilidad o el coeficiente de variación de reproducibilidad de los resultados de medición. 3) La reproducibilidad puede depender del valor del mensurando.

\section{Trazabilidad}

Propiedad del resultado de una medición o del valor de un estándar la cual permite relacionarlos a referencias establecidas, por lo general estándares nacionales o internacionales, a través de una cadena ininterrumpida de comparaciones que posean incertidumbres declaradas. 


\section{Valor de consenso}

Valor promedio obtenido por un conjunto de laboratorios después de haber eliminado los errores marginales.

\section{Veracidad}

Mayor cercanía de acuerdo entre la media obtenida de una gran serie de resultados de medición y un valor verdadero o valor verdadero convencional.

Notas: 1) Es un concepto cualitativo. Su contraparte cuantitativa es el error sistemático.

2) Prácticamente la veracidad es un equivalente del concepto clásico de IFCC de exactitud.

\section{Referencias bibliográficas}

- Coy G.A. Estandarización de métodos analíticos. Instituto de Hidrología, Meteorología y Estudios Ambientales. Ministerio de Ambiente, Vivienda y Desarrollo Territorial. República de Colombia. 2006.

- Estandarización en Química Clínica. Boletín Mensual editado por el Programa de Evaluación Externa de Calidad. Fundación Bioquímica Argentina; febrero 1997.

- Floering D.A. College of American Pathologist experience with the linearity surveys, 1987-1991. Arch Pathol Lab Med. 1992; 116 (7): 739-745.

- Fuentes Arderiú X. Glossary of ISO metrological and related terms and definitions relevant to clinical laboratory sciences. Madison WI: Westgard QC, 1999.

- Fuentes Arderiú X. Trueness and uncertainty. Madison WI: Westgard QC, 2000.

- Izquierdo Alvarez S. Desarrollo e implementación de un sistema de gestión de la calidad en un laboratorio de referencia "Unidad de metales". Acreditación según la UNE-en ISO 15.189. Tesis doctoral. Universidad de Zaragoza. Facultad de Medicina. Departamento de Farmacología y Fisiología. 2007. 
- Jhang J.S., Chang C.C., Fink D.J., Kroll M.H. Evaluation of linearity in the laboratory. Arch Pathol Lab Med. 2004; 128(1):44-8.

- Tholen D.W., Kroll M., Astles J.R., Caffo A.L., Happe T.M., Krouwer J., Lasky F. Evaluation of the linearity of quantitative measurement procedures: A statistical approach; Approved guideline. CLSI, 2003, document EP6-A, Vol.23 No.16. 


\section{Anexos}




\begin{tabular}{|c|}
\hline COD $11509 \quad 4 \times 50 \mathrm{~mL}$ \\
\hline CONSERVAR A 2-8 $\mathrm{C}$ \\
\hline $\begin{array}{c}\text { Reactivos para medir la concentración de hierro } \\
\text { Sólo para uso in vitro en el laboratorio clínico }\end{array}$ \\
\hline
\end{tabular}

\section{FUNDAMENTO DEL MÉTODO}

El ión férrico presente en la muestra y unido a la transferrina es liberado por acción del guanidinio y reducido a ferroso por la hidroxilamina. El ion ferroso forma un complejo coloreado con la ferrozina que se cuantifica por espectrofotometría, ${ }^{1,2,3}$.

\section{CONTENIDO Y COMPOSICIÓN}

A. Reactivo. 4 × $40 \mathrm{~mL}$. Cloruro de guanidinio $1,0 \mathrm{~mol} / \mathrm{L}$, hidroxilamina $0,3 \mathrm{~mol} / \mathrm{L}$, tampón acetato $0,4 \mathrm{~mol} / \mathrm{L}, \mathrm{pH} 4,0$.

B. Reactivo. $4 \times 10 \mathrm{~mL}$. Ferrozina $8 \mathrm{mmol} / \mathrm{L}$.

S. Patrón de Hierro. $1 \times 5 \mathrm{~mL}$. Patrón acuoso. La concentración viene indicada en la etiqueta del vial. El valor de concentración es trazable al Material de Referencia Certificado 937 (National Institute of Standards and Technology, USA).

\section{CONSERVACIÓN}

Conservar a $2-8^{\circ} \mathrm{C}$.

Los Reactivos y el Patrón son estables hasta la fecha de caducidad indicada en la etiqueta, siempre que se conserven bien cerrados y se evite la contaminación durante su uso.

Indicaciones de deterioro:

- Reactivos: Presencia de partículas, turbidez, absorbancia del blanco superior a 0,050 a 560 $\mathrm{nm}$

- Patrón: Presencia de partículas, turbidez.

\section{PREPARACIÓN DE LOS REACTIVOS}

Patrón (S): Está listo para su uso.

Reactivo de Trabajo: Vaciar el contenido de un vial de Reactivo $B$ en un frasco de Reactivo A. Homogeneizar. Si se desea preparar otros volúmenes, mezclar en la proporción: $1 \mathrm{~mL}$ de Reactivo $\mathrm{B}+4 \mathrm{~mL}$ de Reactivo A. Estable 6 meses a $2-8^{\circ} \mathrm{C}$.

\section{EQUIPO ADICIONAL}

- Analizador, espectrofotómetro o fotómetro para lecturas a $560 \pm 20 \mathrm{~nm}$.

\section{MUESTRAS}

Suero o plasma heparinizado recogidos mediante procedimientos estándar.

El hierro en suero o plasma heparinizado es estable 7 días a $2-8^{\circ} \mathrm{C}$.

\section{PROCEDIMIENTO}

1. Atemperar el Reactivo a temperatura ambiente.

2. Pipetear en tubos de ensayo: (Notas 1,2)

\begin{tabular}{|l|c|c|c|c|}
\cline { 2 - 5 } \multicolumn{1}{c|}{} & Blanco React. & Blanco Muestra & Muestra & Patrón \\
\hline Agua destilada & $200 \mu \mathrm{L}$ & - & - & - \\
Muestra & - & $200 \mu \mathrm{L}$ & $200 \mu \mathrm{L}$ & - \\
Patrón de Hierro (S) & - & - & - & $200 \mu \mathrm{L}$ \\
Reactivo (A) & $1,0 \mathrm{~mL}$ & $1,0 \mathrm{~mL}$ & $-\overline{\mathrm{L}}$ & $\overline{-}$ \\
React. de Trabajo & - & $1,0 \mathrm{~mL}$ \\
\hline
\end{tabular}

3. Agitar bien y dejar durante 5 minutos a temperatura ambiente.

4. Leer la absorbancia (A) de los Blancos de Muestra a $560 \mathrm{~nm}$ frente a agua destilada.

5. Leer la absorbancia (A) de las Muestras y del Patrón a $560 \mathrm{~nm}$ frente al Blanco de Reactivos.

\section{CÁLCULOS}

La concentración de hierro en la muestra se calcula a partir de la siguiente fórmula general:

$$
\frac{A_{\text {Muestra }-} A_{\text {Blanco de Muestra }}}{A_{\text {Patrón }}} \times C_{\text {Patrón }}=C_{\text {Muestra }}
$$

\section{VALORES DE REFERENCIA}

Suero y plasma ${ }^{4}$

Hombres: $65-175 \mu \mathrm{g} / \mathrm{dL}=11,6-31,3 \mu \mathrm{mol} / \mathrm{L}$

Mujeres: $50-170 \mu \mathrm{g} / \mathrm{dL}=9,0-30,4 \mu \mathrm{mol} / \mathrm{L}$

Estos valores se dan únicamente a título orientativo; es recomendable que cada laboratorio establezca sus propios intervalos de referencia.

\section{CONTROL DE CALIDAD}

Se recomienda el uso de los Sueros Control de Bioquímica niveles I (cod. 18005 y 18009) y II (cod. 18007 y 18010) para verificar la funcionalidad del procedimiento de medida.

Cada laboratorio debe establecer su propio programa de Control de Calidad interno, así como procedimientos de corrección en el caso de que los controles no cumplan con las tolerancias aceptables.

\section{CARACTERÍSTICAS METROLÓGICAS}

- Límite de detección: $4 \mu \mathrm{g} / \mathrm{dL}$ hierro $=0,71 \mu \mathrm{mol} / \mathrm{L}$ hierro

- Límite de linealidad: $1000 \mu \mathrm{g} / \mathrm{dL}$ hierro $=179 \mu \mathrm{mol} / \mathrm{L}$ hierro. Cuando se obtengan valores superiores, diluir la muestra $1 / 2$ con agua destilada y repetir la medición.

- Repetibilidad (intraserie):

Concentración media de hierro

$103 \mu \mathrm{g} / \mathrm{dL}=18,4 \mu \mathrm{mol} / \mathrm{L}$

$305 \mu \mathrm{g} / \mathrm{dL}=54,6 \mu \mathrm{mol} / \mathrm{L}$

- Reproducibilidad (interserie):

\begin{tabular}{|c|c|c|}
\hline Concentración media de hierro & \multicolumn{1}{c}{ CV } & $\mathrm{n}$ \\
\hline $103 \mu \mathrm{g} / \mathrm{dL}=18,4 \mu \mathrm{mol} / \mathrm{L}$ & $2,9 \%$ & 25 \\
$305 \mu \mathrm{g} / \mathrm{dL}=54,6 \mu \mathrm{mol} / \mathrm{L}$ & $2,2 \%$ & 25 \\
\hline
\end{tabular}

- Sensibilidad: $88 \mathrm{~mA} \cdot \mathrm{dL} / \mu \mathrm{g}=4,86 \mathrm{~mA} \cdot \mathrm{L} / \mu \mathrm{mol}$

- Veracidad: Los resultados obtenidos con estos reactivos no muestran diferencias sistemáticas significativas al ser comparados con reactivos de referencia (Nota 3). Los detalles del estudio comparativo están disponibles bajo solicitud.

- Interferencias: La bilirrubina ( $<20 \mathrm{mg} / \mathrm{dL}$ ) no interfiere. La hemolisis y la lipemia ( triglicéridos $>15 \mathrm{~g} / \mathrm{L}$ ) interfieren. Otros medicamentos y sustancias pueden interferir ${ }^{5}$.

Estos datos han sido obtenidos utilizando un analizador. Los resultados pueden variar al cambiar de instrumento o realizar el procedimiento manualmente.

\section{CARACTERÍSTICAS DIAGNÓSTICAS}

El hierro está distribuido en el organismo en diferentes compartimentos: hemoglobina mioglobina, tisular (principalmente en el hígado, bazo y médula ósea). Solamente el $0,1 \%$ del hierro total del organismo se encuentra en el plasma.

La concentración sérica de hierro resulta afectada por numerosas condiciones fisiológicas 0 patológicas. La variabilidad interdiaria es bastante elevada en personas sanas.

Las principales alteraciones del metabolismo del hierro son la deficiencia de hierro y la sobrecarga de hierro. No obstante, pueden también encontrarse alteraciones del hierro en diversas enfermedades.

El hierro sérico se encuentra aumentado en hemocromatosis, en envenenamiento agudo por hierro, en cirrosis activa o hepatitis aguda y como resultado de concentraciones elevadas de transferrina ${ }^{4,6}$.

La concentración de hierro en suero se encuentra disminuida en muchos pero no en todos los pacientes con anemia por deficiencia de hierro y en alteraciones crónicas inflamatorias. La medición de hierro sérico no debe ser utilizada como prueba para la identificación de una deficiencia de hierro ${ }^{4,6}$

El diagnóstico clínico no debe realizarse teniendo en cuenta el resultado de un único ensayo, sino que debe integrar los datos clínicos y de laboratorio.

\section{NOTAS}

1. Estos reactivos pueden utilizarse en la mayoría de analizadores automáticos. Solicite información a su distribuidor.

2. El material utilizado en el procedimiento debe estar completamente exento de hierro. Se aconseja utilizar material desechable o lavarlo con ácido nitrico al $50 \%$ (v/v).

3. La calibración con el patrón acuoso puede causar sesgos, especialmente en algunos analizadores. En estos casos, se recomienda calibrar usando un patrón de base sérica (Calibrador de Bioquímica, cod. 18011).

\section{BIBLIOGRAFÍA}

1. Stookey LL. Ferrozine-A new spectrophotometric reagent for iron. Anal Chem 1970; 42: 77981

2. Itano M. Serum Iron Survey. Am J Clin Pathol 1978; 70: 516-522.

3. Artiss JD, Vinogradov S, Zak B. Spectrophotometric study of several sensitive reagents for serum iron. Clin Biochem 1981; 14: 311-315.

4. Tietz Textbook of Clinical Chemistry, $2^{\text {nd }}$ edition. Burtis CA, Ashwood ER. WB Saunders Co., 1994.

5. Young DS. Effects of drugs on clinical laboratory tests, 3th ed. AACC Press, 1997.

6. Friedman and Young. Effects of disease on clinical laboratory tests, 3th ed. AACC Press, 1997. 
Método colorimétrico directo para la determinación de hierro en suero o plasma

\section{SIGNIFICACION CLINICA}

El hierro se distribuye en el organismo de diferentes maneras, incluyendo hemoglobina, hierro tisular y mioglobina. El transporte de hierro de un órgano a otro se realiza mediante una proteína transportadora llamada apotransferrina. El complejo que forma con el hierro se conoce como transferrina. La ferritina, localizada en casi todas las células del cuerpo, constituye una reserva de hierro disponible para la formación de la hemoglobina y otras proteínas que contienen el grupo hemo. La absorción de hierro ocurre principalmente en el duodeno. Tanto la ferritina como la transferrina están presentes en las células de la mucosa intestinal y juntas regulan la absorción de hierro.

Los mayores desórdenes del metabolismo de hierro se relacionan con su deficiencia o exceso, sin embargo, se han observado alteraciones en muchas otras enfermedades, incluyendo anemia, enfermedades cardiovasculares, hepatitis crónica, enfermedades renales e infecciones.

La anemia por pérdida de hierro representa uno de los trastornos orgánicos más frecuentes, especialmente en niños, mujeres jóvenes, embarazadas y ancianos. También las úlceras gástricas o duodenales y carcinomas de estómago, constituyen causas de anemia ferropénica.

Por el contrario, el exceso de hierro se asocia con otros desórdenes, como hemosiderosis, hemocromatosis y anemia sideroblástica.

Las técnicas fotométricas para la determinación de hierro en suero se basan en la formación de un complejo con un cromógeno, entre los cuales ferrozina y batofenantrolina han sido ampliamente usados.

El presente método emplea ferene, un agente quelante adicional, con el objetivo de aumentar la sensibilidad del ensayo colorimétrico. Este compuesto presenta una elevada absortividad molar, es más sensible que ferrozina y facilita la detección de hierro.

\section{FUNDAMENTOS DEL METODO}

El hierro se libera del complejo de transferrina en medio ácido y se reduce a $\mathrm{Fe}$ (II) con ácido ascórbico. Seguidamente reacciona con el reactivo de color, ferene, dando un complejo color azul que se mide a $600 \mathrm{~nm}$. La absorbancia obtenida es directamente proporcional a la concentración de hierro.

\section{REACTIVOS PROVISTOS}

A. Reactivo A: solución de ácido cítrico 200 mM, ácido ascórbico $34 \mathrm{mM}$, tiourea $100 \mathrm{mM}$ y tensioactivo.

B. Reactivo B: solución estabilizada de ferene $>3 \mathrm{mM}$.

S. Standard*: solución de iones hierro (III) equivalente a 100 ug/dl.

\section{REACTIVOS NO PROVISTOS}

- Calibrador A plus de Wiener lab.

- Agua desionizada.

\section{INSTRUCCIONES PARA SU USO \\ Reactivos Provistos: listos para usar.}

\section{PRECAUCIONES}

Los reactivos son para uso diagnóstico "in vitro". Evitar la ingestión y el contacto con los ojos.

El Reactivo A contiene tiourea. Estudios experimentales realizados con esta droga en animales han evidenciado un posible efecto carcinogénico.

Utilizar los reactivos guardando las precauciones habituales de trabajo en el laboratorio de análisis clínicos.

Todos los reactivos y las muestras deben descartarse de acuerdo a la normativa local vigente.

\section{ESTABILIDAD E INSTRUCCIONES DE ALMACENAMIENTO}

Reactivos A y B: son estables en refrigerador $\left(2-10^{\circ} \mathrm{C}\right)$ hasta la fecha de vencimiento indicada en la caja.

Standard: es estable a temperatura ambiente $\left(<25^{\circ} \mathrm{C}\right)$ hasta la fecha de vencimiento indicada en la caja.

\section{INDICIOS DE INESTABILIDAD O DETERIORO DE LOS REACTIVOS}

Variaciones en las lecturas de Blancos de Reactivos y/o Standard indican contaminaciones ocasionales (agua, material de vidrio, etc.).

Un aumento en el valor de los Blancos indicará una contaminación con hierro.

\section{MUESTRA}

Suero o plasma heparinizado

a) Recolección: el paciente debe estar en ayunas y las extracciones deben practicarse siempre a la misma hora (preferentemente de mañana) ya que las fluctuaciones fisiológicas son significativas durante el día.

b) Aditivos: en caso de utilizar plasma como muestra debe usarse heparina como anticoagulante.

c) Sustancias interferentes conocidas: no se observan interferencias por hemoglobina hasta $300 \mathrm{mg} / \mathrm{dl}$, bilirrubina conjugada hasta $12 \mathrm{mg} / \mathrm{dl}$, bilirrubina no conjugada hasta $35 \mathrm{mg} / \mathrm{dl}$ y heparina hasta $50 \mathrm{UI} / \mathrm{ml}$. Los triglicéridos no interfieren hasta $1000 \mathrm{mg} / \mathrm{dl}$ utilizando técnica automática y $250 \mathrm{mg} / \mathrm{dl}$ con técnica manual.

Si bien hemólisis ligeras no interfieren con este método, el 
International Committee for Standardization in Hematology (ICSH) recomienda el uso de suero libre de hemólisis.

Referirse a la bibliografía de Young para los efectos de las drogas en el presente método.

d) Estabilidad e instrucciones de almacenamiento: el suero o plasma heparinizado pueden conservarse una semana en refrigerador $\left(2-10^{\circ} \mathrm{C}\right)$ o hasta un año a $-20^{\circ} \mathrm{C}$.

MATERIAL REQUERIDO (no provisto)

- Espectrofotómetro o analizador automático.

- Micropipetas y pipetas para medir los volúmenes indicados.

- Tubos o cubetas espectrofotométricas.

- Cronómetro.

\section{CONDICIONES DE REACCION}

- Longitud de onda: $600 \mathrm{~nm}$

- Temperatura de reacción: temperatura ambiente $\left(<25^{\circ} \mathrm{C}\right)$

- Tiempo de reacción: 5 minutos

- Volumen de muestra: $200 \mathrm{ul}$

- Volumen total de reacción: 1,4 ml

\section{PROCEDIMIENTO}

En tres tubos marcados B (Blanco de Reactivos), S (Standard) y D (Desconocido) colocar:

\begin{tabular}{lccc}
\hline & $\mathrm{B}$ & $\mathrm{S}$ & $\mathrm{D}$ \\
\hline Agua bidestilada & $200 \mathrm{ul}$ & - & - \\
\hline Standard & - & $200 \mathrm{ul}$ & - \\
\hline Muestra & - & - & $200 \mathrm{ul}$ \\
\hline Reactivo A & $1 \mathrm{ml}$ & $1 \mathrm{ml}$ & $1 \mathrm{ml}$ \\
\hline
\end{tabular}

Mezclar. Leer la absorbancia del tubo D (Blanco de Suero BS) en espectrofotómetro a 600 nm llevando a cero el aparato con agua. Luego agregar:

\begin{tabular}{llll}
\hline Reactivo B & $200 \mathrm{ul}$ & $200 \mathrm{ul}$ & $200 \mathrm{ul}$ \\
\hline
\end{tabular}

Mezclar inmediatamente. Volver a leer cada tubo a los 5 minutos, llevando el aparato a cero con agua.

\section{ESTABILIDAD DE LA MEZCLA DE REACCION FINAL}

Los tubos deben ser leídos entre 5 y 30 minutos luego de completados los pasos del procedimiento.

\section{CALCULO DE LOS RESULTADOS}

Corregir las lecturas de S y D, restándoles los Blancos correspondientes:

$S-B=S$ corregida

$\mathrm{D}-(\mathrm{B}+\mathrm{BS})=\mathrm{D}$ corregida

$\mathrm{Fe}(\mathrm{ug} / \mathrm{dl})=\mathrm{D}$ corregida $\mathrm{x}$

donde: $f=\frac{100 \mathrm{ug} / \mathrm{dl}(\text { Standard })^{*}}{\text { S corregida }}$

* Si se emplea Calibrador A plus consultar los valores asig- nados debido a que son lote específico. En este caso, la lectura del calibrador deberá corregirse restando el blanco correspondiente.

\section{METODO DE CONTROL DE CALIDAD}

Procesar 2 niveles de un material de control de calidad (Standatrol S-E 2 niveles) con concentraciones conocidas de hierro, con cada determinación.

\section{VALORES TEORICOS}

Hombres: 65 a $175 \mathrm{ug} / \mathrm{dl}(11,6-31,3 \mathrm{umol} / \mathrm{l})$

Mujeres: 50 a 170 ug/dl (9-30,4 umol/l)

\section{VALORES DE REFERENCIA}

En un grupo de 20 mujeres y 20 varones sanos, con edades oscilando entre los 18 y 51 años, se halló un rango de 55 a $175 \mathrm{ug} / \mathrm{dl}^{*}$ con los siguientes promedios:

Hombres: $114,6 \mathrm{ug} / \mathrm{dl}(20,5 \mathrm{umol} / \mathrm{l})$

Mujeres: 103,3 ug/dl (18,5 umol/l)

*Valores de referencia extraidos de archivos de Wiener lab.

Se recomienda que cada laboratorio establezca sus propios valores de referencia.

\section{CONVERSION DE UNIDADES AL SISTEMA SI}

Hierro $(\mathrm{ug} / \mathrm{dl}) \times 0,179=$ Hierro $(\mathrm{umol} / \mathrm{l})$

\section{LIMITACIONES DEL PROCEDIMIENTO}

- Valores de Blanco aceptables son necesarios para prevenir posibles contaminaciones del agua y los reactivos con hierro. El Blanco de Reactivos, procesado de acuerdo al Manual de Instrucciones, no debe ser superior a 0,05 D.O. debiendo ser además despreciable la contribución del agua en dicho Blanco. Para ello se recomienda el uso de agua de calidad comprobada.

- El Reactivo A puede adquirir un leve color amarillo con el transcurso del tiempo que no afecta su reactividad.

- Limpieza del material: todo el material de laboratorio empleado debe estar libre de hierro, para ello debe ser sumergido durante al menos durante 6 horas en $\mathrm{HCl} 10 \%$, eliminando la acidez mediante numerosos lavados con agua libre de hierro. Todo el material debe ser empleado exclusivamente para la determinación de hierro.

\section{PERFORMANCE}

a) Reproducibilidad: procesando de acuerdo al documento EP15-A del CLSI (ex-NCCLS), se obtuvo lo siguiente:

Precisión intraensayo $(n=20)$

$\begin{array}{ccc}\text { Nivel } & \text { D.S. } & \text { C.V. } \\ 61,84 \mathrm{ug} / \mathrm{dl} & \pm 0,87 \mathrm{ug} / \mathrm{dl} & 1,40 \% \\ 116,89 \mathrm{ug} / \mathrm{dl} & \pm 0,46 \mathrm{ug} / \mathrm{dl} & 0,39 \% \\ 236,31 \mathrm{ug} / \mathrm{dl} & \pm 0,72 \mathrm{ug} / \mathrm{dl} & 0,31 \%\end{array}$

Precisión total $(n=20)$

$\begin{array}{ccc}\text { Nivel } & \text { D.S. } & \text { C.V. } \\ 61,82 \mathrm{ug} / \mathrm{dl} & \pm 0,88 \mathrm{ug} / \mathrm{dl} & 1,42 \% \\ 116,89 \mathrm{ug} / \mathrm{dl} & \pm 1,30 \mathrm{ug} / \mathrm{dl} & 1,11 \% \\ 236,31 \mathrm{ug} / \mathrm{dl} & \pm 2,83 \mathrm{ug} / \mathrm{dl} & 1,20 \%\end{array}$


b) Linealidad: la reacción es lineal hasta $1500 \mathrm{ug} / \mathrm{dl}$ en autoanalizadores y hasta $1000 \mathrm{ug} / \mathrm{dl}$ en técnica manual.

c) Límite de detección: la mínima concentración de hierro detectable, utilizando el método de Fer-color AA líquida es de $1 \mathrm{ug} / \mathrm{dl}$.

d) Límite de cuantificación: la mínima concentración de hierro que se puede determinar cuantitativamente con precisión y exactitud aceptables con el método de Fer-color AA líquida es de $4 \mathrm{ug} / \mathrm{dl}$.

\section{PARAMETROS PARA ANALIZADORES AUTOMATICOS}

Para las instrucciones de programación debe consultarse el Manual del Usuario del analizador en uso. Para la calibración debe emplearse Calibrador A plus de Wiener lab. de acuerdo a los requerimientos del analizador.

\section{PRESENTACION}

$120 \mathrm{ml}$ - 1 x $100 \mathrm{ml}$ Reactivo A

$-1 \times 20$ ml Reactivo $B$

(Cód. 1492360)

$120 \mathrm{ml}$ - 2 x $50 \mathrm{ml}$ Reactivo A

$-2 \times 10 \mathrm{ml}$ Reactivo B

(Cód. 1009285)

$120 \mathrm{ml}:-2 \times 50 \mathrm{ml}$ Reactivo A $-2 \times 10 \mathrm{ml}$ Reactivo B

(Cód. 1009336)

\section{BIBLIOGRAFIA}

- I.C.S.H. - Am. J. Clin. Path. 56/4:543-545 (1971).

- Young, D.S. - "Effects of Drugs on Clinical Laboratory Tests", AACC Press, 5th ed., 2000.

- Burtis,C.A.; Ashwood, E.R. - "Tietz Fundamentals of Clinical Chemistry", 5aㅡ edición, 2001.

- Imbert-Bismut et al, - Clin. Chem., 47/11: 2059-2061, 2001.

- Tietz, N.W.; Rinker, A.D.; Morrison, S.R. - Clin. Chem. 40/ 4:546-551, 1994.

- Artiss, J.D. et al. - Clin. Biochem. 14/6:311-315, 1981.

- Smith, F.E. - Clin. Biochem. 17:306-310, 1984.

- NTP, National Toxicology Program, Departmen of Health and Human Service, Report of Carcinogens, 2005.

- CLSI: Clinical and Laboratory Standards Institute (ex-NCCLS)

- Protocols EP15-A, 2001 / EP6-A, 2003 / EP17-A, 2004.

\section{SIMBOLOS}

Los siguientes símbolos se utilizan en todos los kits de reactivos para diagnóstico de Wiener lab.

Este producto cumple con los requerimientos previstos por la Directiva Europea 98/79 CE de productos sanitarios para el diagnóstico "in vitro"

\begin{tabular}{|l|l|l|l}
\hline EC & REP Representante autorizado en la Comunidad Europea \\
\hline
\end{tabular}

MD Uso diagnóstico "in vitro"

$2 \quad$ Contenido suficiente para $<n>$ ensayos

8 Fecha de caducidad

\ Límite de temperatura (conservar a)

No congelar

Riesgo biológico

$\longrightarrow \quad$ Volumen después de la reconstitución

Cont. Contenido

LoT Número de lote

Elaborado por:

$\underline{x} \quad$ Nocivo

$5 \quad$ Corrosivo / Caústico

$\underline{x_{i}} \quad$ Irritante

[i] Consultar instrucciones de uso

Calibr. Calibrador

Conrral Control

Conrrout Control Positivo

Conrrol- Control Negativo

REF Número de catálogo
Wiener Laboratorios S.A.I.C. Riobamba 2944

2000 - Rosario - Argentina 2000 - Rosario - Argentina http://www.wiener-lab.com.ar Dir. Téc.: Vivion

Producto Autorizado A.N.M.A.T. PM-1102-27
(1) Wiener lab.

2000 Rosario - Argentina 


\section{ANEXO III \\ FUNDACIÓN BIOQUÍMICA ARGENTINA \\ Programa de Evaluación Externa de Calidad \\ INSTRUMENTAL}

Laboratorio: 10073

Encuesta $N^{\circ} 44$ - Septiembre 2009

Informe de Resultados

\section{CONTROL DE LA EXACTITUD FOTOMÉTRICA}

Instrumento de lectura: (4005) - BIOSYSTEMS A 15

Temperatura: $37^{\circ} \mathrm{C}$.

Longitud de onda: $540 \mathrm{~nm}$.

Absorbancia de Referencia: 0,420 UA a 540 nm.

\section{RESULTADOS}

Absorbância promedio informada: 0,410 UA

Inexactitud fotométrica: $-\mathbf{2 , 3 8 \%}$

Intervalo de aceptabilidad

Intervalo óptimo: (inexactitud $<= \pm 2,00 \%$ ) $=0,412$ UA a 0,428 UA

Intervalo aceptable: (inexactitud $<= \pm 3,00 \%$ ) $=0,407$ a 0,433 UA 